\title{
Mecanismos de negociação no módulo de controle de admissão da arquitetura de servidor web com diferenciação de serviços (swds)
}

\author{
Júlio Cézar Estrella
}

Orientador: Prof. Dr. Marcos José Santana

Dissertação apresentada ao Instituto de Ciências Matemáticas e de Computação - ICMC, USP, como parte dos requisitos para a obtenção do título de Mestre em Ciências de Computação e Matemática Computacional.

"VERSÃO REVISADA APÓS A DEFESA"

Data da Defesa:

$11 / 04 / 2006$

Visto do Orientador :

USP - São Carlos

Abril de 2006 
Mecanismos de negociação no módulo de controle de admissão da arquitetura de servidor web com diferenciação de serviços (swds)

Júlio Cézar Estrella 
Dedico estre trabalho a toda a minha familia, em especial aos meus pais, Osvaldo e Maria Odete pelo incentivo e enorme apoio que tem me concedido para buscar novos caminhos e enfrentar as dificuldades da vida. 


\section{Agradecimentos}

Agradeço primeiramente ao senhor Deus Pai por eu existir.

Ao senhor Osvaldo e à senhora Maria Odete, meus queridos pais que sempre me motivaram e incentivaram a ser um homem crítico, lutador e a não desisitir em hipótese alguma diante das dificuldades.

Ao professor Marcos, meu orientador, por ter me dado a chance de trabalhar neste grupo de pesquisa e mostrar que é possível, com muito esforço e dedicação superar nossas deficiências e melhorar sempre. À professora Regina por seus inúmeros conselhos e sugestões no desenvolvimento deste trabalho. Várias foram as vezes que passamos discutindo melhorias para que o trabalho atingisse o estágio atual.

À professora Sarita que desde o começo acompanhou o projeto e me incetivou até o fim, propondo melhorias e sugestões. Graças a sua paciência e dedicação em me atender sempre, colhemos bons frutos com o desenvolvimento deste trabalho. Muito obrigado mesmo. Ao professor Mário que foi meu co-orientador juntamente com a prof. Sarita ao longo desse dois anos de mestrado, apresentando sugestões, incentivando na escrita de artigos e participando ativamente com suas idéias.

As meus colegas e amigos da USP e do LaSDPC, em especial ao Luís, pelas conversas, descontração nas horas vagas, e pela sua simplicidade, que admiro bastante. Ao Augusto pelas várias discussões que tivemos no intuito de apresentar novas soluções para os problemas. Também ao Geraldo, Válter, Marcelo, Hima Carla, Lucas, Tony, Alessandra, enfim, a todos aqueles que contribuiram direta e indiretamente para que eu superasse mais esse desafio.

Aos vigilantes do prédio de laboratórios, Roberto, Arli e ao Dornelas pela disposição em nos atender prontamente sempre que possível. E finalmente ao CNPq pelo apoio financeiro. 


\section{Resumo}

Esta dissertação de mestrado apresenta a implementação e validação de mecanismos de negociação no módulo de controle de admissão de uma arquitetura de servidor web com diferenciação de serviços - $S W D S$. Foram propostos dois algoritmos, um deles denominado algoritmo de negociação forçada e o outro algoritmo de negociação com a participação do cliente, ambos detalhados ao longo deste trabalho. Verificou-se que a técnica de negociação melhorou o atendimento aos clientes pertencentes a uma determinada classe de serviço para que esses tivessem uma qualidade de serviço garantida. Também foi objeto de estudo a criação de uma métrica envolvendo parâmetros relativos à $Q o S$ em servidores web. Os resultados alcançados com desenvolvimento deste trabalho sinalizam para uma melhoria em termos de qualidade de serviços sendo, portanto, mais uma técnica que contribui para a construção de protótipos de servidores web com diferenciação de serviços num futuro não muito distante. 


\begin{abstract}
The aim of this work is to present the implementation and validation of negotiation mechanisms in the admission control module of a web server architecture with differentiation of services - SWDS. Two algorimtos had been considered, one of them called forced negotiation algorithm and the other one, negotiation algorithm with client's participation, both detailed in this work. It was verified that the negotiation technique improved the attendance to the clients pertaining to one determined service class so that these had a guaranteed quality of service. Also was studied the creation of a metric one involving relative parameters to the QoS in web servers. The results reached with development of this work signal for an improvement in terms of quality of services, being therefore, one technique that contributes for the projection of a prototype of web servers with service differentiation in a near future.
\end{abstract}


1 Introdução 1

1.1 Contextualização . . . . . . . . . . . . . . . . . . . . . . . . 1

1.2 Motivação e Objetivos . . . . . . . . . . . . . . . . 2

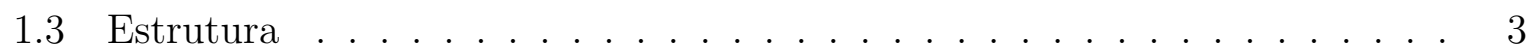

2 A estrutura da Web 5

2.1 Considerações Iniciais . . . . . . . . . . . . . . . . . . . 5

2.2 O modelo de referência ISO/OSI . . . . . . . . . . . . . . . . . . . 6

2.2.1 A pilha de protocolos da Internet . . . . . . . . . . . . . 7

2.3 A World Wide Web . . . . . . . . . . . . . . . . . . 11

2.3.1 Descrição geral do protocolo HTTP . . . . . . . . . . . . . . . . . 11

2.3 .2 Mensagens HTTP . . . . . . . . . . . . . . . . . . . 12

2.4 Considerações Finais . . . . . . . . . . . . . . . . . . . . . . . 15

3 Qualidade de Serviço $\quad 16$

3.1 Considerações Iniciais . . . . . . . . . . . . . . . . . . . . . . . 16

3.2 Qualidade de Serviço . . . . . . . . . . . . . . . . . . . . 16

3.2.1 Categorias de aplicações . . . . . . . . . . . . . . . . . 17

3.3 Garantia de qualidade de serviço . . . . . . . . . . . . . . . . . . . . . . . 19

3.4 Serviços Integrados . . . . . . . . . . . . . . . . . . . . . . . . . . 19

3.4 .1 O protocolo RSVP . . . . . . . . . . . . . . . 19

3.5 Serviços Diferenciados . . . . . . . . . . . . . . . . . 21

3.5.1 Serviços Diferenciados em nível de aplicação . . . . . . . . . . . . . 22

3.6 Considerações Finais . . . . . . . . . . . . . . . . . . . . . 25

4 Servidor Web com Diferenciação de Serviços SWDS 26

4.1 Considerações Iniciais . . . . . . . . . . . . . . . . . . . . . . . . . 26

4.2 O Modelo do sevidor SWDS . . . . . . . . . . . . . . . . . 26

4.2 .1 Classificação das Requisições . . . . . . . . . . . . . . . . . . . . . . 29 
4.2 .2 Mecanismos de Diferenciação de Serviços . . . . . . . . . . . . . . . 30

4.3 O Controle de Admissão . . . . . . . . . . . . . . . . . . . . . . . . . 31

4.3.1 Componentes . . . . . . . . . . . . . . . . 32

4.3 .2 Métricas . . . . . . . . . . . . . . . . . . 33

4.3 .3 Tipos de Admissão . . . . . . . . . . . . . . . . . . . . . . . 34

4.3.4 Novas funcionalidades - Controle de admissão . . . . . . . . . . . 36

4.4 Avaliação de Desempenho do SWDS . . . . . . . . . . . . . . . . . 37

4.4 .1 Simpack . . . . . . . . . . . . . . . . . . 37

4.5 Considerações Finais . . . . . . . . . . . . . . . . . . . . 37

5 Propostas de Avaliação de Mecanismos de Negociação 39

5.1 Considerações Iniciais . . . . . . . . . . . . . . . . . . . . . . . . . . . 39

5.2 Algoritmos de Negociação . . . . . . . . . . . . . . . . . . . . 40

5.2 .1 Algoritmo de Negociação Rigoroso . . . . . . . . . . . . . . . . . . 40

5.2.2 Algoritmo de Negociação com o Cliente . . . . . . . . . . . . . . . . 42

5.3 Características da Simulações . . . . . . . . . . . . . . . . . . . . . . 42

5.4 Cenários para os testes . . . . . . . . . . . . . . . . . . . . . 45

5.5 Desempenho do Servidor Web . . . . . . . . . . . . . . . 47

5.5.1 Número de descartes . . . . . . . . . . . . . . . . . . . . . 55

5.5 .2 Tempo de resposta médio . . . . . . . . . . . . . . . . . 58

5.6 Considerações Finais . . . . . . . . . . . . . . . . . . . 60

6 Métrica para Avaliação de Servidores Web 61

6.1 Considerações Iniciais . . . . . . . . . . . . . . . . . . . . . . . . 61

6.2 Composição de uma métrica . . . . . . . . . . . . . . . . . . . 61

6.3 Cenários para os testes . . . . . . . . . . . . . . . . . . 63

6.4 Desempenho do Servidor Web . . . . . . . . . . . . . . . . . . 64

6.4 .1 Simulação X . . . . . . . . . . . . . . . . . . . 64

6.4 .2 Simulação Y . . . . . . . . . . . . . . . . . 65

6.4 .3 Simulação Z . . . . . . . . . . . . . . . . . . . . . . 67

6.4.4 Validação da métrica DQT nos resultados . . . . . . . . . . . . 68

6.5 Considerações Finais . . . . . . . . . . . . . . . . . . . . . . . 69

7 Conclusões $r 1$

7.1 Considerações Iniciais . . . . . . . . . . . . . . . . . . . . 71

7.2 Trabalhos Relacionados . . . . . . . . . . . . . . . . . 72

7.3 Resultados e Contribuições . . . . . . . . . . . . . . . . . . . . . . 72

7.4 Trabalhos Futuros . . . . . . . . . . . . . . . . . . 74 


\section{Lista de Figuras}

2.1 A pilha de protocolos da Internet e suas PDUs . . . . . . . . . . . . . 7

2.2 Camada de aplicação . . . . . . . . . . . . . . . . . . . . . 8

2.3 Camada de transporte . . . . . . . . . . . . . . . . . . . . 9

2.4 Camada de rede . . . . . . . . . . . . . . . . . . . . . . 9 9

2.5 Camada de enlace . . . . . . . . . . . . . . . . . 10

2.6 Comportamento de requisição-resposta do HTTP . . . . . . . . . . . . . . 11

4.1 Servidor web com diferenciação de serviços (TEIXEIRA, 2004a) . . . . . . . . 27

4.2 Módulo de controle de admissão (TEIXEIRA, 2004a) . . . . . . . . . . . 33

5.1 SWDS e o Algoritmo de Negociação Rigoroso - ANR . . . . . . . . . . . . 41

5.2 Características do rebaixamento para a classe $2 \ldots \ldots$. . . . . . . . 41

5.3 Pseudo-Código para o Algoritmo de Negociação Rigoroso . . . . . . . . . . . 42

5.4 SWDS e o Algoritmo de Negociação com o Cliente - ANC . . . . . . . . . 43

5.5 Pseudo-Código para o Algoritmo de Negociação com o cliente . . . . . . . 44

5.6 Número de descartes das simulações A e B por classe . . . . . . . . . . . . 47

5.7 Tempo de médio de fila das simulações A e B por classe . . . . . . . . . . . 48

5.8 Número de descartes das simulações C e D por classe . . . . . . . . . . . . 49

5.9 Tempo médio de fila da simulações C e D por classe . . . . . . . . . . . . . 49

5.10 Número de descartes das simulações E e F por classe . . . . . . . . . . . . 50

5.11 Tempo médio de fila da simulações E e F por classe . . . . . . . . . . . . . 51

5.12 Número de descartes das simulações G e H por classe . . . . . . . . . . . . 52

5.13 Tempo médio de fila das simulações $\mathrm{G}$ e H por classe . . . . . . . . . . . 52

5.14 Número de descartes das simulações I e J por classe . . . . . . . . . . . . . 53

5.15 Tempo médio de fila das simulações I e J por classe . . . . . . . . . . . . 53

5.16 Número de descartes das simulações K e L por classe . . . . . . . . . . . . 54

5.17 Tempo médio de fila das simulações K e L por classe . . . . . . . . . . . . 54

5.18 Variação de descartes segundo a taxa de chegada - Sem Negociação . . . . 55 
5.19 Variação de descartes segundo a taxa de chegadas - Com Negociação com o cliente . . . . . . . . . . . . . . . . . . 56 56

5.20 Variação de descartes segundo a taxa de chegada - Classe 0 . . . . . . . . 57

5.21 Variação de descartes segundo a taxa de chegada - Classe 1 . . . . . . . . . 57

5.22 Variação de descartes segundo a taxa de chegada - Classe 2 . . . . . . . . 58

5.23 Variação do tempo de resposta médio segundo a taxa de chegada - Sem Negociação . . . . . . . . . . . . . . . . . . . . . . 59

5.24 Variação do tempo de resposta médio segundo a taxa de chegada - Com Negociação . . . . . . . . . . . . . . . . . . . . . . . 59

6.1 Comparação do número de descartes usando diferentes limiares - Simulação X 64 6.2 Tempo de fila médio - Simulação X . . . . . . . . . . . . . . 65

6.3 Comparação do número de descartes usando diferentes limiares - Simulação Y 66

6.4 Tempo de fila médio - Simulação Y . . . . . . . . . . . . . . 66

6.5 Comparação do número de descartes usando diferentes limiares - Simulação Z 67

6.6 Tempo de fila médio - Simulação Z . . . . . . . . . . . . . . . 67 


\section{Lista de Tabelas}

2.1 O modelo de referência OSI . . . . . . . . . . . . . . . 6

2.2 Métodos do protocolo HTTP/1.1 . . . . . . . . . . . . . . . 14

2.3 Classes de código de status HTTP . . . . . . . . . . . . . . . . . . . . . 14

3.1 Categorias de tráfego e suas aplicações . . . . . . . . . . . . . . . . . . . . 18

5.1 Parâmetros utilizados nas simulações . . . . . . . . . . . . . . . . . 45

5.2 Cenários das simulações . . . . . . . . . . . . . . . . . . . 46

5.3 Valores de descartes segundo as simulações A e B . . . . . . . . . . . . . 47

5.4 Valores comparativos dos tempos de fila . . . . . . . . . . . . . . 47

5.5 Valores de descartes segundo as simulações C e D . . . . . . . . . . . . 49

5.6 Valores comparativos dos tempos de fila . . . . . . . . . . . . . 50

5.7 Valores de descartes segundo as simulações E e F . . . . . . . . . . . . . 51

5.8 Valores comparativos dos tempos de fila . . . . . . . . . . . . . 51

5.9 Valores de descartes segundo as simulações $\mathrm{G} \mathrm{e} \mathrm{H} \ldots$. . . . . . . . . . 52

5.10 Valores comparativos dos tempos de fila . . . . . . . . . . . . . . 53

5.11 Valores de descartes segundo as simulações I e J . . . . . . . . . . . . . . 53

5.12 Valores comparativos dos tempos de fila . . . . . . . . . . . . 54

5.13 Valores de descartes segundo as simulações K e L . . . . . . . . . . . . . 54

5.14 Valores comparativos dos tempos de fila . . . . . . . . . . . . . 55

6.1 Composição da Métrica . . . . . . . . . . . . . . . . . . . . . . . 62

6.2 Significado da Métrica . . . . . . . . . . . . . . . . . . . . 63

6.3 Cenários da Simulação . . . . . . . . . . . . . . . . . . . . . 63

6.4 Diferentes Limiares . . . . . . . . . . . . . . . . . . . . . . . . 64

6.5 DQT - Simulação X . . . . . . . . . . . . . . . . . . . . . 68

6.6 DQT - Simulação Y . . . . . . . . . . . . . . . . . . . . . . . . 69

6.7 DQT - Simulação Z . . . . . . . . . . . . . . . . . . . . . . . 69 


\section{Lista de Símbolos}

$\begin{array}{ll}\text { ATM } & \text { Asynchronous Transfer Mode } \\ \text { DiffServ } & \text { Differentiated Service } \\ \text { DoD } & \text { Department of Defense } \\ \text { FCFS } & \text { First Come First Served } \\ \text { FTP } & \text { File Transfer Protocol } \\ \text { HTTP } & \text { Hypertext Transfer Protocol } \\ \text { IntServ } & \text { Integrated Service } \\ \text { IETF } & \text { Internet Engeneering Task Force } \\ \text { ISO } & \text { International Organization for Standardization } \\ \text { MIT } & \text { Massachusetts Institute of Technology } \\ \text { OSI } & \text { Open Systems Interconnection } \\ \text { PDU } & \text { Protocol Data Unit } \\ \text { PPP } & \text { Point to Point Protocol } \\ \text { QoS } & \text { Quality of Service } \\ \text { RFC } & \text { Request for Comments } \\ \text { RSV } & \text { Mecanismo de Reserva de Recursos } \\ \text { RSVP } & \text { Resource Reservation Protocol } \\ \text { SLA } & \text { Service Level Agreement } \\ \text { SMTP } & \text { Simple Mail Transfer Protocol } \\ \text { SWDS } & \text { Servidor Web com Diferenciação de Serviços } \\ \text { TCP } & \text { Transmission Control Protocol } \\ \text { UDP } & \text { User Datagram Protocol } \\ \text { WWW } & \text { World Wide Web } \\ \text { W3C } & \text { World Wide Web Consortium } \\ & \end{array}$




\section{Capítulo \\ 1 \\ Introdução}

\subsection{Contextualização}

A World Wide $W e b-W W W$ é uma estrutura que permite o acesso a documentos digitais interligados, espalhados por milhões de máquinas na Internet. Em dez anos ela deixou de ser um meio de distribuição de dados sobre assuntos específicos, como física por exemplo, para se tornar a aplicação mais utilizada por milhões de pessoas em todo o mundo (TANEMBAUM, 2002). Sua enorme popularidade se deve a sua interface gráfica, de fácil utilização para principiantes. Além disso, ela oferece uma imensa variedade de informações sobre quase todos os assuntos imagináveis (TANEMBAUM, 2002).

A $W W W$ teve início em 1989 no $C E R N$, o centro europeu para pesquisa nuclear, sendo concebida por Tim Berners-Lee (FIELDING et al., 1999). Nasceu da necessidade de fazer com que grupos de cientistas de diferentes nacionalidades pudessem colaborar uns com os outros através da troca de imagens, relatórios e outros documentos em formato digital. O primeiro protótipo da Web (no modo texto) já estava operacional no ano de 1991, durante uma demonstração pública na conferência Hypertext'91 em San Antonio, no Texas. Em 1994, o CERN e o MIT assinaram um acordo criando o World Wide Web Consortium, também conhecido como W3C, uma organização voltada para o desenvolvimento da $W e b$, cujo objetivo era padronizar protocolos e incentivar a interoperabilidade entre os sites. Desde então, centenas de universidades e empresas juntaram-se ao consórcio. (TANEMBAUM, 2002)

Com o surgimento da $W W W$, a Internet tem passado por profundas modificações. Uma dessas diz respeito ao tipo de conteúdo veiculado na rede mundial de computadores. O tráfego não era originalmente tão intenso e tão diferenciado como nos dias atuais. $\mathrm{O}$ crescimento dos provedores comerciais aliado ao surgimento de novas mídias, fizeram com 
que a ordem de grandeza do tráfego na rede crescesse assustadoramente. A utilização de dados multimídia na rede, tais como áudio e vídeo e a convergência de novas tecnologias, como telefonia IP e TV Digital para a Internet, alterou a maneira como as informações chegam aos usuários.

Atualmente, a rede fornece um serviço baseado no modelo de melhor esforço (besteffort), isto é, procura realizar a tarefa de envio, recebimento e transporte de informações da melhor maneira possível em um tempo adequado. O grande problema é que não há nenhuma garantia desse serviço às aplicações (COMER, 1995). Uma das soluções para o problema acima mencionado tem sido o aumento da largura de banda da rede. Certamente não é a mais viável, visto que esse aumento pode ser rapidamente consumido pela demanda dos usuários.

Uma outra tentativa para melhorar a provisão de serviços na Internet é a utilização da abordagem de serviços diferenciados, que disponibiliza novos recursos ao tráfego. Embora essa seja uma boa alternativa, ela não resolve o problema por completo, pois tal abordagem é restrita à camada de rede da pilha de protocolos $T C P / I P$. Resumidamente, a qualidade de serviço é implantada em termos de datagramas e não em termos de dados da camada de aplicação.

Embora seja limitado o uso da diferenciação de serviços na camada de aplicação, novas propostas têm surgido ultimamente. Um exemplo disso é um modelo de servidor web com serviços diferenciados implementado em (TEIXEIRA, 2004a). O modelo de Servidor Web com Diferenciação de Serviços - SWDS (TEIXEIRA, 2004a) foi definido com o objetivo de introduzir $Q_{o} S^{1}$ em nível de aplicação. Possui também critérios para classificar requisições, com o intuito de subdividí-las em classes de serviços e outras características, tal como a presença de algoritmos para a diferenciação de serviços além de um módulo de controle de admissão. O esforço para o fornecimento de qualidade de serviço diferenciada na web, dificilmente terá sucesso se apenas mecanismos em nível de rede e sistema operacional forem utilizados, pois são os servidores web os responsáveis pelo fornecimento de conteúdo da Internet, e também pelo atendimento às solicitações dos usuários.

\subsection{Motivação e Objetivos}

Esforços têm sido realizados e propostas de provisão de $Q o S$ na camada de aplicação estão surgindo nos últimos anos, dentre os quais merece destaque o modelo de servidor web com diferenciação de serviços proposto em (TEIXEIRA, 2004a). Esse modelo de servidor é capaz de fornecer diferentes níveis de serviço a seus clientes. Possui também critérios para classificá-los, com o intuito de subdividí-los em classes de serviços e outras características, tal como a presença de algoritmos para a diferenciação de serviços além de um módulo de controle de admissão.

\footnotetext{
${ }^{1}$ Quality of Service
} 
O módulo de controle de admissão presente no modelo do servidor $S W D S^{2}$ tem a função de gerenciar a aceitação de novas requisições pelo servidor, impedindo que o mesmo seja sobrecarregado. Por isso, ele utiliza informações atualizadas da carga presente no sistema e leva em conta as políticas de atendimento vigentes. A arquitetura do controle de admissão é formada pelos seguintes componentes: uma área de variáveis globais, uma área de buffer, um módulo de controle de informações, e a presença de mecanismos de controle.

Atualmente, o modelo de servidor $S W D S$ possui três mecanismos de controle de admissão. O primeiro limita o tamanho máximo da fila de processos servidores e recusa novas requisições quando o limite for atingido. O segundo, controla o tempo de resposta das requisições de maior prioridade e aloca buffers de tamanho fixo para as diferentes classes, como uma forma de limitar a carga no sistema. Finalmente, o terceiro mecanismo, baseia suas decisões de descarte numa média exponencialmente ponderada da utilização do sistema, permitindo ajustar esse mecanismo para ser mais ou menos sensível a mudanças no perfil da carga de trabalho.

O presente trabalho tem como objetivo geral avaliar alternativas para definir e implementar a funcionalidade de negociação no módulo de controle de admissão, numa arquitetura de servidor web com provisão de serviços diferenciados. A idéia é permitir que uma requisição possa ser atendida numa classe de serviços inferior àquela inicialmente estabelecida entre o cliente e o servidor. Para isso são propostos dois algoritmos, os quais são avaliados através de testes de análise de desempenho no modelo $S W D S$. Além disso, propõe-se também uma métrica com o obejtivo de avaliar o comportamento do modelo diante da mudança de diversos parâmetros e a alternância dos algoritmos implementados com aqueles existentes no modelo original.

\subsection{Estrutura}

Este documento apresenta a seguinte organização:

- O capítulo 2 apresenta uma revisão geral sobre a estrutura da web, bem como os protocolos da arquitetura TCP/IP. Uma visão geral do protocolo HTTP também será objeto de estudo deste capítulo.

- No capítulo 3 é feita uma introdução aos serviços diferenciados, incluindo classes de seviços, QoS, e sua limitação na Internet atual, visto que essa abordagem é amplamente utilizada no nível de rede e não no nível de aplicação.

- No capítulo 4 é apresentado um modelo de servidor web com provisão de serviços diferenciados, sua estrutura e seus componentes. Esse capítulo discorre também

\footnotetext{
${ }^{2}$ Servidor web com diferenciação de serviços
} 
sobre o módulo de controle de admissão do servidor $S W D S$, sua estrutura, seus componentes, os mecanismos de controle e os tipos de admissões permitidas no modelo de servidor.

- No capítulo 5 são apresentados os mecanismos de negociação implementados, a metodologia utilizada para o desenvolvimento do trabalho e a análise de desempenho dos mecanismos propostos.

- O capítulo 6, por sua vez, define uma métrica com parâmetros de $Q o S$ para servidores web e sua aplicação em diferentes cenários.

- O capítulo 7 conclui o trabalho a partir dos resultados obtidos.

- Finalmente são apresentadas as Referências Bibliográficas. 


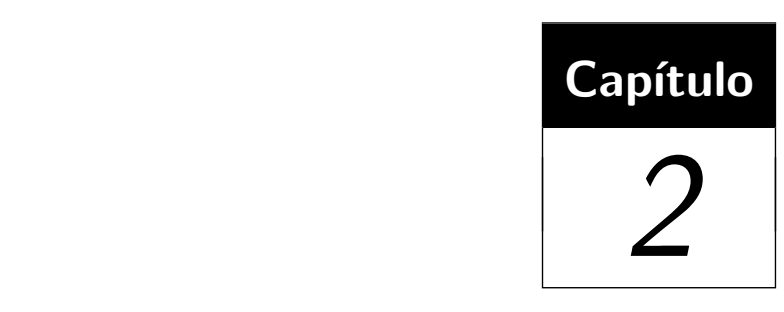

A estrutura da Web

\subsection{Considerações Iniciais}

Nos anos 60, o principal setor estratégico americano, o $D o D^{1}$, se interessou por um protocolo que estava sendo desenvolvido e utilizado por universidades para interligação de seus sistemas computacionais e que utilizava a tecnologia de chaveamento de pacotes. $\mathrm{O}$ $D o D$ desejava manter a comunicação entre os diversos sistemas espalhados pelo mundo, no caso de um desastre nuclear, por exemplo. (SOARES; LEMOS; COLCHER, 1995) O problema residia na compatibilidade entre os sistemas computacionais, que quase sempre eram de diferentes fabricantes e possuiam diferentes sistemas operacionais, topologia e protocolos. Nesse sentido, foi atribuída à $A R P A^{2}$ a tarefa de encontrar uma solução para resolver o problema de compartilhamento e integração das informações. Foi feita uma aliança entre universidades e fabricantes para o desenvolvimento de padrões de comunicação. Essa aliança especificou e construiu uma rede de teste de quatro nós, chamada ARPANET, que acabou sendo a origem da Internet de hoje.

No final dos anos 70, esta rede inicial teve seu protocolo principal desenvolvido e transformado na base para o $T C P / I P^{3}$. A aceitação mundial dos conjuntos de protocolos TCP/IP deveu-se principalmente à versão UNIX Berkely que, além de incluir estes protocolos, colocava-os em uma situação de domínio público, onde qualquer organização através de sua equipe técnica poderia modificá-los e assim garantir seu desenvolvimento.

Dentre os vários comitês e organizações que participaram deste desenvolvimento e divulgação, destaca-se o $I E T F^{4}$, cuja principal função atual é a manutenção e apoio aos

\footnotetext{
${ }^{1}$ Department of Defense

${ }^{2}$ Advanced Research Project Agency

${ }^{3}$ Transmission Control Protocol / Internet Protocol

${ }^{4}$ Internet Engineering Task Force
} 
padrões de Internet e TCP/IP, principamente através da série de documentos conhecidos como RFCs ${ }^{5}$. Estes documentos descrevem diversos protocolos e servem de base para novas tecnologias. Em resumo, o maior trunfo do TCP/IP é o fato desses protocolos apresentarem interoperabilidade de comunicação entre todos os tipos de hardware e sistemas operacionais. Sendo assim, o impacto positivo da comunicação computacional aumenta com o número de computadores que participam da Internet.

\subsection{O modelo de referência ISO/OSI}

No contexto de grande variedade de sistemas operacionais, interfaces de rede, tecnologia e várias outras variáveis, e a necessidade de interconexão entre os diversos sistemas computacionais, a $I S O{ }^{6}$ criou em 1977 um comitê para o desenvolvimento de padrões de comunicação para promover interoperabilidade entre as diversas plataformas (SOARES; LEMOS; COLCHER, 1995). Foi então desenvolvido o modelo de referência $O S I^{7}$.

É importante observar que o modelo OSI apenas especifica as funções a serem implementadas pelos diversos fabricantes em suas redes. Este modelo não detalha como estas funções devem ser implementadas, deixando isto para cada empresa/organização. O comitê ISO assumiu o método "dividir para conquistar", dividindo o processo complexo de comunicação em pequenas sub-tarefas (camadas), de maneira que os problemas se tornassem menos complicados e as sub-tarefas melhor otimizadas. O modelo ISO/OSI é constituído por sete camadas descritas sucintamente na tabela 2.1.

\begin{tabular}{|c|c|}
\hline \hline Camada & Função \\
\hline \hline Aplicação & Aplicações definidas pelo usuário \\
\hline \hline Apresentação & Conversão dos dados em formato universal \\
\hline \hline Sessão & Estabelece e encerra enlaces de comunicação \\
\hline \hline Transporte & Sequenciamento, confirmação, recebimento de pacotes de dados \\
\hline \hline Rede & Roteamento dos dados através da rede \\
\hline \hline Enlace & Formatação da informação em quadros \\
\hline \hline Física & Conexão física entre os dispositivos de rede \\
\hline
\end{tabular}

Tabela 2.1: O modelo de referência OSI

Antes do desenvolvimento do modelo de camada ISO/OSI, o DoD definiu seu próprio modelo de rede conhecido como modelo $D o D$ de rede ou também modelo Internet de rede. Posteriormente, este modelo passou a ser conhecido como modelo de camadas TCP/IP.

\footnotetext{
${ }^{5}$ Request for Comments

${ }^{6}$ International Organization for Standardization

${ }^{7}$ Open Systems Interconnection
} 


\subsubsection{A pilha de protocolos da Internet}

O modelo de camadas ISO/OSI acabou se tornando apenas uma base para praticamente todos os protocolos desenvolvidos pela indústria. Cada desenvolvedor possui uma arquitetura que difere em detalhes, às vezes fundamentais, no seu desenvolvimento. Sendo assim, é de se esperar uma variação nas descrições do conjunto de protocolos $T C P / I P$. Diferentemente do modelo ISO/OSI, a pilha da Internet consiste em cinco camadas: camada física, camada de enlace, camada de rede, camada de transporte e camada de aplicação (KUROSE; ROSS, 2005). Ao invés de usar a terminologia $n$-PDU ${ }^{8}$ para cada uma das cinco camadas, nomes especiais serão dados para quatro das cinco $P D U s$ : quadro, datagrama, segmento e mensagem. A pilha da Internet e os nomes das PDUs correspondentes estão ilustrados na figura 2.1:
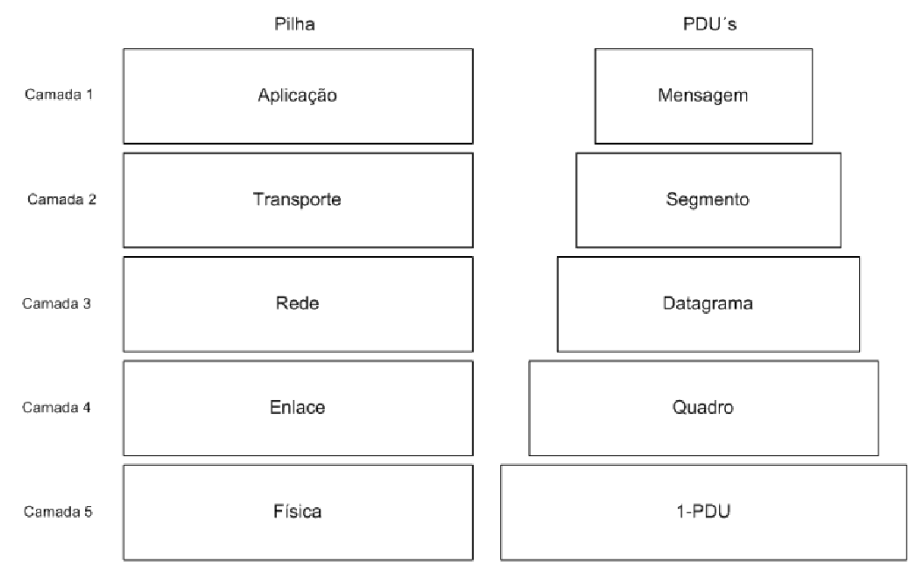

Figura 2.1: A pilha de protocolos da Internet e suas PDUs

Uma camada de protocolo pode ser implementada em software, hardware ou usando-se uma combinação dos dois. Os protocolos da camada de aplicação - como HTTP e SMTP são implementados nos softwares dos sistemas finais; isso também vale para os protocolos de camadas de transporte. Como a camada física e a camada de enlace são responsáveis pelo manuseio da comunicação por um enlace específico, elas são implementadas em uma placa de interface com a rede (por exemplo, as placas de interface da Ethernet ou das redes $A T M$ ) associada a um dado enlace. A camada de rede é freqüentemente uma implementação mista de hardware e software. (KUROSE; ROSS, 2005)

Serão apresentados a seguir as camadas da Internet e os serviços que estas oferecem.

\section{Camada de aplicação}

A camada de aplicação é responsável pelo suporte das aplicações de rede. Ela inclui muitos protocolos, dentre eles o HTTP, que fornece comnunicação com a $W e b$, o SMTP, que permite a troca de mensagens através do correio eletrônico, e o FTP, para dar suporte ao transporte de arquivos, como mostra a figura 2.2 .

\footnotetext{
${ }^{8}$ Protocol Data Unit
} 


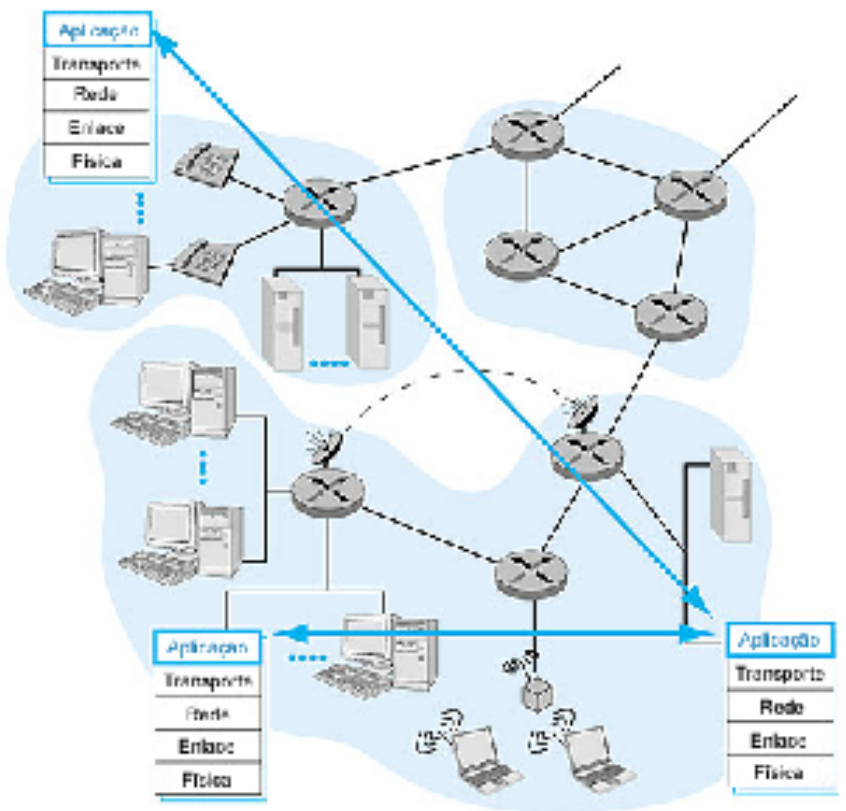

Figura 2.2: Camada de aplicação

\section{Camada de transporte}

A camada de transporte fornece serviço de transporte confiável de mensagens da camada de aplicação entre os lados do cliente e do servidor de uma aplicação, como mostra a figura 2.3. Na Internet há dois protocolos de transporte: o $T C P^{9}$ e o UDP ${ }^{10}$. O $T C P$ provê serviços orientados à conexão para suas aplicações. Esse serviço inclui a entrega garantida das mensagens da camada de aplicação no destino e o controle de fluxo (isto é, o ajuste entre as velocidades do remetente/receptor). O TCP também fragmenta mensagens longas em segmentos mais curtos e provê mecanismo de controle de congestionamento, de modo que a origem regula sua velocidade de transmissão quando a rede está congestionada. O UDP, por outro lado, fornece a suas aplicações um serviço não orientado à conexão.

\section{Camada de rede}

A camada de rede é responsável pelo roteamento dos datagramas de uma máquina para outra, como pode ser verificado na figura 2.4. Esta camada apresenta dois componentes principais: um protocolo que determina os campos no datagrama $I P$, bem como o modo como agem os sistemas finais e os roteadores nesses campos. Este é chamado de protocolo IP. A camada de rede da Internet também contém protocolos de roteamento que determinam as rotas que os datagramas seguem entre a origem e o destino.

Os protocolos de camada de transporte da Internet ( TCP e UDP) de uma máquina de origem passam um segmento de camada de transporte e um endereço de destino à camada

\footnotetext{
${ }^{9}$ Transport Control Protocol

${ }^{10}$ User Datagram Protocol
} 


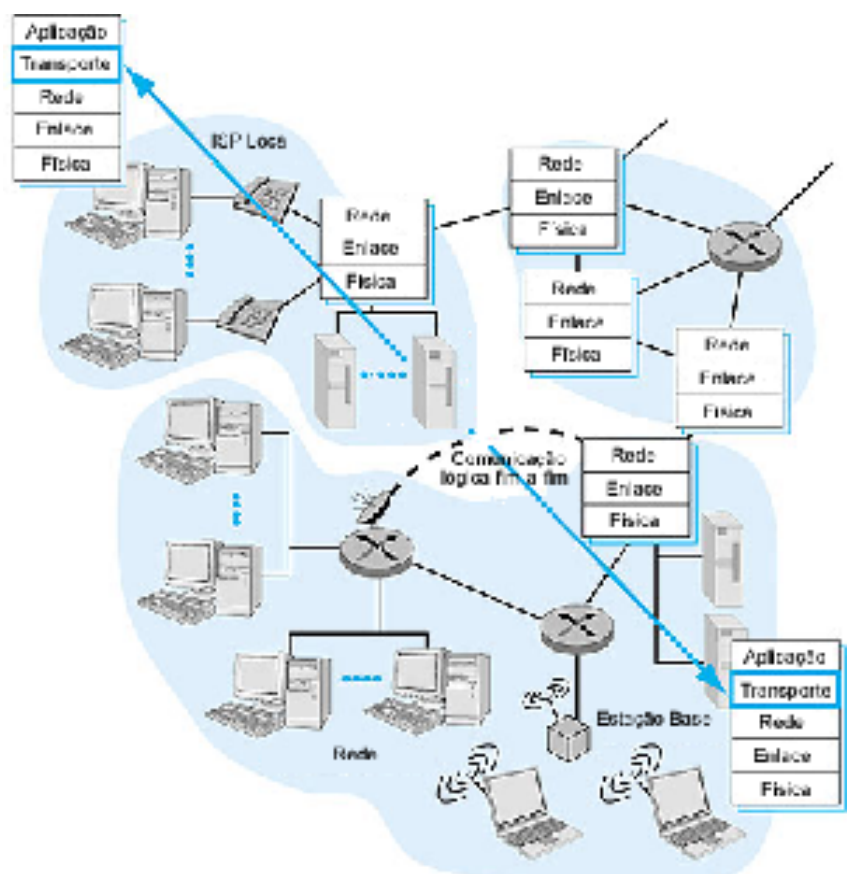

Figura 2.3: Camada de transporte

$I P$, exatamente da maneira que o serviço de correios fornece uma carta para o destinatário. A camada $I P$ então provê o serviço de roteamento do segmento a seu destino. Quando o pacote chega ao destino, o IP passa o segmento para a camada de transporte interna do destino.

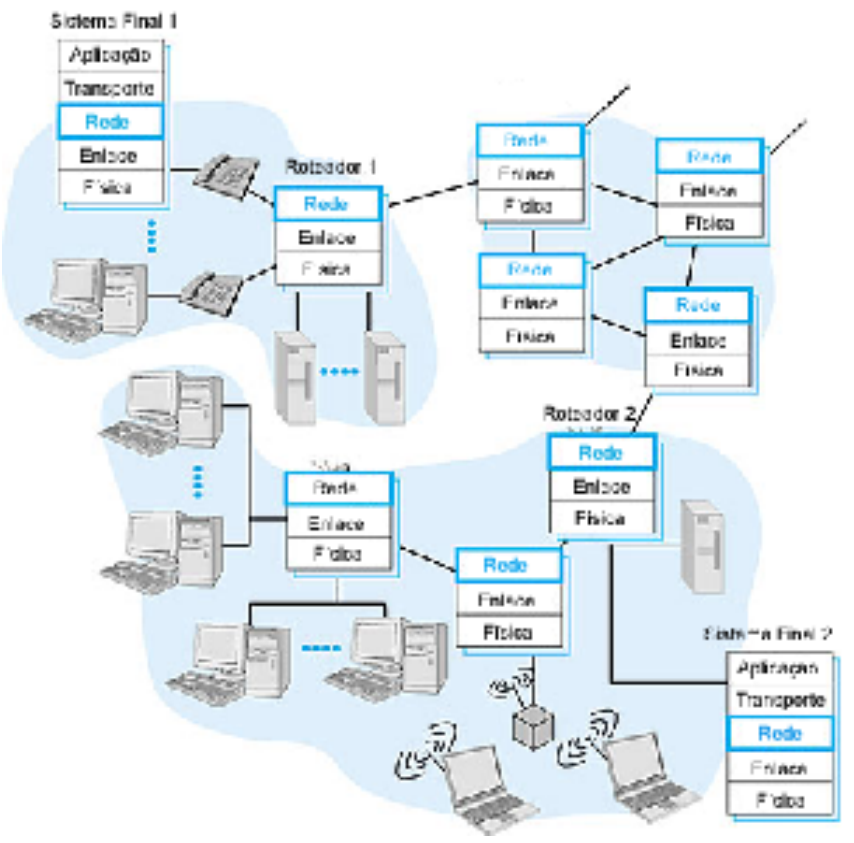

Figura 2.4: Camada de rede

\section{Camada de enlace}

A camada de rede roteia um pacote por meio de uma série de comutadores de pacotes (Roteadores) entre a origem e o destino. Para levar um pacote de um nó (Sistema 
final ou comutador de pacotes) ao nó seguinte na rota, a camada de rede depende dos serviços da camada de enlace, de acordo com a figura 2.5. Na verdade, a cada nó, o IP passa o datagrama para a camada de enlace, que o entrega ao nó seguinte ao longo da rota. Nesse próximo nó, a camada de enlace passa o datagrama IP à camada de rede. O processo é análogo ao carteiro de uma central de correios, que despacha a carta de avião para outra central de correios ao longo da rota. Os serviços prestados na camada de enlace dependem de protocolos específicos desta camada. Sendo assim, alguns protocolos fornecem entrega garantida sobre os enlaces, isto é, desde o nó transmissor, passando por um único enlace, até o receptor. É importante mencionar que esse serviço de entrega confiável é diferente do serviço de entrega garantida do $T C P$, que presta serviço de entrega garantida de um sistema final a outro. Como exemplo de protocolo da camada de enlace, podemos citar o PPP (Point to Point Protocol). Como o datagrama normalmente precisa transitar por diversos enlaces para ir da origem ao destino, ele vai ser manuseado por diferentes protocolos de camada de enlace em diferentes enlaces ao longo da rota. Por exemplo, um datagrama pode ser operado por Ethernet em um enlace e por PPP no enlace seguinte. O IP vai receber um serviço diferente de cada um dos diferentes protocolos da camada de enlace.

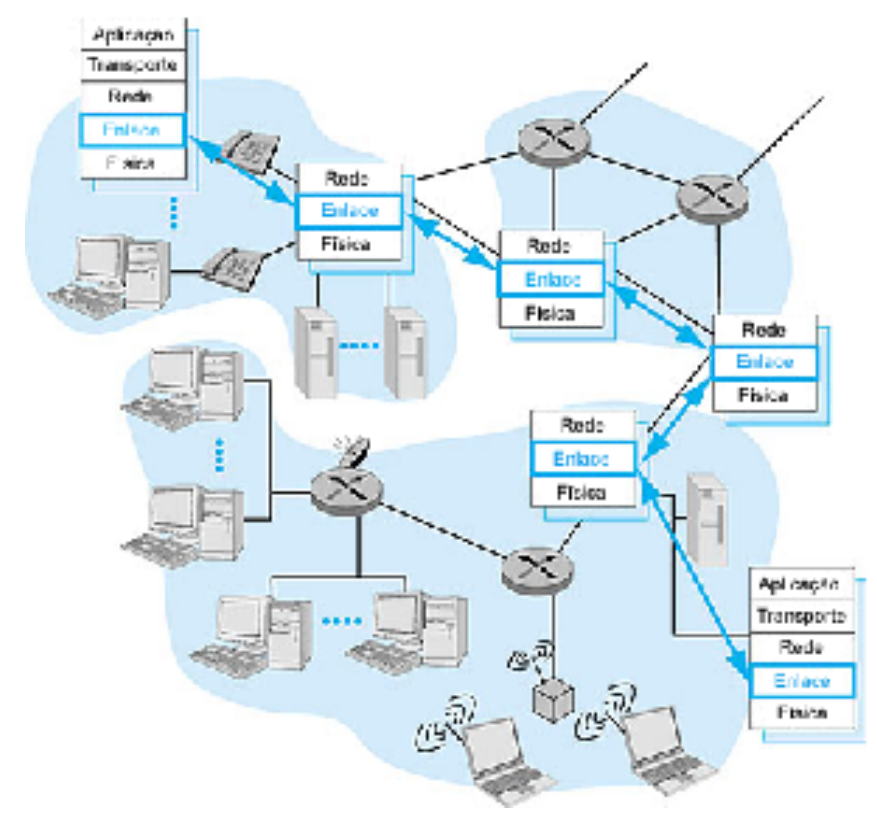

Figura 2.5: Camada de enlace

\section{Camada física}

Enquanto a tarefa da camada de enlace é movimentar quadros inteiros de um elemento da rede até o elemento adjacente, a tarefa da camada física é movimentar os bits individuais interiores ao quadro, de um nó para o seguinte. Os protocolos desta camada novamente dependem do enlace; além disso, dependem do próprio meio de transmissão 
do enlace (Par de fios de cobre trançados ou fibra ótica). Por exemplo, a Ethernet apresenta muitos protocolos da camada física: um para fio de cobre trançado, outro para cabo coaxial, outro para fibra ótica e assim por diante. Em cada caso, o bit é movimentado pelo enlace de maneira diferente.

\section{$2.3 \quad$ A World Wide Web}

Até a década de 90, a Internet era usada basicamente por pesquisadores, acadêmicos e estudantes universitários. Eles a usavam para se conectar com hospedeiros remotos, transferir arquivos, enviar e receber notícias e correio eletrônico. Embora essas aplicações fossem (e continuem a ser) muito úteis, a Internet não era conhecida fora das comunidades acadêmicas e de pesquisa (KUROSE; ROSS, 2005). Foi no início dessa década que entrou em cena a aplicação-chave da Internet - a $W W W$ (Berners-Lee, 1994). A Web foi a aplicação que mais chamou a atenção do público em geral e provocou uma drástica transformação na maneira como as pessoas interagem dentro e fora de seu ambiente de trabalho. Ela gerou milhares de novas empresas, elevou a Internet do nível que ocupava, como apenas mais uma das muitas redes de dados (X.25, Frame Relay), para o nível que agora ocupa, a maior rede de dados. Para a disseminação da $W W W$, houve a definição de um protocolo da camada de aplicação denominado HTTP, o qual será abordado na próxima seção.

\subsubsection{Descrição geral do protocolo HTTP}

O HTTP, o protocolo da camada de aplicação da Web, está implementado em dois programas: um programa cliente e um programa servidor. Os programas cliente e servidor, executados em diferentes sistemas finais, "conversam" pela troca de mensagens HTTP. Este protocolo define como os clientes Web (isto é, os browsers) solicitam páginas Web aos servidores e como os servidores $W e b$ transferem páginas $W e b$ aos seus clientes. A idéia geral é ilustrada na figura 2.6 a seguir.

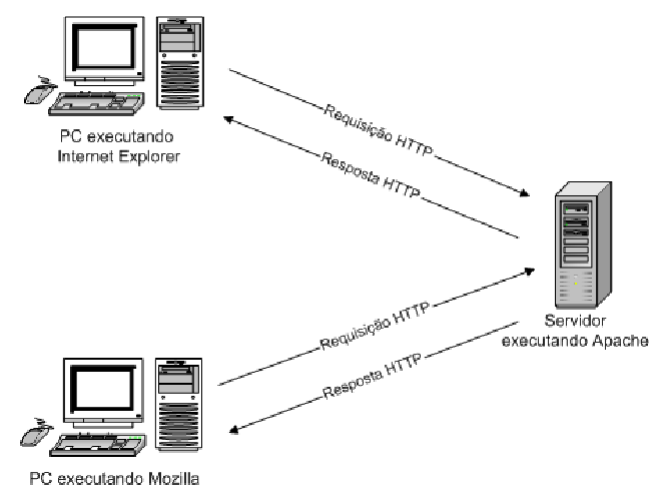

Figura 2.6: Comportamento de requisição-resposta do HTTP

Quando um usuário solicita uma página Web (por exemplo, clica sobre um hiperlink), o browser envia ao servidor mensagens de requisição HTTP para os objetos da 
página. O servidor recebe as requisições e responde com uma mensagem de resposta HTTP que contém os objetos. Até 1997, essencialmente todos os browsers e servidores Web implementavam a versão HTTP/1.0, definida na RFC 1945 (BERNERS-LEE; FIELDING; FRYSTYK, 1996). A partir de 1998, alguns servidores Web e browsers começaram a implementar a versão HTTP/1.1, definida na RFC 2616 (FIELDING et al., 1999). O $H T T P / 1.1$ é compatível com o HTTP/1.0; um servidor web que executa a versão 1.1 pode "conversar" com um browser que executa a versão 1.0, e um browser que executa a versão 1.1 pode "conversar" com um servidor que executa a versão 1.0. Além disso, o HTTP/1.1 utiliza o conceito de conexões persistentes, permitindo que os dados de uma aplicação (carregar os objetos de uma página no browser, por exemplo) sejam transportados utilizando apenas uma conexão TCP, ao invés de uma conexão TCP para cada objeto da página.

Tanto o HTTP/1.0 quanto o HTTP/1.1 usam o TCP como seu protocolo de transporte subjacente (em vez de utilizarem o UDP). O cliente HTTP primeiramente inicia uma conexão TCP com o servidor. Assim que a conexão é estabelecida, os processos do browser e do servidor acessam o TCP por meio de sua interface de porta. O cliente envia mensagens de requisição HTTP para a interface desse protocolo através da porta e recebe mensagens de resposta HTTP de sua interface de porta. De maneira semelhante, o servidor HTTP recebe mensagens de requisição de sua interface de porta e envia mensagens de resposta através da interface de porta. Como se sabe, o TCP fornece ao HTTP um serviço confiável de transferência de dados, isto é, toda mensagem de requisição HTTP emitida por um processo cliente chegará intacta ao servidor. Uma das grandes vantagens de uma arquitetura de camadas é que o HTTP não precisa se preocupar com os dados perdidos ou com os detalhes de como o TCP recupera a perda de dados ou os reordena dentro da rede. Esta é uma tarefa do TCP e dos protocolos das camadas mais inferiores da pilha de protocolos.

O servidor envia os arquivos solicitados ao cliente sem armazenar nenhuma informação de estado sobre o cliente. Se um determinado cliente solicita o mesmo objeto duas vezes em um período de poucos segundos, o servidor não responde dizendo que ele acabou de servir o objeto ao cliente; em vez disso, ele reenvia o objeto, pois já esqueceu completamente o que fez antes. O protocolo HTTP por não manter nenhuma informação sobre os clientes é conhecido como protocolo sem estado.

\subsubsection{Mensagens HTTP}

As especificações do HTTP/1.0 (BERNERS-LEE; FIELDING; FRYSTYK, 1996) e do HTTP/1.1 (FIELDING et al., 1999) definem os formatos das mensagens HTTP. Há dois tipos de mensagens HTTP: as mensagens de requisição e as mensagens de resposta, que serão discutidas a seguir. 


\section{Mensagem de requisição HTTP}

Uma mensagem de requisição HTTP, típica de um cliente a um servidor, inclui em sua linha inicial o método HTTP a ser aplicado ao recurso, a localização do objeto no servidor e a versão do protocolo em uso, como pode ser observado a seguir:

GET /dir/page.html HTTP/1.1

Host: www.someschool.edu

Connection: close

User-agent: Mozilla/4.0

Accept-language: fr

(extra carriage return, line feed)

No exemplo, o cliente solicita através do método GET o arquivo /dir/page.html do servidor web cujo nome é www.someschool.edu, utilizando o protocolo HTTP/1.1. Embora o browser que gerou essa mensagem de requisição implemente o HTTP/1.1, não será possível utilizar conexões persistentes, uma vez que a linha de cabeçalho Connection está ajustada como close. A linha de cabeçalho User-agent especifica o agente de usuário, isto é, o tipo de browser que está fazendo a requisição ao servidor. O campo Accept-language é apenas um dos muitos cabeçalhos de negociação de conteúdo disponíveis no HTTP.

O protocolo HTTP também disponibiliza um conjunto de métodos para indicar o propósito das requisições. Esses métodos funcionam como comandos enviados ao servidor web. A tabela 2.2 apresenta um resumo dos métodos implementados pelo protocolo HTTP.

\section{Mensagem de resposta HTTP}

Será apresentada a seguir uma mensagem de resposta HTTP típica. Essa mensagem pode ser a resposta ao exemplo de mensagem de requisição que foi discutida anteriormente.

HTTP/1. 1200 OK

Connection: close

Date: Thu, 06 Aug 2003 12:00:15 GMT

Server: Apache/1.3.31 (Linux)

Last-Modified: Mon, 22 Oct 2003 09:23:24 GMT

Content-Length: 6831

Content-Type: text/html

(data data data data data ...) 


\begin{tabular}{|c|l|}
\hline \hline Método & Funcionalidade \\
\hline \hline GET & $\begin{array}{l}\text { Solicita que seja retornado o re- } \\
\text { curso identificado pela URL }\end{array}$ \\
\hline \hline HEAD & $\begin{array}{l}\text { Obtém informações sobre o re- } \\
\text { curso sem que o mesmo seja retor- } \\
\text { nado ao cliente. Testa validade } \\
\text { de links, acessibilidade e a data } \\
\text { da última modificação }\end{array}$ \\
\hline \hline OPTIONS & $\begin{array}{l}\text { Estabelece e encerra enlaces de } \\
\text { comunicação }\end{array}$ \\
\hline \hline PUT & $\begin{array}{l}\text { Sequenciamento, confirmação, re- } \\
\text { cebimento de pacotes de dados }\end{array}$ \\
\hline \hline DELETE & $\begin{array}{l}\text { Formatação da informação em } \\
\text { quade dos dados através da }\end{array}$ \\
\hline \hline TRACE & $\begin{array}{l}\text { Conexão física entre o sistema o- } \\
\text { peracional e a rede }\end{array}$ \\
\hline \hline CONNECT & $\begin{array}{l}\text { Conexão física entre o sistema o- } \\
\text { peracional e a rede }\end{array}$ \\
\hline
\end{tabular}

Tabela 2.2: Métodos do protocolo HTTP/1.1

Uma mensagem de resposta possui como conteúdo em sua linha inicial, a versão do protocolo HTTP e um código de status. Neste exemplo, a linha inicial informa que o servidor utiliza o protocolo HTTP versão 1.1 e que a solicitação foi completada com sucesso (código de status 200). O servidor usa a linha de cabeçalho Connection: close para informar ao cliente que ele vai fechar a conexão TCP após enviar a mensagem. O campo Data (cabeçalho geral) especifica a data e o horário da resposta, e o campo Server (cabeçalho de resposta) informa o tipo de servidor web (Apache 1.3.31). Os campos seguintes pertencem ao cabeçalho da entidade que denotam o tipo de documento (text/html), o seu tamanho em bytes (6831) e quando foi atualizado pela última vez.

O protocolo HTTP oferece um lista de códigos de status para os servidores web informarem aos clientes, de acordo com o grau de sucesso obtido na tentativa de atender uma requisição. As classes de códigos de respostas podem ser visualizadas na tabela 2.3 a seguir:

\begin{tabular}{|c|c|}
\hline \hline Classe & Descrição \\
\hline \hline $1 \mathrm{xx}$ & Requisição recebida e em fase de processamento \\
\hline \hline $2 \mathrm{xx}$ & Requisição recebida, entendida e processada com sucesso \\
\hline \hline $3 \mathrm{xx}$ & Redireciona o cliente a outra URL \\
\hline \hline $4 \mathrm{xx}$ & Requisição inválida, feita pelo cliente \\
\hline \hline $5 \mathrm{xx}$ & Incapacidade do servidor de processar a requisição \\
\hline
\end{tabular}

Tabela 2.3: Classes de código de status HTTP 


\subsection{Considerações Finais}

Este capítulo abordou a infra-estrutura da web, assunto de grande importância para o desenvolvimento deste trabalho. Primeiramente foi introduzido o modelo de referênca ISO/OSI e em discussão mais detalhada a pilha de protocolos $T C P / I P$, visto que estes são os protocolos base da Internet. Também foi abordado o protocolo HTTP, bem como as mensagens de requisição e resposta, além de suas características.

Um breve conhecimento de como a estrutura da $W e b$ funciona é importante para se entender quais as características atuais da Internet. A $W e b$ tem se tornado nos últimos anos um canal para troca de informações críticas, negócios e e-commerce, sendo necessário, portanto, um tratamento diferenciado para as aplicações que trafegam pela rede. No próximo capítulo serão abordados os conceitos de serviços integrados e serviços diferenciados no nível da rede de comunicação. No entanto, uma atenção especial será dada aos serviços diferenciados no nível de aplicação, ou seja, nos servidores web. 


\section{Capítulo \\ 3 \\ Qualidade de Serviço}

\subsection{Considerações Iniciais}

Atualmente, o tráfego na rede é muito diversificado e cada tipo possui um requisito único em termos de largura de banda, atraso, perda e disponibilidade. Com o crescimento explosivo da Internet, a maioria das redes do momento são baseadas no protocolo IP. O fato de possuir um único protocolo de transporte é benéfico, visto que a manutenção dos esquipamentos de rede se torna menos complexa, resultando em custos operacionais mais baixos. Entretanto, isso é contrastado pelo fato de que o IP é um protocolo sem conexões, isto é, os pacotes IP não possuem um caminho específico à medida que trafegam pela rede. Isso resulta numa qualidade de serviço inadequada em uma rede best effort (NETWORKS, 2003). Por isso, neste capítulo, serão introduzidos os conceitos de qualidade de serviços em redes $I P$ e também os esforços realizados para melhorar a $Q o S$ no nível de aplicação, principalmente nos servidores web, os principais responsáveis pelo atendimento das requisições que trafegam pela rede mundial de computadores.

\subsection{Qualidade de Serviço}

$\mathrm{Na}$ Internet e nas Intranets, a largura de banda é um assunto importante. Atualmente, há um cenário em que mais e mais pessoas estão utilizando a Internet por motivos comerciais e particulares. Novos aplicativos, como RealAudio, RealVideo, Internet Phone, bem como sistemas de videoconferência precisam mais de largura de banda que os aplicativos usados nos primeiros anos da Internet, tais como aplicativos de transferências de arquivos e de login remoto. Enquanto aplicativos tradicionais, tais como $W W W$ e FTP não toleram perda de pacotes, mas são menos sensíveis aos atrasos variáveis, a maioria dos 
aplicativos em tempo real apresenta exatamente o comportamento oposto, pois podem compensar uma quantidade razoável de perda de pacotes mas são normalmente muito críticos em relação aos atrasos variáveis. Diante dessa situação, na ausência de algum tipo de controle de largura de banda, a qualidade desses fluxos de dados em tempo real torna-se dependente dessa ausência. (FERGUSON; HUSTON, 1998)

Larguras de banda baixas, ou mesmo instáveis, causam má qualidade de transmissões em tempo real, com eventuais interrupções ou paradas definitivas da transmissão. Mesmo a qualidade de uma transmissão usando o protocolo RTP (Real Time Protocol) depende da utilização do serviço de entrega IP subjacente. Por isso são necessários conceitos novos para garantir uma QoS específica para aplicativos em tempo real na Internet.

Qualidade de serviço $(Q o S)$ refere-se à capacidade de uma rede prover melhores serviços para um dado tráfego selecionado, podendo utilizar várias tecnologias incluindo Frame Relay, ATM, Ethernet, redes 802.1, SONET e redes IP (VEGESNA, 2000). Dentre os parâmetros para descrever $Q o S$ destacam-se, por exemplo, largura de banda, utilização de buffers, atraso, jitter, prioridades, utilização de $C P U$, etc.

A pilha do protocolo $I P$ básica fornece somente uma $Q_{o} S$ que é chamada de "melhor esforço". Os pacotes são transmitidos de um ponto a outro sem qualquer garantia de uma largura de banda especial ou retardo mínimo. No modelo de tráfego de melhor esforço, as requisições na Internet são processadas conforme a estratégia da primeira a chegar, primeira a ser atentida. Isso significa que todas as requsições têm a mesma prioridade e são processadas uma após a outra sem nenhuma distinção.

Sem a possibilidade de fazer reserva de largura de banda para conexões específicas ou aumentar a prioridade de uma requisição especial, foram desenvolvidas novas estratégias para oferecer serviços previsíveis na Internet. Dentre as estratégias para conseguir QoS atualmente podem ser citadas os Serviços Integrados e os Servidores Diferenciados, ambos objetos de estudo das próximas seções deste capítulo.

\subsubsection{Categorias de aplicações}

Aplicações de rede podem ser divididas de acordo com as expectativas dos usuários, ou de acordo com os requisitos das aplicações. Algumas aplicações estão entre pessoas, enquanto outras estão entre pessoas e uma aplicação de um dispositivo de rede, por exemplo um $P C$ e um servidor web. Finalmente, algumas aplicações estão entre dispositivos; entre dois roteadores por exemplo.

A tabela 3.1, ilustra quatro categorias diferentes de tráfego nas quais as aplicações acima mencionadas fazem parte: interativa, orientada a resposta, orientada ao tempo e controle de rede. 


\begin{tabular}{|c|c|}
\hline \hline Categoria do tráfego & Exemplo de aplicação \\
\hline \hline Cotrole de rede & Alarmes críticos, roteamento \\
\hline \hline Interativas & VoIP, game interativo, videoconferência \\
\hline \hline Orientadas à resposta & Streaming de áudio e vídeo, cliente-servidor \\
\hline \hline Orientadas ao tempo & E-mail \\
\hline
\end{tabular}

Tabela 3.1: Categorias de tráfego e suas aplicações

\section{Aplicações Interativas}

Algumas aplicações são interativas, isto é, há a participação de mais de um indivíduo. Os participantes de uma videoconferência, por exemplo, esperam que a aplicação de rede responda em tempo real. Neste contexto, tempo real quer dizer que há um atraso mínimo (latência) e uma variação de atraso (jitter) controlada entre o emissor e o receptor. As chamadas telefônicas têm operado em tempo real numa rede de comutação de circuitos por mais de cem anos, mas tem havido uma grande convergência de aplicações de voz para redes de comutação de pacotes como a Internet por exemplo. A maior parte das aplicações interativas tem como protocolo base o UDP, que permite a retransmissão de pacotes perdidos, mas mesmo assim, as perdas de pacotes devem ser minimizadas, pois tais aplicações operam em tempo real.

\section{Aplicações orientadas à resposta}

Usuários finais necessitam que determinadas aplicações forneçam uma resposta rápida, permitindo, assim, que a interatividade seja mantida. Por exemplo, quando um cliente envia uma requisição ao servidor, uma resposta relativamente rápida deve ser enviada ao cliente. Aplicações com estas características são conhecidas como quase tempo real e utilizam em sua maioria o protocolo de transporte $T C P$, cuja perda de pacotes é gerenciada por um mecanismo de retransmissão. Requerem, portanto, atraso entre pacotes, jitter e também perdas mínimas. Entretanto, os requisitos de $Q o S$ para este tipo de aplicação são menos severos em relação às aplicações de tempo real.

\section{Aplicações orientadas ao tempo}

Outra categoria de aplicações trabalha com o critério de que a informação deve estar disponível numa faixa de tempo pré-determinada. Como exemplo, podem-se citar as aplicações de email e também as de transferência de arquivos. A importância relativa dessas aplicações é baseada nas prioridades de negócios. Por exemplo, se um e-mail de um amigo para outro leva alguns minutos para chegar ao destinatário, isso é perfeitamente aceitável. No entanto, num ambiente empresarial, se um e-mail demora dez minutos para atingir o destino, isso indica algum problema. Em resumo, aplicações orientadas ao tempo esperam que a $Q o S$ da rede tolere um determinado atraso de pacotes. O jitter apresenta um efeito pequeno sobre este tipo de aplicação e as perdas são menores devido ao mecanismo de recuperação do $T C P$. 


\section{Aplicações de controle de rede}

Há um determinado tipo de aplicação cujo objetivo é controlar a operação e a administração da rede. Tais aplicações incluem protocolos de rede e medição além de monitoramento de $Q o S$ para os chamados $S L A s^{1}$. Para criar redes de alta disponibilidade, aplicações de controle de rede requerem prioridades sobre as aplicações de usuários finais, pois, se a rede não estiver operando apropriadamente, a performance das aplicações dos usuários finais pode ser prejudicada. Em resumo, as aplicações da categoria aqui exemplificada necessitam de uma quantidade relativamente baixa de atraso. Além disso, perdas precisam ser minimizadas pois algumas das aplicações não são transportadas via $T C P$ e, por isso, não são capazes de tratar a perda de pacotes.

\subsection{Garantia de qualidade de serviço}

A largura de banda não é suficiente para que a qualidade de serviço de uma determinada aplicação seja garantida. Essa insuficiência deve-se aos longos congestionamentos, aos atrasos inadmissíveis em redes compartilhadas por milhares de usuários e, na maioria das vezes, a longas distâncias. Existem algumas formas de prover qualidade de serviço às aplicações críticas (voz e videoconferencia, por exemplo), com destaque para os serviços integrados, seviços diferenciados, prioridade relativa e label switching. Pesquisas recentes têm mostrado que a $Q o S$ também pode ser obtida em nível de aplicação. (ANDREOLINI et al., 2004)

\subsection{Serviços Integrados}

O RFC 1633 descreve um modelo que inclui serviços de melhor esforço e de tempo real. O serviço de tempo real é utilizado para prover $Q o S$ em aplicações multimídia sobre redes $I P$. Destaca-se na arquitetura IntServ o protocolo $R S V P^{2}$, responsável pela reserva de recursos ao longo do caminho entre uma origem e um destino.

\subsubsection{O protocolo RSVP}

RSVP é um protocolo de controle que atua sobre o $I P$, ocupando o lugar do protocolo de transporte, da mesma forma que o ICMP, IGMP ou protocolos de roteamento. As aplicações utilizam o $R S V P$ para reservar e manter durante a conexão uma determinada qualidade de serviço até a aplicação destino, e o $R S V P$ faz isso criando um caminho entre origem e destino, perguntando a todos os nós intermediários se eles suportam a QoS desejada, e reservando as necessidades daquela aplicação. Para tanto, todos os nós no meio

\footnotetext{
${ }^{1}$ Service Level Agreements

${ }^{2}$ Resource Reservation Protocol
} 
do caminho devem suportar esse protocolo. O protocolo $R S V P$ utiliza outros protocolos para efetuar roteamento e transmissão. Seu único objetivo é a reserva, manutenção e liberação de recursos quando solicitado. Assim, ele pode operar em unicast, multicast, IPV4, IPV6 e outros. Os módulos necessários para uma implementação $R S V P$ e um resumo destes é mostrado a seguir.

- Controle de admissão: utilizado no início da chamada para verificar se o nó possui recursos suficientes para fornecer a qualidade de serviço solicitada;

- Controle de políticas: determina se o usuário tem permissão administrativa para fazer a reserva;

- Classificador e escalonador de pacotes: o classificador de pacotes determina a classe de $Q o S$. Quando a solicitação passa pelo controle de admissão e políticas, são configurados alguns parâmetros nesses módulos, a fim deles reconhecerem os pacotes para ordenar corretamente na saída, dando a necessária qualidade de serviço para cada fluxo;

- Fluxo de dados: O RSVP é simplex, isto é, faz reservas para fluxos unidirecionais.

O processo do RSVP também estabelece comunicação com as rotinas de roteamento para determinar o caminho das solicitações de reserva. Uma mudança de uma rota na tabela de roteamento (que é dinâmica), pode causar um problema, gerando neste caso uma necessidade de reserva através do novo caminho. Isso ocorre pois o caminho estabelecido é do tipo soft state necessitando de mensagens periódicas para se manter. Na ausência de tais mensagens (por uma mudança de rota ou saída de cliente), a interface gera um time-out e a reserva passa a ser liberada. A reserva de $Q o S$ é feita na ordem reversa, ou seja, do receptor ao transmissor. Essa solicitação de reserva se repete até que chegue no transmissor ou encontre um nó com as mesmas necessidades. Tais reservas são implementadas através das mensagens PATH e RESV.

As mensagens PATH são enviadas periodicamente pelo transmissor ao endereço multicast e contém a especificação de fluxo (formato de dados, endereço fonte, porta fonte) e características de tráfego. Esse tipo de informação é utilizada pelos receptores para encontrar o caminho reverso ao transmissor e determinar quais recursos devem ser reservados.

Por sua vez, as mensagens $R E S V$ são geradas pelos receptores, contendo parâmetros de reserva, como especificação de fluxo e de filtro. O filtro determina quais pacotes no fluxo de dados devem ser utilizados no classificador de pacotes. A especificação é usada no escalonador, que objetiva manter a necessidade do receptor.

Com a utilização do protocolo $R S V P$, consegue-se atingir a maior QoS possível na Internet (STARDUST.COM, 1999), pois ele permite fazer o gerenciamento em uma granulosidade bem fina, em nível de fluxo, conseguindo dar excelentes garantias de qualidade 
às aplicações. No entanto, o RSVP possui problemas de escalabilidade (VASILIOU, 2000). Cada roteador ao longo do caminho precisa dar suporte à $R S V P$ para que se possa assegurar a $Q o S$, sendo necessário manter as informações de estado e fazer escalonamento e enfileiramento dos pacotes para cada fluxo (TEIXEIRA, 2004a).

Com isso, vê-se que o $R S V P$ introduz uma complexidade significativa ao núcleo da Internet, o que representa uma ruptura com o seu modelo tradicional de serviços, que sempre procurou manter a rede simples e levar a complexidade para os hosts finais (STARDUST.COM, 1999).

\section{Prioridade relativa}

No modelo de prioridade relativa, a aplicação configura uma determinada prioridade (ou precedência) para o pacote e os nós ao longo do caminho aplicam essa regra no momento de encaminhar o quadro. O comportamento que pode ser configurado é de atraso relativo ou prioridade de descarte. A arquitetura DiffServ pode ser considerada um refinamento desse modelo, pois especifica com maiores detalhes a importância dos domínios de tráfego. Alguns exemplos desse tipo de $Q o S$ são o modelo de precedência do IPV4 definido na $R F C$ 791, a prioridade das redes Token Ring e a interpretação das classes de tráfego dada no protocolo IEEE 802.1p (VASILIOU, 2000).

\subsection{Serviços Diferenciados}

A arquitetura de serviços diferenciados é uma das propostas recentes para melhorar a qualidade de serviço em redes IP. Problemas de escalabilidade da arquitetura IntServ e a dificuldade de sua implantação em uma rede como a Internet motivaram o desenvolvimento da arquitetura DiffServ ${ }^{3}$ (BLAKE et al., 1998). Esta seção fornece uma visão geral sobre os fundamentos e as idéias da diferenciação de serviços na Internet.

O principal objetivo do desenvolvimento de serviços diferenciados é a possibilidade de fornecer classes diferenciadas de serviços para o tráfego na Internet e suportar vários tipos de aplicativos e requisitos específicos de negócios. Este tipo de serviço oferece desempenho previsível (retardo, perda de pacotes, etc) para uma determinada carga em um dado momento. A diferença entre os serviços integrados e os serviços diferenciados é que estes propiciam discriminação de serviços progressiva na Internet sem precisar de estados por fluxo e de sinalização a cada roteador. Não há necessidade de realizar reserva de $Q o S$ em cada fluxo, pois com serviços diferenciados, o tráfego Internet é dividido em diferentes classes com diferentes requisitos de QoS.

Um componente central dos serviços diferenciados é denominado de $S L A^{4}$ - acordo de nível de serviço. O SLA é um contrato de serviço entre um cliente e um provedor de

\footnotetext{
${ }^{3}$ Diferentiated Service

${ }^{4}$ Service Level Agreement
} 
serviços. Este tem a função de especificar para o cliente, os detalhes da classificação de tráfego e o serviço de encaminhamento correspondente a ser recebido. Neste contexto, o provedor de serviços precisa garantir que o tráfego de um cliente com o qual ele tem um $S L A$, obtenha a $Q o S$ contratada. Assim, a administração da rede do provedor de serviços precisa definir os planos de ação dos serviços apropriados e medir o desempenho da rede para garantir o desempenho do tráfego combinado.

Para distinguir os pacotes de dados de clientes diferentes em dispositivos de redes que trabalham com a arquitetura DiffServ, os datagramas IP são modificados em um campo específico. Para tanto, é redefinido o layout do octeto Type of Service do cabeçalho do protocolo IPV4 (ou Trafic Class do IPV6), que passa a se chamar DS (Differentiated Service), de acordo com a definição do RFC 2474.

Para oferecer o serviço em conformidade com o $S L A$, os mecanismos a seguir precisam ser combinados em uma rede:

- Configurar o campo $D S$ do cabeçalho do $I P V 4$ nas bordas da rede e nas fronteiras administrativas;

- Utilizar os bits do campo $D S$ para determinar como os pacotes serão tratados pelos roteadores dentro da rede;

- Condicionar os pacotes marcardos nas fronteiras da rede de acordo com os requisitos de $Q o S$ de cada serviço.

\subsubsection{Serviços Diferenciados em nível de aplicação}

O conceito de $Q o S$ em nível de rede apresentado anteriormente será aproveitado para a discussão de $Q o S$ no nível de aplicação. Como se sabe, um servidor web, na atualidade, não está preparado para oferecer $Q o S$ aos seus usuários. Por isso, de nada adianta a provisão de qualidade de serviço empreendida pela rede, se um servidor trata todas as requisições da mesma forma.

A disponibilidade universal e a facilidade para utilizar a interface provida pelos web browsers, juntamente com o crescimento do número de usuários da Internet tem motivado empresas de grande porte a migrar serviços de missão crítica para a Web. Bancos online, reservas de passagens são exemplos de serviços que estão sendo oferecidos via web frontends. Tais características são uma tendência na $W e b$, de modo que as considerações de qualidade de serviço têm ganhado muita importância. Por exemplo, o tempo de resposta muito grande, por parte de um site da web, é um dos problemas enfrentados pelos usuários finais (BHOJ; RAMANATHAN; SINGHAL, 2000).

Enquanto prever a demanda e aumentar a capacidade dos servidores em geral pode permitir a um web site descobrir as expectativas de $Q o S$ dos usuários, saber com certeza 
a demanda de novos usuários é mais custoso e apresenta maiores dificuldades. A alternativa para o tratamento desse problema tem sido a provisão de qualidade de serviço em servidores web, de modo que quando um servidor esteja sobrecarregado, este tenha a habilidade para estabelecer prioridades dentre as requisições que a ele chegam e, seletivamente, processar aquelas que são consideradas mais importantes pelo operador do site. Para o usuário final, deve haver um limite no tempo de resposta às resquisições enviadas a um cluster de servidores web. Se o tempo de resposta exceder um determinado limiar, o usuário tende a ficar insatisfeito com o serviço oferecido. Por isso são necessários algoritmos de balanceamento de carga como sugerem os trabalhos de (HO et al., 2004) e (CHEN; CHEN, 2004) para permitir alta disponibilidade dos servidores, evitar a sobrecarga, além de possibilitar uma resposta rápida aos clientes.

Muitos esforços têm sido direcionados para mensurar o comportamento de servidores web sob determinadas condições de sobrecarga. Para melhorar o desempenho destes, (PAI; DRUSCHEL; ZWAENEPOEL, 1999) desenvolveu-se um web server denominado Flash. A idéia é que as threads e os processos desse servidor nunca sejam bloqueados e que a multiplexação efetiva dos recursos durante a chegada das requisições permita significativos benefícios no desempenho. Outra otimização de um Web Server é proposta por (CROVELla; FRANGIOSO; HARCHOL-BALTER, 1999). Nessa abordagem, um servidor web escalona a ordem em que as requisições são processadas, de modo que requisições para páginas estáticas e pequenas tenham um tratamento preferencial quando comparadas com outras requisições.

Outros estudos têm sido realizados no sistema operacional do servidor para habilitar suporte a $Q o S$. (BHATTI; FRIEDRICH, 1999) destacam a importância de $Q o S$ em Web Servers e propõem uma arquitetura para suportar tiered web services. (TAI; SALEHI, 1998) descrevem a implementação de um middleware que habilita um servidor web não modificado garantir transparentemente bom desempenho num ambiente de host compartilhado. (ABDELZAHER; BHATTI, 1999) descreve como servidores web podem atender conteúdo de uma classe de serviço inferior, sobre condições de sobrecarga, para otimizar a utilização do servidor. Eles utilizam técnicas de controle industrial para determinar a proporção de requisições de usuários de melhor esforço, que serão descartadas permitindo assim que requisições de usuários de alta prioridade não sofram degradação.

Quando está sobrecarregado, um servidor web possui um mecanismo de controle de admissão para manter a qualidade de serviço para os usuários existentes. (CHERKASOVA; PHAAL, 1999) propõem que um servidor web deva permitir um controle de admissão sob as sessões dos usuários, já abertas, ao invés de realizar o controle para cada requisição que chega ao servidor. Uma sessão é uma série de requisições criadas pelo usuário dentro de um período pré-determinado de tempo. O controle de admissão baseado em sessão é importante porque muitos serviços baseados na web são transacionais por natureza. Por exemplo, para uma transação bancária, um usuário pode precisar acessar a página 
de um banco, se identificar, checar o saldo bancário, pagar contas e finalmente finalizar a transação. Em condições de sobrecarga, o esquema de controle de admissão baseado em sessão permite que as sessões de usuários já existentes tenham continuidade, enquanto novas sessões ou são redirecionadas para outros web sites, ou têm acesso negado ao serviço associado.

O trabalho de (EGGERT; HEIDEMANN, 1999) mostra que é possível fornecer serviços diferenciados em servidores web empregando-se apenas técnicas em nível de aplicação. Nesse trabalho, a diferenciação de serviços considera apenas processos de alta e baixa prioridade. (PANDEY; BARNES; OLLSSON, 1998) propõem uma arquitetura de serviços web que permite uma granulosidade mais fina no escalonamento das requisições. Com isso, é possível personalizar como um servidor HTTP deve responder às requisições dos clientes, através da atribuição de prioridades e da alocação dos recursos do servidor às requisições de páginas.

(CHEN; MOHAPATRA, 1999) apresenta uma solução que consiste de um servidor web distribuído com roteamento de tarefas centralizado. O servidor é formado por quatro componentes principais: um iniciador de tarefas, um escalonador, um conjunto de servidores de tarefas e o canal de comunicação. As requisições são recebidas pelo iniciador, que pode aceitá-las ou rejeitá-las, caso a capacidade do sistema tenha sido excedida. Uma vez aceita, a requisição recebe um nível de prioridade, dado pelo escalonador e é atendida por um dos servidores de tarefas. O canal de comunicação trata da modelagem da carga na rede, que é um dos parâmetros levados em conta no escalonamento.

O trabalho de (ALMEIDA et al., 1998) volta-se à area de web hosting, isto é, o caso de um provedor de Internet que possui vastos recursos e abriga sites de diferentes empresas, instituições e indivíduos. A diferenciação de $Q_{o S}$ se dá entre os diferentes sites hospedados no provedor e o mecanismo para prover $Q o S$ é o escalonamento baseado em prioridades, tanto no modo usuário quanto no modo kernel. São oferecidos dois níveis de QoS: alta prioridade e baixa prioridade. A primeira classe de seviço é para clientes que pagam uma taxa de hospedagem e a segunda, para aqueles que a tem de graça.

Outro trabalho interessante apresentado em (BLANQUER et al., 2004) mostra como é possível garantir $Q o S$ em nível de aplicação. Os autores argumentam que a melhor abordagem para garantir qualidade de serviço para os servidores web é a utilização de um mecanismo de controle de admissão e técnicas de controle de tráfego nos pontos de entrada dos hosts da Internet. Eles propõem uma técnica que não requer conhecimento ou modificação do sistema (hardware ou software) que implementa os serviços oferecidos pelo site, de modo a conseguir melhorias na utilização dos recursos do sistema, baixo custo e maior flexibilidade. Juntamente com as técnicas de diferenciação de serviços fazse necessário a utilização de algoritmos de escalonamento para distribuir as requisições que chegam a um cluster de servidores web por exemplo. Isso pode ser visto no trabalho de (BHINDER et al., 2004), no qual os autores estudam diversos esquemas de distribuição 
de requisições, utilizando métricas tais como a vazão, taxa de acertos, etc.

(ANDREOLINI et al., 2004) implementam princípios de QoS em um cluster de servidores web, isto é, uma arquitetura composta de vários servidores e um front-end denominado Web switch. Esse trabalho propõe uma metodologia para determinar um conjunto de acordos de nível de serviço num web cluster real para múltiplas classes de usuários e serviços. Os autores consideram quatro princípios básicos necessários para prover garantia de QoS para aplicações de rede: classificação, controle de admissão, isolamento de desempenho e alta utilização de recursos. Investigam como estes princípios de $Q o S$ no nível de rede podem ser extendidos para servidores web baseados em cluster e quais mecanismos podem ser implementados no nível de Web switch.

Além de todas as propostas apresentadas anteriormente para melhorar a qualidade de serviço há também o modelo de servidor web idealizado por (TEIXEIRA, 2004a) capaz de oferecer diferentes classes de serviço a seus clientes e garantir a qualidade de serviço fornecida. O modelo também trata da implementação de esquemas de balancemaneto de carga para a alocação de tarefas, como será abordado no capítulo 4.

\subsection{Considerações Finais}

Neste capítulo foram estudados os conceitos gerais de qualidade de serviço tanto no nível de rede quanto no nível de aplicação, além da estrutura da Web. Discutiramse também os diversos tipos de aplicações que circulam pela Internet atualmente, destacando-se as aplicações interativas, aplicações orientadas à resposta, etc. Para melhor entendimento da arquitetura dos serviços integrados foi abordado o funcionamento do protocolo $R S V P$, cuja principal característica é manter durante a conexão uma determinada $Q o S$ até a aplicação destino por meio de reserva de recursos. Uma visão sobre as idéias e os fundamentos da arquitetura de serviços diferenciados também foi objeto de estudo do presente capítulo.

Além da diferenciação de serviços no nível de rede, foi reiterado a importância do fornecimento de $Q o S$ no nível de aplicação, mostrando os esforços realizados por diversos pesquisadores para melhorar o desempenho dos servidores web, estes os principais responsáveis pelo atendimento às requisições $h t t p$.

O próximo capítulo objetiva a descrição do modelo de servidor web com diferenciação de serviços proposto em (TEIXEIRA, 2004a) e que é a base para o desenvolvimento do trabalho discutido nesta dissertação de mestrado. 


\section{Capítulo \\ 4 \\ Servidor Web com Diferenciação de Serviços SWDS}

\subsection{Considerações Iniciais}

Este capítulo descreve o modelo do Servidor Web com Diferenciação de Serviços idealizado em (TEIXEIRA, 2004a).

Serão detalhados seus principais componentes e sua validação, feita através de simulação dirigida por traces. Para a geração da carga de trabalho foram utilizados logs de acesso a servidores web reais, os quais serão discutidos oportunamente. É fornecida também uma visão geral dos algoritmos de controle de admissão e diferenciação de serviços, além de alguns cenários de uso para serviços diferenciados. O modelo $S W D S$ foi implementado com o objetivo de caracterizar o conceito de diferenciação de serviços em nível de aplicação ao permitir que requisições tenham um tratamento diferenciado em relação ao atendimento, diferente da característica atual dos servidores $W e b$, na qual as requisições são atendidas segundo a disciplina FCFS.

\subsection{O Modelo do sevidor SWDS}

Os servidores web atuais tratam as requisições que recebem segundo uma disciplina $F C F S^{1}$, onde é mantida uma única fila de espera na qual cada requisição aguarda o momento de ser atendida, de acordo com sua ordem de chegada. Embora diferentes esquemas de controle de concorrência possam ser implementados no servidor, visando agilizar o atendimento às requisições, estes ocorrem em geral de maneira uniforme, sem

\footnotetext{
${ }^{1}$ First Come First Serve
} 
considerar as particularidades e a urgência de cada tipo de requisição. (TEIXEIRA, 2004a)

Um modelo de servidor web com diferenciação de serviços, representa uma arquitetura de servidor web cujo intuito é o fornecimento de serviços diferenciados a seus clientes, segundo requisitos de $Q o S$ previamente acertados. A arquitetura do servidor $S W D S$ mostrada na figura 4.1 é composta dos módulos descritos a seguir:

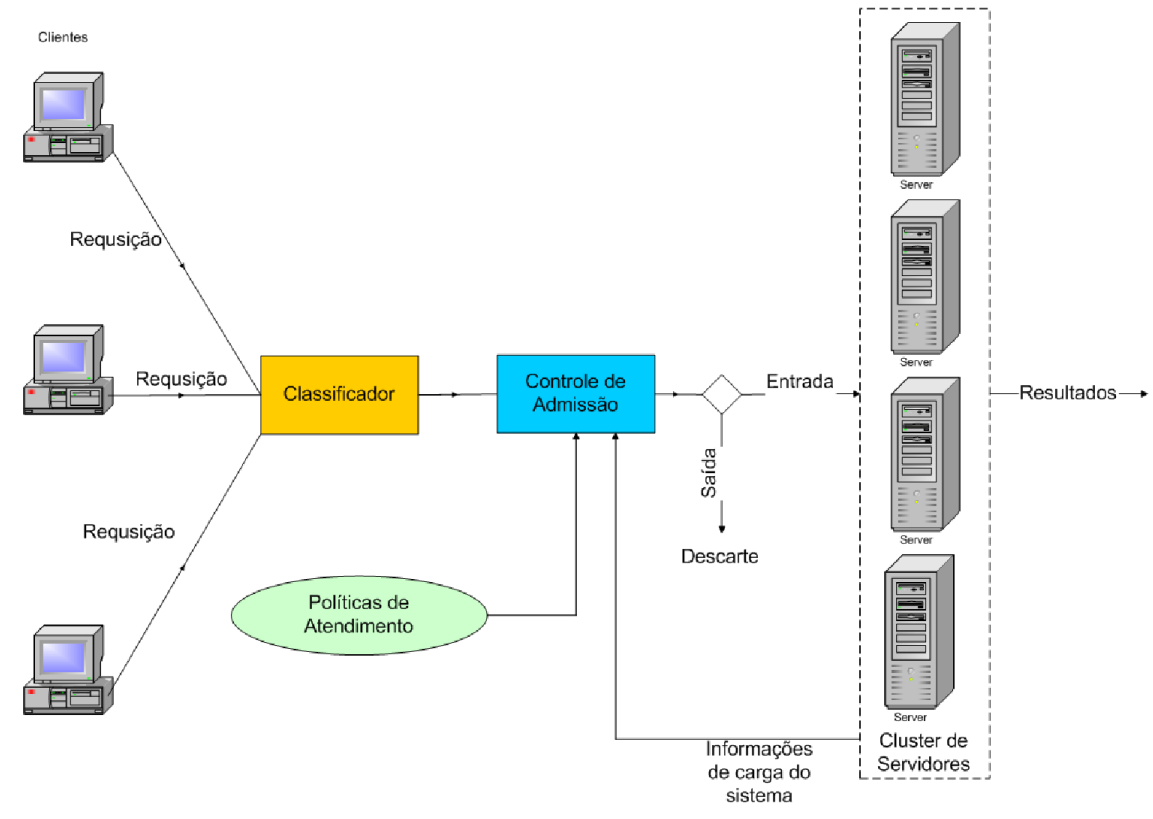

Figura 4.1: Servidor web com diferenciação de serviços (TEIXEIRA, 2004a).

\section{Classificador}

Esse é o elemento responsável por receber as requisições que chegam ao sistema e subdividí-las em classes de serviço, segundo critérios pré-estabelecidos. Terminada esta fase, a nova requisição entra no sistema em uma determinada categoria e recebe um tratamento de acordo com a classe à qual pertence.

\section{Controle de Admissão}

O objetivo do controle de admissão é receber as requisições já classificadas e gerenciar a sua aceitação pelo servidor, levando em consideração as políticas de atendimento vigentes e as informações da carga de trabalho do sistema. Se o servidor estiver sobrecarregado, uma requisição poderá ser rejeitada ou ter suas exigências de qualidade de serviço relaxadas, de modo que possa ser aceita em uma classe de prioridade inferior.

\section{Cluster de Servidores Web}

Uma vez admitida no sistema, a requisição é atribuída a um dos nós do cluster de servidores web, sendo atendida de acordo com o algoritmo de escalonamento ou diferenciação de serviços implementado. Depois da fase de processamento, os resultados são retornados ao cliente que deu origem à solicitação. 
Segundo o modelo definido e implementado em (TEIXEIRA, 2004a) cada nó do cluster é considerado como um servidor web convencional, sendo composto de uma $C P U$, disco e interface de rede. Cada nó é constituído de várias filas de prioridade, com o objetivo de acomodar as diferentes classes de serviço.

O cluster é formado por servidores web, mas nada impede que se faça uma abstração dos mesmos para processos ou até mesmo CPUs em um computador paralelo, pois o modelo não exige que a arquitetura seja necessariamente formada por máquinas dispostas em um sistema distribuído. Igualmente, não é suposta nenhuma plataforma de hardware ou sistema operacional em particular.

O modelo do servidor $S W D S$ foi construído com o intuito de integrar $Q o S$ às arquiteturas de servidores tradicionalmente encontradas. Comparado aos trabalhos da literatura da área, o modelo destaca-se por sua flexibilidade, a qual é conferida pelos variados mecanismos de controle de admissão e diferenciação de serviços. Também consegue adaptar-se a diferentes perfis de carga de trabalho e distribuições dos clientes pelas classes. O modelo tanto pode ser usado como ponto de partida para implantação de infra-estruturas de servidores web distribuídos, voltadas ao fornecimento de serviços diferenciados, quanto para o desenvolvimento de um programa de servidor web com características de diferenciação de serviços, caso em que os nós do cluster seriam abstraídos para processos ou threads, executando em um ou múltiplos processadores. (TEIXEIRA, 2004a).

\section{Carga de trabalho e análise do log}

Dada a dificuldade de produzir sinteticamente uma carga de trabalho com características de cauda pesada e com tráfego em rajadas, uma vez que estudos mostram que a web apresenta uma grande variabilidade nas caracteríticas de sua carga (ARLITT; WILLIAMSON, 1996), optou-se por empregar no desenvolvimento do modelo uma simulação dirigida por traces. Para a validação do modelo $S W D S$ foram utilizadas logs de acessos a servidores reais para a geração de carga, coletados durante a Copa do Mundo de 98.

Segundo (TAI, 1999), algumas das mais importantes características observadas na carga de trabalho da Copa do Mundo de 98 são mostradas a seguir:

- Clientes HTTP/1.1 estão se tornando mais comuns aos acessos aos servidores web;

- A maioria das requisições usa o método GET para a obtenção dos dados, seguido por um percentual mínimo de métodos HEAD e POST;

- $88 \%$ de todas as requisições foram para arquivos de imagens, enquanto que $10 \%$ foram para arquivos $H T M L$. Isso indica que o maior interesse dos usuários era para o acesso a páginas estáticas;

- Quase $19 \%$ de todas as respostas foram Not Modified, indicando que a consistência de cache teve um impacto maior na carga de trabalho da Copa da Mundo do que em outras cargas presentes em servidores web; 
- O tráfego na rede se apresenta em rajadas, em diferentes escalas de tempo;

A caracterização da carga de trabalho dos servidores web é apenas um dos passos necessários para compreender as mudanças ocorridas no tráfego da Internet. Pesquisas sobre cargas de trabalho em clientes web (BARFORD et al., 1999), bem como em servidores proxy (ARLITT; TAI; FRIEDRICH, 1999), além da caracterização do tráfego da rede (THOMPSON; WILDER, 1997), são também importantes para o melhor entendimento da Internet na atualidade.

\subsubsection{Classificação das Requisições}

Para que seja possível o fornecimento de serviços diferenciados aos clientes é necessário trabalhar com o conceito de classes de serviço. Cada classe agrupa um conjunto de clientes com necessidades de atendimento bem definidas. Estas podem ser expressas, de várias formas, como por exemplo em termos de utilização do sistema, throughput a ser atingido, tempo de resposta médio, percentual de requisições completadas, etc.

Como a população de clientes de um servidor web é bastante variada, com diferentes necessidades e expectativas, cabe ao módulo classificador a atribuição de identificar as características das requisições HTTP que chegam ao servidor SWDS e subdividí-las em classes de serviço. Para cada classe é associado um determinado nível de serviço oferecido aos clientes, que podem deixar que o próprio servidor saiba em que classe alocar as requisições recebidas, ou que o cliente contrate um serviço específico, de forma explícita.

Os critérios abaixo podem ser utilizados para realizar a divisão das requisições em classes de serviço:

- Origem da requisição: as solicitações podem ser classificadas como locais, isto é, pertencentes ao mesmo domínio do servidor web e também como remotas, ou seja, provenientes de outros domínios;

- Conteúdo solicitado: o tipo de arquivo requisitado também pode ser um critério para a classificação das requisições, por exemplo: texto, código $H T M L$, imagens, applets, scripts, áudio/vídeo, dentre outros;

- Políticas de atendimento diferenciadas: os clientes podem ser divididos em classes de serviço segundo políticas externas, por exemplo, usuários pagantes/não pagantes. Outra possibilidade é o caso de múltiplos sites armazenados no mesmo servidor (web hosting), onde os clientes são atendidos de acordo com o contrato de hospedagem firmado pelo proprietário do site.

- Mecanismo de geração de conteúdo: as requisições HTTP podem ser divididas em estáticas ou dinâmicas, segundo a forma de geração do conteúdo retornado ao cliente. As requisições dinâmicas podem ainda envolver sessões convencionais ou seguras; 
- Urgência de atendimento: o tráfego que chega a um servidor web pode ser classificado como real ou especulativo. Tráfego real é aquele que surge como resultado de requisições emitidas, de fato, por um cliente. Tráfego especulativo são requisições emitidas geralmente de forma automática, por exemplo, a partir de um servidor proxy ou originadas por pré-buscas.

No estágio atual, as requisições que chegam ao servidor $S W D S$ são classificadas através de uma distribuição de probabilidade acumulada e não pelos critérios acima mencionados. Isso é feito sem perda de generalidade do modelo, uma vez que, para mecanismos de diferenciação de serviços definidos, é indiferente o critério utilizado para a classificação das requisições. (TEIXEIRA, 2004a).

\subsubsection{Mecanismos de Diferenciação de Serviços}

A diferenciação de serviços proposta no modelo de servidor é realizada através de algoritmos específicos que serão explicados a seguir. Segundo (TEIXEIRA, 2004a), os algoritmos implementados possuem duas variantes: podem ser aplicados ainda na fase de despacho das requisições HTTP, determinando a forma de distribuição das mesmas entre os nós do cluster, ou agir diretamente sobre a disciplina de fila dos nós, a fim de alterar a ordem do processamento das requisições. No primeiro caso, o módulo de controle de admissão assume também o papel de escalonador e atribui as requisições a grupos de processos servidores segundo a classe a que pertencem. Realiza-se, portanto, uma forma de enfileiramento baseado em classes, abordagem na qual é reservada parte da capacidade de processamento do servidor para cada classe de requisições.

Na primeira fase de experimento foram implementados dois algoritmos de balanceamento de carga conhecidos, Round Robin e Shortest Queue First, na alocação das tarefas ou requisições aos nós do cluster de modo a se familiarizar com o modelo.

Na segunda fase, porém, verificou-se a adequação da arquitetura proposta para a diferenciação de serviços. Para tanto foi apresentado o algoritmo $R S V$ que permite alocar um ou mais servidores do cluster somente para as tarefas pertencentes a uma certa classe de serviço. O objetivo é permitir a reserva efetiva de um percentual fixo da capacidade de processamento total do servidor $S W D S$ para uma classe privilegiada de tarefas. Um esquema semelhante a esse é encontrado em roteadores, sob o nome de Class-Based Queueing e se caracteriza pela alocação estática das filas de saída às diferentes classes de tráfego. Maiores detalhes estão descritos em (TEIXEIRA; SANTANA; SANTANA, 2003b).

Além das formas de diferenciação de serviços anteriormente mencionadas, o trabalho também confere atenção especial aos mecanismos de escalonamento baseado em prioridades. Outra possibilidade de prover serviços diferenciados em servidores web, é introduzir o conceito de negociação, de modo que uma requisição possa ser aceita em uma classe de 
serviço inferior e ter seus critérios de $Q o S$ relaxados. A introdução de sessões no modelo $S W D S$ é uma outra possibilidade, e está em estudo no LaSDPC ${ }^{2}$.

\section{Utilização}

Embora haja vários cenários possíveis para a utilização de serviços diferenciados na $W e b$, este tópico discutirá os cenários considerados mais importantes para a utilização de servidores web com $Q o S$ e também para a utilização de mecanismos de negociação.

Lojas Virtuais são um meio propício para o emprego de serviços diferenciados. Suas principais características advêm do uso intenso de páginas dinâmicas e imagens, além do alto nível de concorrência entre os usuários, do uso de mecanismos de busca e também sessões seguras. Um exemplo desse cenário é um processo de compra realizado por um cliente. Uma preferência poderia ser dada ao cliente em processo de conclusão de uma compra, em lugar daquele que esteja simplesmente navegando pelo site em busca de informações.

Outros exemplos de aplicação de serviços diferenciados são sites de empresas de serviços de download, disponibilização de conteúdo multimídia, bancos e outros. Em qualquer caso deverá sempre haver um acompanhamento do serviço fornecido, não só para garantir que o mesmo esteja dentro dos padrões de $Q o S$ desejados, mas também para permitir um atendimento adequado às diversas classes de usuários.

A seção a seguir discute mais detalhadamente as características, o funcionamento e a importância do módulo de controle de admissão na arquitetura do servidor $S W D S$. Essa discussão é imprescindível, uma vez que o futuro mecanismo de negociação, uma contribuição esperada deste trabalho de mestrado, será implementado nesse componente da arquitetura anteriormente descrita.

\subsection{O Controle de Admissão}

Muitos servidores web realizam o controle de admissão para manter um alto throughput e também um baixo tempo de resposta durante períodos em que a carga de trabalho do servidor é excessiva. Os servidores tornam-se sobrecarregados quando um ou mais recursos críticos tais como $C P U$, disco e interface de rede excedem sua capacidade de processamento. Dependendo da carga de trabalho atual, alguns recursos do servidor podem ser muito utilizados, enquanto a demanda para outros recursos não é muito alta porque determinados tipos de requisições utilizam mais um tipo de recurso do que outro. (LIM et al., 2002).

Na literatura sobre $Q o S$ em servidores web, há abordagens recentes de controle de admissão que merecem destaque. (VOIGT; GUNNIMGBERG, 2002) propõem um novo me-

\footnotetext{
${ }^{2}$ Laboratório de Sistemas Distribuídos e Programação Concorrente do ICMC-USP
} 
canismo de controle de admissão chamado $Q-P I D^{3}$, no qual um servidor web é capaz de garantir aos seus clientes um serviço num tempo de resposta pré-especificado. $\mathrm{O}$ controlador $Q-P I D$ é baseado num mecanismo de realimentação, cuja a saída do sistema é ligada à entrada do mesmo, de maneira a controlar a próxima saída apropriadamente. O controlador aceita ou rejeita novas requsições, de acordo com a taxa de acerto, que é estimada dinamicamente em tempo de execução, pelo tempo de resposta médio das requisições aceitas anteriormente.

Destaca-se também o mecanismo de controle de admissão evidenciado por (KANODIA; KNIGHTLY, 2003). Essa proposta consiste em um esquema que permite oferecer qualidade de serviço a múltiplas classes, de modo a satisfazer suas restrições de latência.

É definido um servidor virtual de alto nível, baseado em mecanismos de controle de admissão, isolamento de desempenho e diferenciação de serviços, a partir do qual podem-se incrementar servidores web já existentes com características de $Q o S$. Os autores utilizam um conceito de envelope, que representa estatisticamente a carga de requisições que chega a um servidor e a sua capacidade de serviço. Com isso evita-se a necessidade de modelar e avaliar cada componente do servidor (CPU, Disco e Memória) individualmente. Ao decidir pela aceitação de uma nova requisição em uma classe de serviço, o controle de admissão procura determinar os efeitos dessa escolha não apenas na classe pretendida, mas também em todas as outras. O objetivo é atingir um alto nível de isolamento de desempenho entre as classes, de modo que os limites de latência previamente estabelecidos sejam respeitados.

Outro mecanismo de controle de admissão importante foi implementado em (TEIXEIRA, 2004a). O objetivo desta seção é descrever o módulo de controle de admissão, que faz parte da arquitetura de servidor web com serviços diferenciados - $S W D S$. Sendo assim, serão discutidos a arquiterua desse módulo, seus componentes, as métricas utilizadas e os mecanismos de controle implementados.

\subsubsection{Componentes}

A principal função do módulo de controle de admissão do modelo de servidor $S W D S$ é o gerenciamento e a aceitação de novas requisições pelo servidor. Com essas características, o módulo impede que o servidor atinja a sobrecarga. O controle de admissão do servidor $S W D S$ foi projetado de modo a ser ampliado conforme a necessidade. Dentre seus componentes destacam-se: um módulo de coleta de informações de carga, uma área de váriáveis globais e um módulo de mecanismo de controle, como mostra a figura 4.2.

- Mecanismos de Controle: São os mecanismos de controle de admissão implementados no servidor $S W D S$.

\footnotetext{
${ }^{3}$ QoS, Proportional, Integral and Derivative
} 


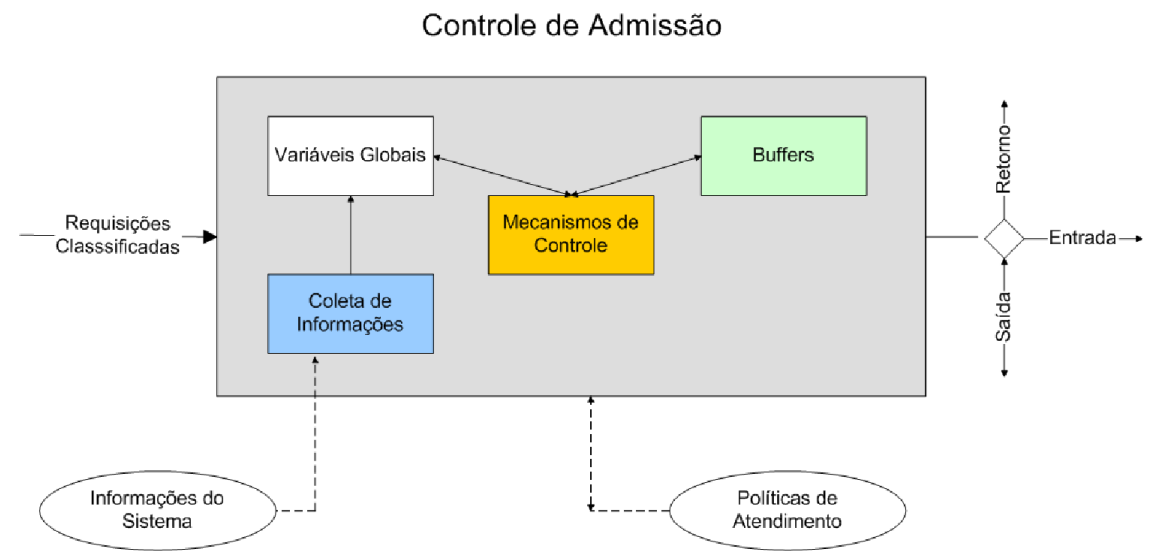

Figura 4.2: Módulo de controle de admissão (TEIXEIRA, 2004a).

- Área de buffers: Composta por buffers que são utilizados para limitar o número de clientes de uma certa classe presentes no servidor num dado instante, por exemplo;

- Área de variáveis globais: guarda informações referentes ao estado do sistema e às métricas relevantes para o controle de admissão.

- Coleta de informações: Coleta informações atualizadas da carga do sistema. Estas são utilizadas como base para a tomada de decisão;

A versão atual do servidor $S W D S$ apresenta três mecanismos distintos, que serão explicados detalhadamente a seguir. O primeiro limita a fila dos processos servidores a um tamanho máximo e não aceita novas requisições quando esse limite for atingido. $\mathrm{O}$ segundo, por sua vez, faz o controle a partir do tempo de resposta das requisições de maior prioridade, além de alocar buffers de tamanho fixo para as diferentes classes, de modo a limitar a carga no sistema. O terceiro mecanismo baseia suas decisões de descarte numa média exponencialmente ponderada da utilização do sistema, podendo-se ajustá-lo para ser mais ou menos sensível a mudanças no perfil da carga de trabalho (TEIXEIRA; SANTANA; SANTANA, 2004b).

\subsubsection{Métricas}

Há várias maneiras de se medir a carga de um sistema, de acordo com o objetivo que se tenha em mente. Exemplos de métricas comumente utilizadas são o tamanho das filas, a utilização do sistema, o tempo de resposta, a taxa de chegada, o nível de ocupação dos buffers, dentre outras. É de fundamental importância a seleção apropriada das métricas a serem utilizadas pelo controle de admissão. Uma vez selecionada a métrica, é necessário determinar sua periodicidade. Esta pode variar desde medições instantâneas, feitas a cada segundo, até um acompanhamento por um longo período de tempo (BANGA; DRUSCHEL, 1997). 
Também deve ser considerada a abrangência da métrica, a qual pode se referir a uma classe de serviço específica ou ao comportamento global do sistema. O uso de métricas globais ou locais tem suas implicações dependendo do que se deseja quantificar. Métricas globais fornecem um panorama geral, no entanto, há perdas dos detalhes de cada classe de serviço, informação essencial para honrar os acordos de serviço. Por outro lado, métricas que dizem respeito a uma determinada classe permitem acompanhar de perto o comportamento de suas requisições, porém perde-se a visão sistêmica. (TEIXEIRA; SANTANA; SANTANA, 2004b)

A seleção da métrica a ser utilizada, sua peridiocidade, abrangência e limiares préestabelecidos vão depender dos objetivos colocados para o controle de admissão. Para o controle de admissão do servidor $S W D S$, foram escolhidas como métricas o tamanho das filas do servidor, o tempo de resposta da classe de maior prioridade e uma média exponencialmente ponderada da utilização do sistema. (TEIXEIRA; SANTANA; SANTANA, 2004b). Além da utilização das métricas contidas no servidor $S W D S$, está prevista a avaliação de mais métricas para a validação do mecanismo de negociação proposto com o desenvolvimento do presente projeto de mestrado.

\subsubsection{Tipos de Admissão}

\section{Admissão segundo o tamanho das filas}

A admissão segundo o tamanho das filas é um mecanismo que estabelece um tamanho máximo para as filas dos servidores do cluster, de acordo com o valor do parâmetro MAXFILA. Caso um do nós que compõem o cluster tenha uma fila que atingiu o limiar MAXFILA, uma requisição ao tentar ser atendida pelo servidor, será sumariamente recusada, indepedentemente de sua classe.

Uma abordagem como esta também ocorre em nível de rede. Baseia-se na rejeição dos pacotes mais novos que chegam às filas de um roteador. O servidor web Apache também possui um mecanismo deste tipo. Ele rejeita novas requisições HTTP se o tamanho de sua fila exceder 1.024 clientes. Embora simples, esse mecanismo foi o primeiro a ser implementado no servidor $S W D S$, com o objetivo de adquirir uma familiaridade inicial com a tarefa de controle de admissão.

\section{Admissão segundo o tempo de resposta}

O objetivo desse mecanismo é controlar a carga do sistema usando como referência o tempo de resposta das requisições da classe de alta prioridade, o qual é colhido a cada término de serviço. As requisições de alta prioridade são atendidas sempre que possível e as de baixa prioridade são admitidas somente quando a carga do sistema estiver abaixo de um limiar pré-determinado. 
São alocados também dois buffers de tamanho fixo para as requisições de cada classe (BUFLOW e BUFHIGH), a fim de controlar o número máximo de clientes de cada categoria presentes no sistema. O objetivo da utilização dos buffers é proporcionar uma maior estabilidade ao tempo de resposta, evitando que o mesmo apresente picos quando ocorrerem súbitos aumentos na carga de trabalho.

O algoritmo de controle de admissão, para duas classes de serviço, funciona do seguinte modo. Se a carga (tempo de resposta) for menor que THRESHOLD, o sistema aceitará qualquer cliente da classe alta e os clientes da classe baixa só serão admitidos até o limite estabelecido por BUFLOW. Se a carga exceder THRESHOLD, os clientes da classe alta somente serão aceitos até o limite imposto por BUFHIGH e nenhum cliente da classe baixa será admitido no sistema.

\section{Admissão segundo a utilização do sistema}

O mecanismo de controle de admissão proposto em (TEIXEIRA, 2004a) emprega a utilização média do cluster de servidores web como métrica, a qual é calculada através da média exponencialmente ponderada descrita a seguir:

$$
U_{m e d}=(1-p) U_{a n t}+p U_{a t u a l}
$$

onde:

- $U_{\text {ant }}$ é o valor anterior da média

- $U_{\text {atual }}$ é o valor atual observado para a utilização

- $p$ é o peso, sendo $0 \leq \mathrm{p} \leq 1$.

A escolha da utilização como parâmetro de controle é bastante conveniente, pois ela é capaz de indicar, numa visão global, se um sistema está de fato sobrecarregado. O uso de uma média, em vez do valor real da utilização, tem o objetivo de minimizar o efeito de um congestionamento momentâneo no servidor. O peso escolhido determina a sensibilidade da média a mudanças na utilização do cluster. Abordagem semelhante a essa é encontrada no algoritmo $R E D^{4}$ (FLOYD; JACOBSON, 1993), o qual descarta os pacotes das filas dos roteadores antes que ocorra uma situação de sobrecarga. O algoritmo utiliza uma média exponencialmente ponderada do tamanho das filas, além de limiares probabilísticos.

O mecanismo proposto no trabalho de (TEIXEIRA; SANTANA; SANTANA, 2004b) funciona da seguinte forma: a utilização atual do cluster é medida a cada nova requisição que chega ao servidor. Esse valor é combinado com dados históricos a fim de obter a média exponencialmente ponderada, $U_{\text {med }}$. Caso a mesma esteja acima de um limiar préestabelecido (MAXUTIL), então o servidor SWDS recusará quaisquer novas requisições,

\footnotetext{
${ }^{4}$ Random Early Detection
} 
independentemente de sua classe, até que $U_{\text {med }}$ caia para níveis aceitáveis, isto é, abaixo do limiar.

Entre esses dois valores extremos do peso $p$, têm-se diferentes perfis de comportamento do módulo de controle de admissão, desde o mais complacente até o mais rigoroso. Em uma primeira configuração, o servidor apresenta uma política de admissão mais restritiva, devido ao peso da utilização medida $U_{\text {atual }}$ no cálculo da média. Neste caso, o tempo de resposta e as filas tendem a ser menores, pois as recusas de serviço precoces evitam a sobrecarga do sistema. Numa segunda configuração, a política de admissão leva em conta o histórico da carga do sistema $U_{\text {ant }}$, minimizando o impacto da utilização atual na tomada de decisões. Neste caso, para cargas altas, o tempo de resposta e o número de requisições não completadas tendem a ser maiores, já que o servidor é menos criterioso na seleção das requisições (TEIXEIRA; SANTANA; SANTANA, 2004b).

\subsubsection{Novas funcionalidades - Controle de admissão}

Além da funcionalidade de coleta de informações sobre a carga atual do sistema, outras abordagens podem ser implementadas no módulo de controle de admissão. Por exemplo, falta para o módulo trabalhar com o gerenciamento de sessões, políticas de atendimento a clientes e também mecanismos de negociação. A última abordagem é objeto de estudo deste trabalho de mestrado, enquanto que o gerenciamento de sessões deverá ser implementado em um outro trabalho em andamento no grupo de Sistemas Distribuídos e Programação Concorrente.

Uma política de atendimento pode ter um objetivo mais específico, por exemplo, o tempo de resposta da classe 1 nunca será superior a um segundo, ou o percentual de requisições completadas com sucesso deverá ser sempre superior a 90\%, ou algo tão genérico quanto garantir que as requisições de alta prioridade tenham um tratamento preferencial. Diferentes políticas podem mapear um ou mais controles. Pode até mesmo não haver mecanismos disponíveis que satisfaçam a uma certa política, levando à necessidade de criação de novos algoritmos. O trabalho de (TEIXEIRA, 2004a) apenas descreve os mecanismos de controle de admissão implementados até o momento e seu funcionamento, mas não os relaciona especificamente a qualquer política de atendimento a clientes. Outra abordagem prevista no modelo de servidor $S W D S$ e que será abordada neste trabalho, é a funcionalidade de Negociação. No modelo original, uma requisição, após passar pelo controle de admissão, será apenas aceita ou descartada pelo servidor, como será visto no próximo capítulo.

O capítulo 5 mostrará situações que no caso de uma requisição ser recusada, o servidor $S W D S$ poderá trocar informações com o cliente que a emitiu e propor a aceitação da requisição em uma classe de serviço inferior.

Outra possibilidade é fazer uma espécie de negociação forçada, em que a nova re- 
quisição é remarcada para a classe de serviço imediatamente inferior e, então, tenta-se novamente sua admissão no sistema. No pior caso, a requisição acabaria sendo admitida na classe de melhor esforço, embora não seja conveniente para alguns tipos de aplicações.

\subsection{Avaliação de Desempenho do SWDS}

O $S W D S$ foi modelado utilizando a técnica de redes de fila, e o programa de simulação foi desenvolvido utilizando uma biblioteca que apresenta características essenciais para esta finalidade. Assim como no modelo original do servidor web com diferenciação de serviços, não houve preocupação com a modelagem da rede externa, assumindo-se portanto, que há largura de banda suficiente e que a rede não é o gargalo do sistema. O modelo $S W D S$ envolve, como apresentado em seções anteriores, um cluster de servidores, cada um com sua CPU, disco e interface de rede. A parametrização completa do modelo, e que é utilizada no desenvolvimento do mestrado, pode ser melhor verificada em (TEIXEIRA, 2004a).

\subsubsection{Simpack}

A escolha da simulação como técnica de análise de desempenho é importante porque trata-se de uma abordagem flexível, onde os resultados podem ser obtidos de forma mais rápida ao passo que fossem realizados experimentos reais. O uso do Simpack (CUBERT; FISHWICK, 1995) para o desenvolvimento do projeto de mestrado deve-se à experiência na utilização do mesmo em trabalhos anteriores no LaSDPC ${ }^{5}$ com o SMPL (MACDOUGALL, 1987), o que certamente proporcionou uma rápida curva de aprendizado.

Simpack é um simulador desenvolvido a partir da biblioteca SMPL, e possui uma biblioteca escrita em $\mathrm{C}++$, denominada $\mathrm{Sim}++$, composta por uma ampla gama de métodos voltados à simulação de redes de filas, orientada a eventos discretos (KUMAR; MAJHI, 2004). O simulador é distribuído com seu código fonte completo, incluindo inúmeros exemplos de aplicações. Sendo assim, é possível realizar modificações na estrutura do código fonte do simulador para atender às necessidades do projeto.

\subsection{Considerações Finais}

O objetivo do presente capítulo foi o de apresentar o modelo de arquitetura para um Servidor Web com Diferenciação de Serviços $(S W D S)$. Sua principal característica é o atendendimento aos seus clientes com uma qualidade diferenciada, uma vez que é fornecido a cada classe de serviço um tratamento condizente com suas características de demanda. Também foi objeto de estudo deste capítulo a abordagem e parametrização

\footnotetext{
${ }^{5}$ Laboratório de Sistemas Distribuídos e Programação Concorrente
} 
utilizadas para a solução do modelo. Além disso, foram detalhados o módulo de controle de admissão (mecanismos de controle atuais, as métricas utilizadas, os componentes do módulo, novas funcionalidades, tais como a negociação e políticas de atendimento aos clientes) e os mecanismos de diferenciação de serviços, discutindo-se alguns trabalhos relacionados. Finalmente, foram comentados alguns cenários de aplicação de serviços diferenciados.

O próximo capítulo descreve mais detalhadamente os mecanismos de negociação propostos para o desenvolvimento deste trabalho de mestrado. 


\section{Capítulo \\ 5 \\ Propostas de Avaliação de Mecanismos de Negociação}

\subsection{Considerações Iniciais}

Este capítulo descreve como podem ser implementados mecanismos de negociação no modelo de servidor web com serviços diferenciados, definido em (TEIXEIRA, 2004a), objetivando a diminuição do tempo de resposta para requisições de alta prioridade e também para que requisições tenham uma nova chance de entrar no sistema, mesmo com seus critérios de $Q_{o S}$ rebaixados. Serão apresentados além dos mecanismos de negociação as características da simulação, bem como alguns resultados preliminares que serão complementados com os outros resultados apresentados no capítulo 6 .

A motivação para a implementação de algoritmos de negociação é permitir que requisições que não puderam ser atendidas num determinado instante pelo cluster de servidores (ou processos servidores), possam ser atendidas futuramente, mesmo com seus critérios de $Q o S$ rebaixados. A limitação do modelo desenvolvido em (TEIXEIRA; SANTANA; SANTANA, 2005), é que este apenas descreve os mecanismos de controle de admissão implementados e seu funcionamento, mas não os relaciona especificamente a qualquer política de atendimento a clientes e também a nenhum mecanismo de negociação. Em seu modelo original, uma requisição, após passar pelo controle de admissão, será apenas aceita ou descartada pelo servidor.

Nesse sentido, este trabalho contribui para as pesquisas da área com a implementação de dois algoritmos de negociação, que serão discutidos nas seções posteriores. 


\subsection{Algoritmos de Negociação}

Os algoritmos de negociação propostos neste trabalho diferenciam-se no modo como a negociação é realizada. Uma primeira abordagem é tentar atender a requisição rebaixando os critétios de $Q o S$ mesmo sem o cliente saber dessa negociação. Em uma segunda abordagem, o cliente é que decide sobre o rebaixamento dos critérios de $Q o S$ e reencaminha a requisição. De acordo com essas abordagens optou-se pela utilização de três classes de serviço, de modo a validar os algoritmos implementados. As classes foram assim numeradas como 2, 1 e 0 respectivamente. É importante ressaltar que nas simulações o atendimento das requisições pertencentes às classes de serviço obedeceram á seguinte ordem: $2>1>0$. Essa característica de prioridade é dada pela natureza do algoritmo de diferenciação de serviço denominado PRIAdap (TEIXEIRA, 2004a), presente no cluster de servidores (ou processos servidores). A maioria dos trabalhos relacionados que foram objetos de estudos para o desenvolvimento do presente trabalho, utilizam somente 2 classes de serviços (CHERKASOVA; PHAAL, 1999), (CHEN; MOHAPATRA, 1999), (PAI; DRUSCHEL; ZWAENEPOEL, 1999). Naturalmente, é possível estender para N classes, muito embora seja imprescíndivel um estudo bem detalhado para verificar o impacto desse aumento no desempenho do sistema.

\subsubsection{Algoritmo de Negociação Rigoroso}

O algoritmo de negociação rigoroso $(A N R)$ oferece uma "nova chance" para que requisições de determinadas classes de serviço possam ser readmitidas no sistema e, futuramente, possam ser atendidas, mas, com seus requisitos de $Q o S$ rebaixados. Para que sejam novamente admitidas no sistema, as requisições devem retornar ao controle de admissão, e este, com base numa média exponencialmente ponderada da utilização do cluster de servidores web, decide ou não pela entrada da requisição no sistema.

O algoritmo implementado no modelo de servidor $S W D S$ trabalha com três classes de serviço, diferentemente da implementação original que apresentava somente duas classes. O principal objetivo do algoritmo é mostrar a validade do mecanismo de negociação e verificar se este pode ser aplicado no modelo de servidor e em outros que serão desenvolvidos futuramente, para suprir diferentes necessidades no cenário da Web. O modelo do $S W D S$ agora caracterizado com o algoritmo de negociação rigoroso pode ser observado na figura 5.1 .

Como mencionado, são utilizadas três classes de serviços: (classe 2, classe 1 e classe 0 ). As requisições que pertencem à classe 2 têm mais chance de serem admitidas no sistema em relação às classes 1 e 0 , ou seja, a ordem de atendimento prioritário é da classe 2 , passando para classe 1 e finalmente para a classe 0 . Uma requisição da classe 0 só possui uma chance de entrar no sistema, isto é, ou ela é atendida ou é descartada, não podendo 


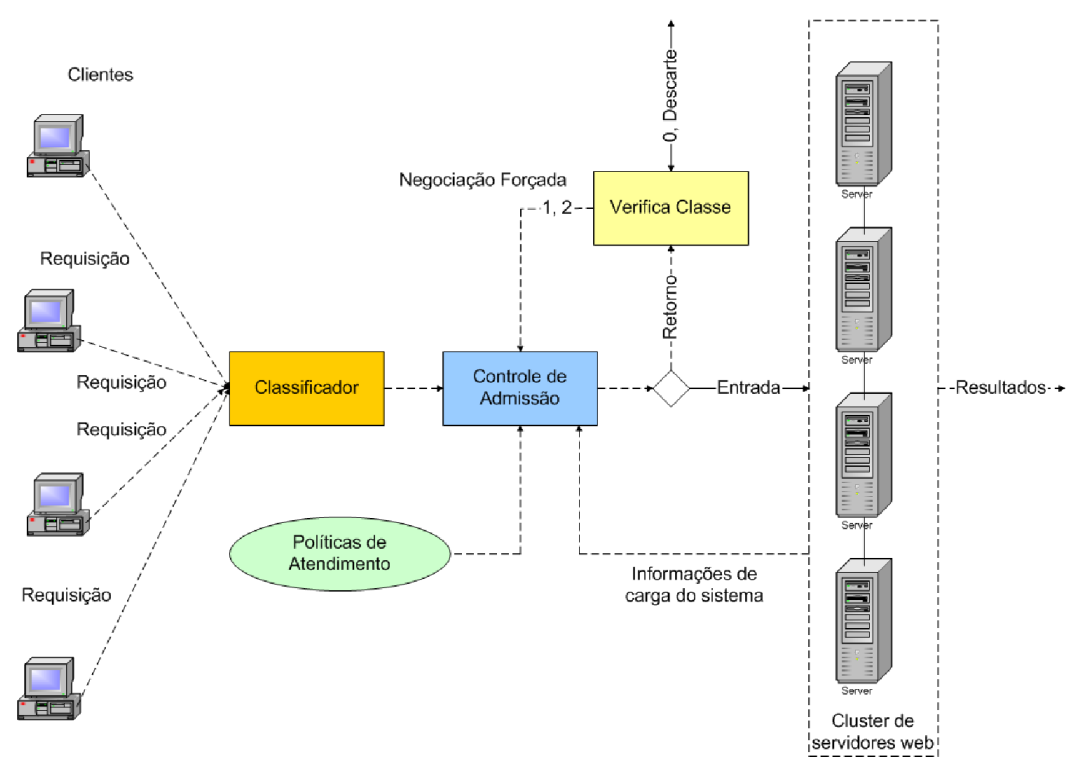

Figura 5.1: SWDS e o Algoritmo de Negociação Rigoroso - ANR

em nenhuma hipótese ser negociada. As requisições da classe 2 possuem três chances de serem admitidas: como pertencente da classe 2, da classe 1 ou da classe 0 . As requisições da classe 1 possuem duas chances: como da classe 1 e outra como da classe 0. Essas duas situações podem ser observados na figura 5.2.

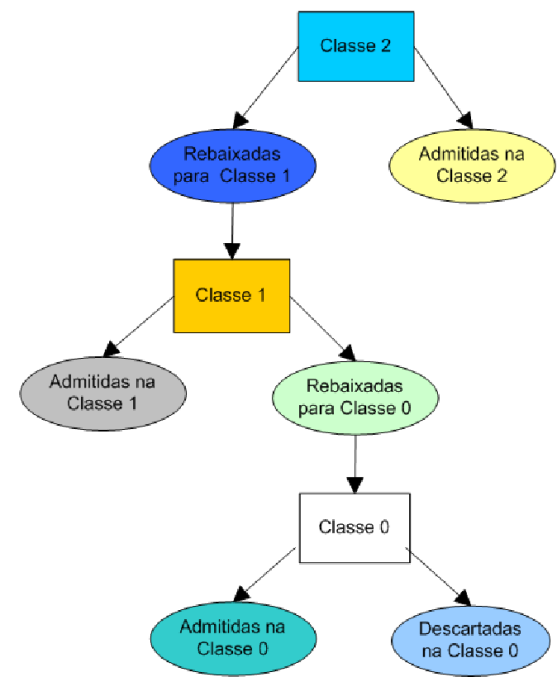

Figura 5.2: Características do rebaixamento para a classe 2

O algoritmo de negociação rigoroso implementado no modelo de servidor web com qualidade de serviço é melhor caracterizado na figura 5.3.

O resultados obtidos com a ulitização deste algoritmo no modelo $S W D S$ serão apresentados no próximo capítulo, e podem ser verificados em (ESTRELLA et al., 2005). 


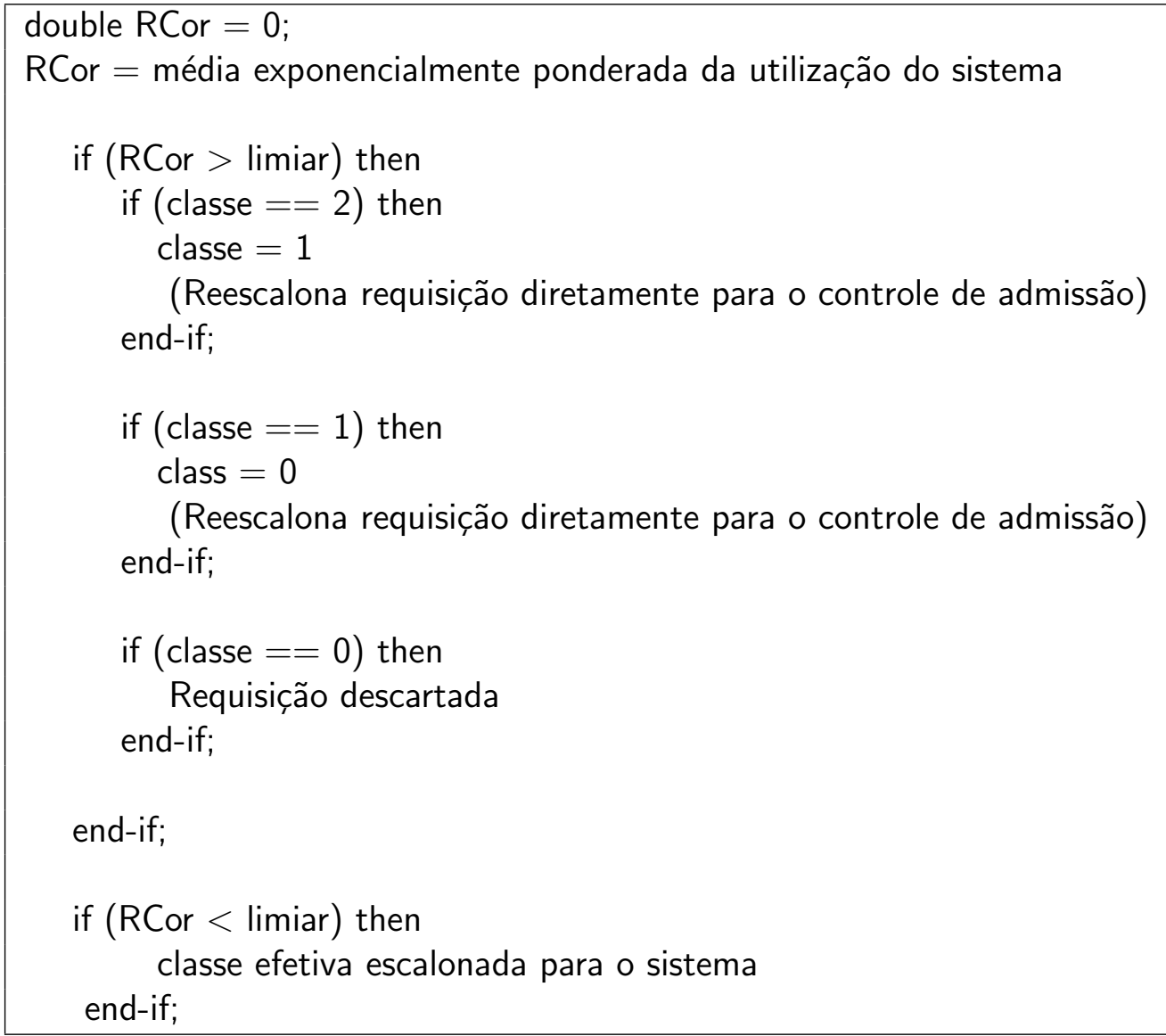

Figura 5.3: Pseudo-Código para o Algoritmo de Negociação Rigoroso

\subsubsection{Algoritmo de Negociação com o Cliente}

Diferentemente do algoritmo de negociação rigoroso, o algoritmo de negociação com o cliente $(A N C)$ é resultado de modificações no código do modelo do servidor $S W D S$, de modo que a requisição que não pode ser admitida retorne ao cliente (e não mais diretamente ao controle de admissão) e este decida se aceita ou não o rebaixamento. Por isso, foi necessária a criação de um novo elemento (denominado ReqThink) que simula o tempo de pensar do cliente (think time) utilizando para isso a função exponencial com valores de média correspondente ao tempo de execução de uma requisição no cluster de servidores web, os quais serão justificados em seções posteriores do presente trabalho. A figura 5.4 ilustra o conceito acima descrito.

Para melhor explanação, observa-se na figura 5.5 o pseudo-código do algoritmo de negociação com a participação do cliente.

\subsection{Características da Simulações}

Para elucidar o mecanismo de negociação na arquitetura de servidor web com diferenciação de serviços foi utilizada a simulação como técnica de avaliação de desempenho. Para 


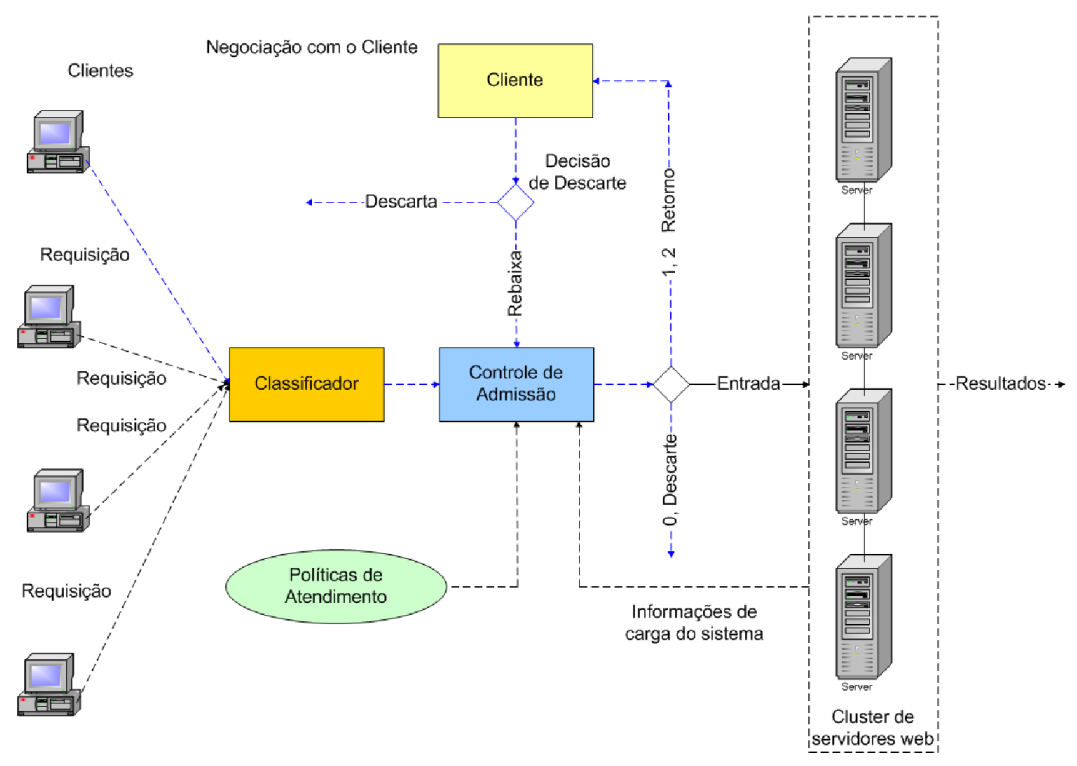

Figura 5.4: SWDS e o Algoritmo de Negociação com o Cliente - ANC

a construção do modelo de servidor, bem como dos algoritmos de negociação foi utilizado o programa para avaliação do $S W D S$ desenvolvido por ?? e foram feitas alterações nesse programa de modo a implementar os dois algoritmos de negociação propostos.

Para a geração da carga de trabalho usada nas simulações, foram escolhidos logs de acesso a servidores web reais coletados durante a Copa do Mundo de 1998 (TAI, 1999), principalmente em função da dificuldade de produzir sinteticamente uma carga com as características da web (distribuição dos tamanhos dos arquivos com características de cauda pesada, tráfego da rede em rajadas) (ARLITT; WILLIAMSON, 1996), apresentando um comportamento auto-similar (CROVELLA; BESTAVROS, 1997). A justificativa para a utilização de um log datado desse ano, se deve por alguns motivos: 1) a escassez de logs disponíveis para o desenvolvimento de pesquisas relacionados à análise de desempenho de aplicações web. 2) de meados de 1998 à atualidade, as grandes empresas passaram a utilizar informações contidas nos logs de servidores web principalmente com o intuito comercial. 3) mais importante, o log da copa de 1998, em específico, apresenta características importantíssimas que permitem a validação dos algoritmos de negociação abordados neste trabalho. Dentre essas destacam-se tráfego em rajadas, características de cauda pesada, etc.

Os parâmetros utilizados na simulação e seus respectivos significados são definidos na tabela 5.1. Vale ressaltar que esses parâmetros (exceto o valor de Med-Resched) são os mesmos utilizados para a validação do $S W D S$ em sua forma original (TEIXEIRA; SANTANA; SANTANA, 2005). Também são levados em consideração indicações de outros trabalhos envolvendo qualidade de serviço em aplicações web, tais como (MENASCE; ALMEIDA, 2003), (CARDELlini et al., 2001), (CHEN; MOHAPATRA, 1999), (CASALICCHIO; COLAJANNI, 2000) e (HU; NANDA; YANG, 1999). 


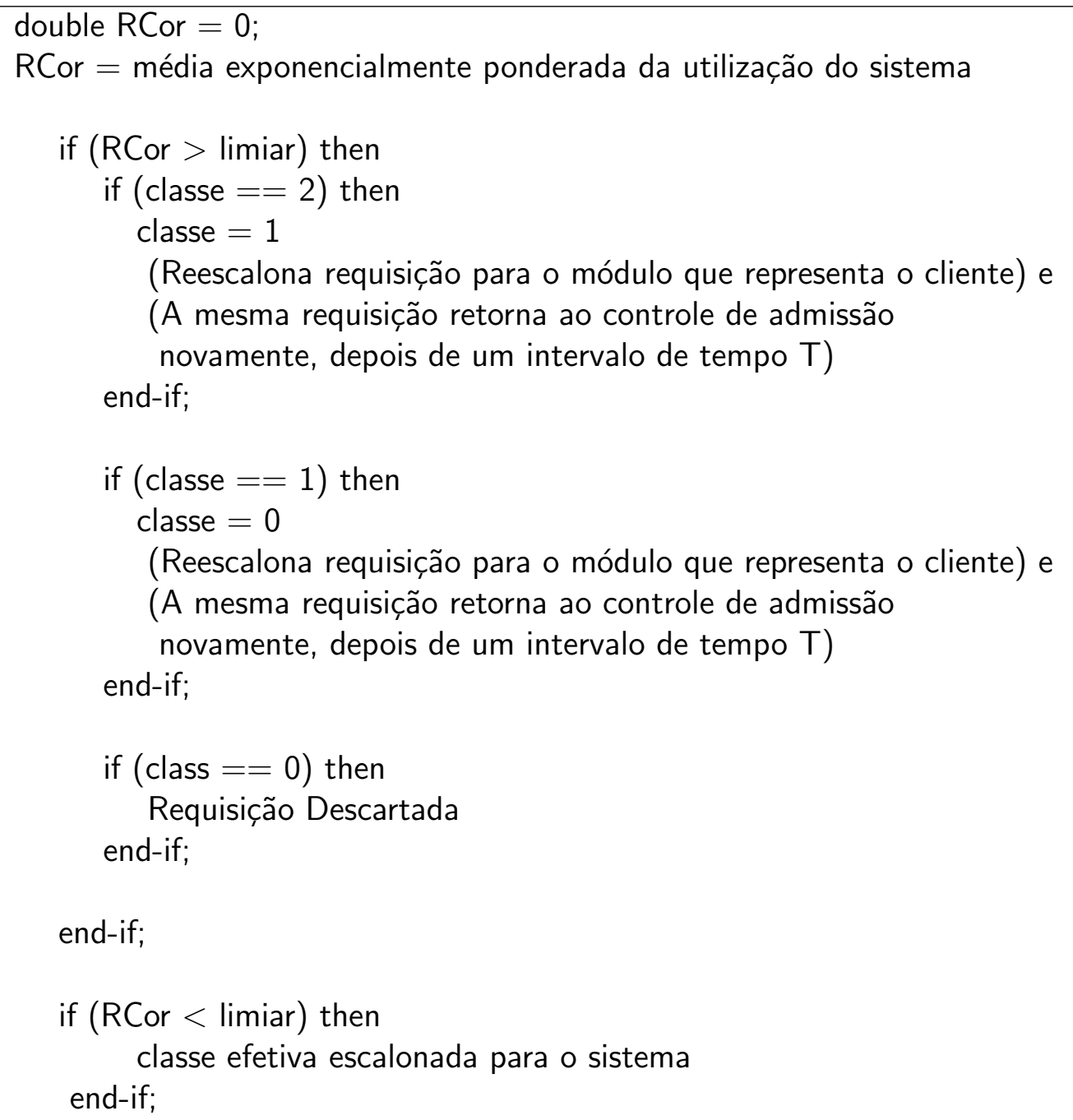

Figura 5.5: Pseudo-Código para o Algoritmo de Negociação com o cliente

O mecanismo de controle de admissão caracterizado na figura 5.4 utiliza uma média do cluster de servidores web como métrica, sendo esta calculada através de uma média exponencialmente ponderada descrita na equação 4.1. Essa média indica qual o comportamento da carga de trabalho do cluster de servidores web num determinado instante, isto é, se há alguma sobrecarga ou se o cluster de servidores encontra-se disponível para efetuar o atendimento das requisições. A escolha da utilização, segundo (TEIXEIRA; SANTANA; SANTANA, 2005) como parâmetro de controle é satisfatório, pois ela é capaz de indicar, em uma visão global, se um sistema está realmente sobrecarregado. Nesse sentido, o peso escolhido ( $\mathrm{p}$, na tabela 5.1) e que compõe a média, determina a sensibilidade dessa mudança na utilização do cluster.

O parâmetro Med-Resched é a média que deve ser passada a uma função exponencial, utilizada por um método definido no simulador Simpack. Esse método, denominado Schedule, é reponsável por escalonar as requisições para o cluster de servidores web ou para o controle de admissão, dependendo do algoritmo abordado. O parâmetro Reg representa 


\begin{tabular}{|c|c|}
\hline \hline Parâmetro & Significado \\
\hline \hline $\mathrm{p}$ & Valor que compõe a média ponderada do cluster \\
\hline \hline Med-Resched & Valor para a função de escalonamento \\
\hline \hline SQF & Algoritmo de Escalonamento utilizado \\
\hline \hline C & Número de classes para a simulação \\
\hline \hline Serv & Total de servidores \\
\hline \hline Reg & Número total de registros lidos do log \\
\hline \hline
\end{tabular}

Tabela 5.1: Parâmetros utilizados nas simulações

o número de registros lidos do log utilizado como carga de trabalho para as simulações.

$\mathrm{Na}$ seqüência tem-se o algoritmo de escalonamento que pode ser $S Q F$ ou RSV ou Round Robin, o parâmetro $C$, que representa o número de classes de serviços utilizadas durante os testes e o parâmetro Serv que é a quantidade de servidores. Esses parâmetros são setados antes do início da simulação e podem ser modificados de acordo com o objetivo que se deseja alcançar em relação à análise de desempenho.

Finalmente, look-ahead é um parâmetro que determina o número máximo de posições da fila de espera que serão percorridas a partir do início, à procura de requisições de uma determinada prioridade. Caso não encontre nenhuma requisição do tipo especificado, o algoritmo será repetido para o nível de prioridade imediatamente inferior e assim sucessivamente.

\subsection{Cenários para os testes}

Nesta seção serão apresentadas as características dos conjuntos de testes que foram realizados para validar os algoritmos implementados. Para cada conjunto são definidas medidas, taxas de chegadas das requisições, limiares da utilização do cluster de servidores web, bem como os algoritmos de escalonamento, número de servidores, etc. Para os testes apresentados neste capítulo, o limiar de utilização do cluster de servidores será constante e igual a $90 \%$.

As simulações realizadas para validar os mecanismos de negociação propostos neste trabalho foram efetivadas segundo doze cenários.

No primeiro e segundo cenários, as requisições foram assim distribuídas: 25\% da classe 0, 25\% da classe 1 e $50 \%$ da classe 2 . O valor do peso $p$ em todas as simulações foi de 0.9 , enquanto que para o parâmetro passado à função de escalonamento foi atribuído um valor igual a 0.006, válido para os dois cenários discutidos anteriormente. No terceiro e quarto cenários, foi alterado o valor de 0.006 para 0.009 , permanecendo a mesma porcentagem para as três classes. No quinto e sexto cenários, foi mantido o valor de 0.006 passado à função de escalonamento, mas a proporção das requisições ficou assim definida: $33 \%$ 
da classe $2,33 \%$ da classe 1 e $33 \%$ da classe 0 , com o objetivo de melhor refletir uma situação real. O sétimo e oitavo cenários caracterizaram-se pela modificação do valor de 0.006 para 0.009 na função de escalonamento, ainda obedecendo a porcentagem de $33 \%$ para cada classe. Um resumo dos cenários pode ser verificado na tabela 5.2.

Os valores 0.006 e 0.009 foram definidos a partir do tempo médio de atendimento das requisições processadas no cluster de servidores web, presentes no modelo $S W D S$. O valor obtido foi de 0.018 , o qual independe da classe à qual a requisição pertence pois considera-se somente o tempo de atendimento e não o tempo de fila. Para verificar o impacto desse valor médio no tempo de fila e também em relação ao número de descartes, foram definidas algumas simulações com 1/3 (0.006) e metade (0.009) desse valor.

\begin{tabular}{|c|c|c|c|c|c|}
\hline \hline Simul. & Algorit. & Med-Resched & \multicolumn{3}{|c|}{ Classes / Chegadas } \\
\hline \hline & & & 0 & 1 & 2 \\
\hline \hline A & ANR & 0.006 & $25 \%$ & $25 \%$ & $50 \%$ \\
\hline \hline B & ANC & 0.006 & $25 \%$ & $25 \%$ & $50 \%$ \\
\hline \hline C & ANR & 0.009 & $25 \%$ & $25 \%$ & $50 \%$ \\
\hline \hline D & ANC & 0.009 & $25 \%$ & $25 \%$ & $50 \%$ \\
\hline \hline E & ANR & 0.006 & $33 \%$ & $33 \%$ & $33 \%$ \\
\hline \hline F & ANC & 0.006 & $33 \%$ & $33 \%$ & $33 \%$ \\
\hline \hline G & ANR & 0.009 & $33 \%$ & $33 \%$ & $33 \%$ \\
\hline \hline H & ANC & 0.009 & $33 \%$ & $33 \%$ & $33 \%$ \\
\hline \hline I & ANR & 0.006 & $50 \%$ & $25 \%$ & $25 \%$ \\
\hline \hline J & ANC & 0.006 & $50 \%$ & $25 \%$ & $25 \%$ \\
\hline \hline K & ANR & 0.009 & $50 \%$ & $25 \%$ & $25 \%$ \\
\hline \hline L & ANC & 0.009 & $50 \%$ & $25 \%$ & $25 \%$ \\
\hline
\end{tabular}

Tabela 5.2: Cenários das simulações

A justificativa para os valores de 0.006 e 0.009 na função de escalonamento é a necessidade de verificar o impacto do "desafogamento"do cluster de servidores web. De certa forma, quando utilizamos o algoritmo de negociação com a participação do cliente, esse aumento pode indicar uma variação do tempo de pensar do cliente (think time), ou seja, o intervalo de tempo que ele demora para decidir se aceita ou não o rebaixamento da requisição de uma determinada classe. Durante esse intervalo a situação de sobrecarga no cluster de servidores web pode ser diminuída. A tendência, portanto, é que as requisições tenham mais chances de serem atendidas. O aumento desse valor, permite que ocorram melhorias quanto ao número de descartes de requisições, como será verificado nos resultados mostrados na próxima seção.

É importante destacar também os valores dos parâmetros da tabela 5.1. O parâmetro $C$ é igual a 3 e o parâmetro Serv recebeu o valor 4 . Na sequência, look-ahead recebeu o valor 300 e o número total de registros (representado pelo parâmetro Reg) lidos a partir 
do logs comentados anteriormente, foi igual a 1 milhão.

\subsection{Desempenho do Servidor Web}

As simulações $A$ e $B$ representam respectivamente o primeiro e o segundo cenários, definidos na tabela 5.2. A simulação $B$, por sua vez, apresenta um diferencial em relação à simulação $A$, pois aquela possui um centro de serviço adicional que representa o tempo de pensar do cliente web, utilizando portanto o algoritmo de negociação com a participação do cliente.

O objetivo é comparar o número de requisições descartadas em cada classe usando o modelo $S W D S$ com e sem o mecanismo de negociação, como mostra a figura 5.6. Para o melhor entendimento desses gráficos, são mostradas respectivamente as tabelas 5.3 e 5.4, com os resultados obtidos.

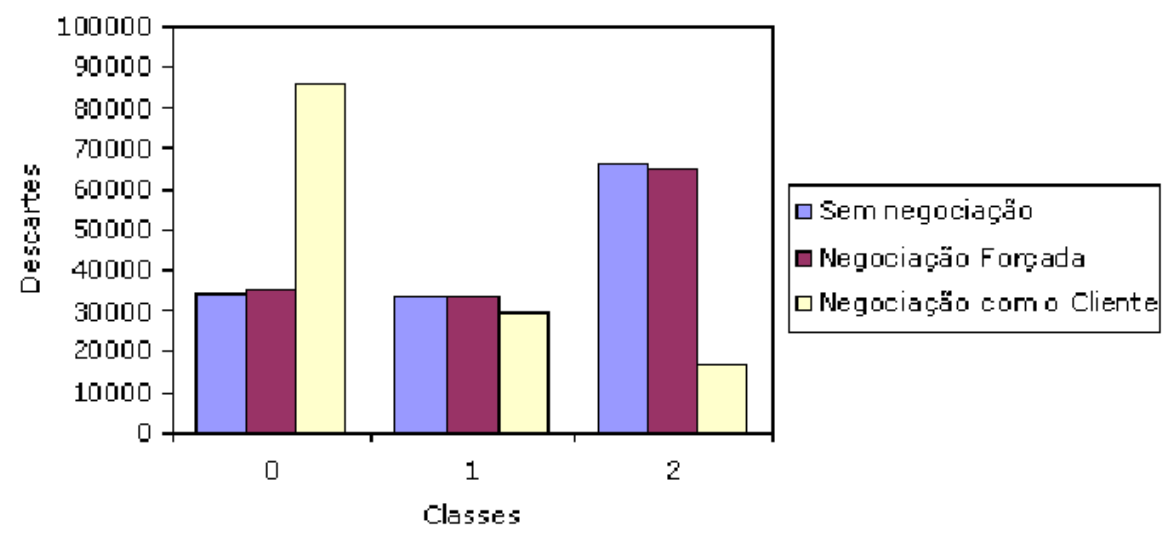

Figura 5.6: Número de descartes das simulações A e B por classe

\begin{tabular}{|c|c|c|c|}
\hline Classe & Sem Negoc. & Negoc. Forçada (A) & Negoc. Cliente (B) \\
\hline 0 & 34176 & 35142 & 86133 \\
\hline 1 & 33168 & 33187 & 29419 \\
\hline 2 & 66394 & 65182 & 16569 \\
\hline
\end{tabular}

Tabela 5.3: Valores de descartes segundo as simulações A e B

\begin{tabular}{|c|c|c|c|}
\hline Classe & Sem Negoc. & Negoc. Forçada (A) & Negoc. Cliente (B) \\
\hline 0 & 1.32 & 1.32 & 2.33 \\
\hline 1 & 0.57 & 0.57 & 0.51 \\
\hline 2 & 0.19 & 0.19 & 0.19 \\
\hline
\end{tabular}

Tabela 5.4: Valores comparativos dos tempos de fila

É possível verificar que na simulação A não houve uma diminuição significativa de descartes quando se compara o modelo $S W D S$ sem um mecanismo de negociação e poste- 


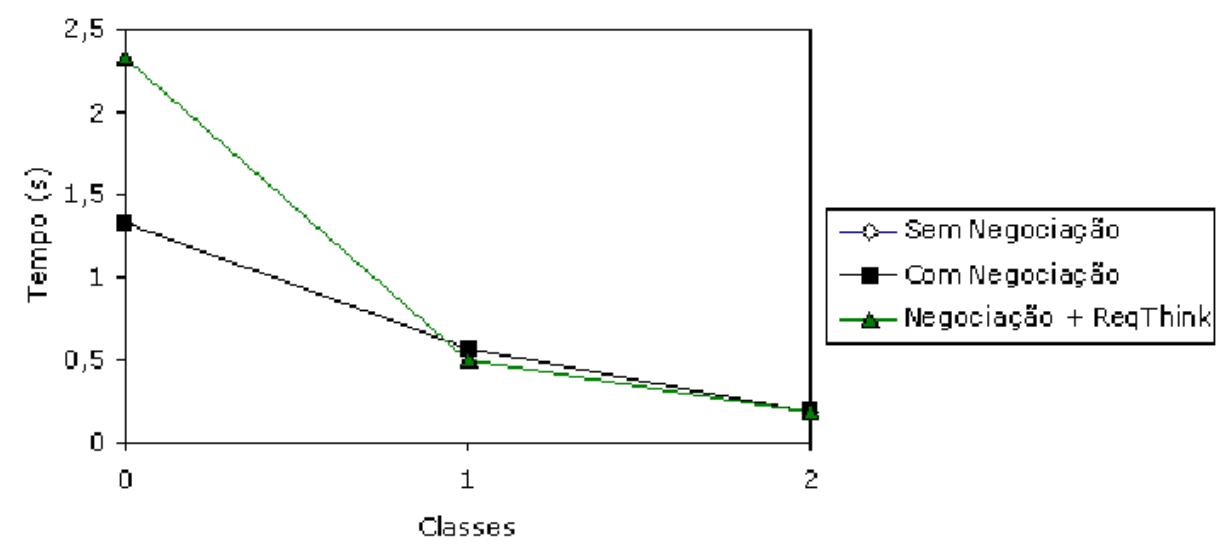

Figura 5.7: Tempo de médio de fila das simulações A e B por classe

riormente com um mecanismo de negociação forçada. Em relação à simulação B, os ganhos são consideráveis, visto que neste caso houve a simulação de um cliente no processo de negociação das requisições. Observa-se que o número de descartes da classe 2 caiu consideravelmente (tabela 5.3), criando-se a possibilidade de a requisição vir a ser aceita nas classes inferiores, já que a classe principal está sobrecarregada. Na classe 0, o número de descartes é bem maior na simulação B que na simulação A, pois esta classe representa a última chance da requisição ser aceita no sistema. Caso não seja admitida, ela é descartada definitivamente. O algoritmo de negociação com o cliente, portanto, permite efetivamente que as requisições tenham novas chances de serem aceitas pelo servidor, não descartando-as de pronto, como no caso sem negociação.

Com relação à figura 5.7 e sua correspondente tabela 5.4, que mostram os tempos de residência médio (na fila dos servidores) de uma requisição de uma determinada classe de serviço, verifica-se que não houve um ganho considerável com o uso da negociação forçada, isto é, com a utilização do algoritmo de negociação rigoroso.

Isso se deve ao fato de apenas jogar os descartes para as classes inferiores, aumentando seu tempo de resposta, mas sem melhorar realmente o tempo de resposta da classe de maior prioridade, ou seja, a classe 2. Nem mesmo a classe 1 obteve um ganho. Outro fator, é que como a classe 2 possui muitos clientes, então eles acabam monopolizando o sistema e o tempo de 0,19 , obtido sem negociação, já seria o melhor possível para esta classe, nessas condições (em função do algoritmo PRIAdap, segundo (TEIXEIRA; SANTANA; SANTANA, 2004b)). Por outro lado, observa-se uma diminuição acentuada dos tempos de espera (tempo de residência) da classe 2 , em virtude do algoritmo de negociação com o cliente somente admitir requisições que realmente possam ser atendidas em um tempo aceitável, não deixando-as esperar inutilmente na fila.

Ainda considerando os mesmos percentuais das simulações $A$ e $B$, mas modificando o parâmetro passado para a função de escalonamento para 0.009, foram obtidos outros 
resultados como ilustram os gráficos que representam as simulações $C$ e $D$ respectivamente (terceiro e quarto cenários), de acordo com as figuras 5.8 e 5.9 .

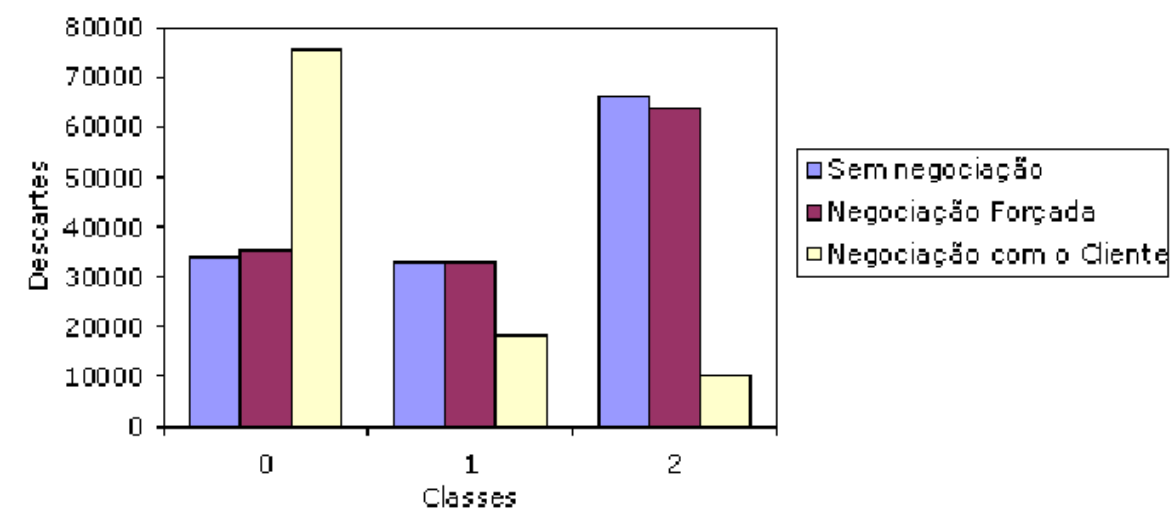

Figura 5.8: Número de descartes das simulações C e D por classe

\begin{tabular}{|c|c|c|c|}
\hline Classe & Sem Negoc. & Negoc. Forçada (C) & Negoc. Cliente (D) \\
\hline 0 & 34176 & 35780 & 75902 \\
\hline 1 & 33168 & 33323 & 18474 \\
\hline 2 & 66394 & 64158 & 9805 \\
\hline
\end{tabular}

Tabela 5.5: Valores de descartes segundo as simulações C e D

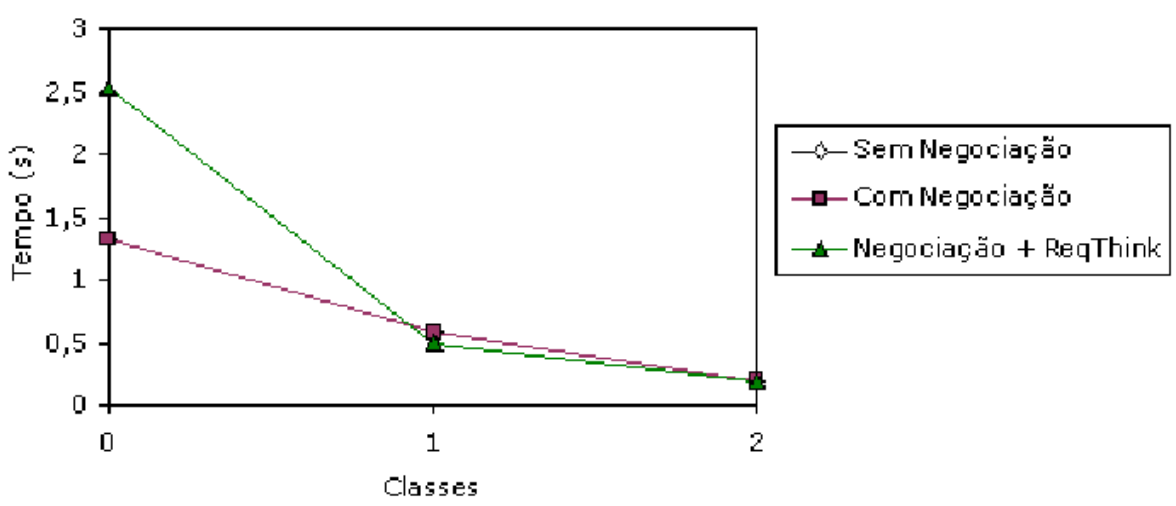

Figura 5.9: Tempo médio de fila da simulações C e D por classe

De modo a auxiliar o entendimento dos experimentos, juntamente com a explanação dos gráficos correspondentes as simulações $\mathrm{C}$ e $\mathrm{D}$, verifica-se que o número de descartes das requisições da classe 2 foi muito baixo, quando se compara os resultados da negociação forçada com os da negociação com a participação do cliente, como mostra a tabela 5.5.

A diminuição do número de descartes das requisições da classe 2 e 1 , e o aumento de requisições negociadas deve-se também ao aumento do tempo de pensar do cliente. 


\begin{tabular}{|c|c|c|c|}
\hline Classe & Sem Negoc. & Negoc. Forçada (C) & Negoc. Cliente (D) \\
\hline 0 & 1.32 & 1.32 & 2.52 \\
\hline 1 & 0.57 & 0.57 & 0.49 \\
\hline 2 & 0.19 & 0.19 & 0.19 \\
\hline
\end{tabular}

Tabela 5.6: Valores comparativos dos tempos de fila

Isto é perfeitamente justificável, pois, dá-se uma possibilidade a mais de a situação de sobrecarga no cluster ficar em níveis aceitáveis e, então, na nova tentativa de admissão, a probabilidade de aceitação tende a ser maior. Ainda referindo-se às simulações C e D, nota-se um aumento do tempo de residência das requisições das classes 0 e 1 respectivamente, devido ao fato de as requisições da classe 2 terem que ser atendidas em primeiro lugar. Esses resultados reforçam a tese de que a participação do cliente no mecanismo de negociação é bastante relevante para a criação de servidores web capazes de fornecer serviços diferenciados aos seus clientes. Observa-se que, neste caso, o tempo de residência da classe 2 é consideravelmente menor que os das classes 1 e 0 , resultado do melhor tratamento recebido pela classe de maior prioridade.

Numa outra situação foram modificados os percentuais de chegadas de requisições das classes 0, 1 e 2 para 33\% respectivamente (simulações E e F). Para esta configuração foi atribuído o valor de 0.006 passado à função de escalonamento. Com este novo cenário, outos resultados foram coletados, evidenciados nas figuras 5.10, 5.11 e que também podem ser acompanhados pelas tabelas 5.7 e 5.8 respectivamente.

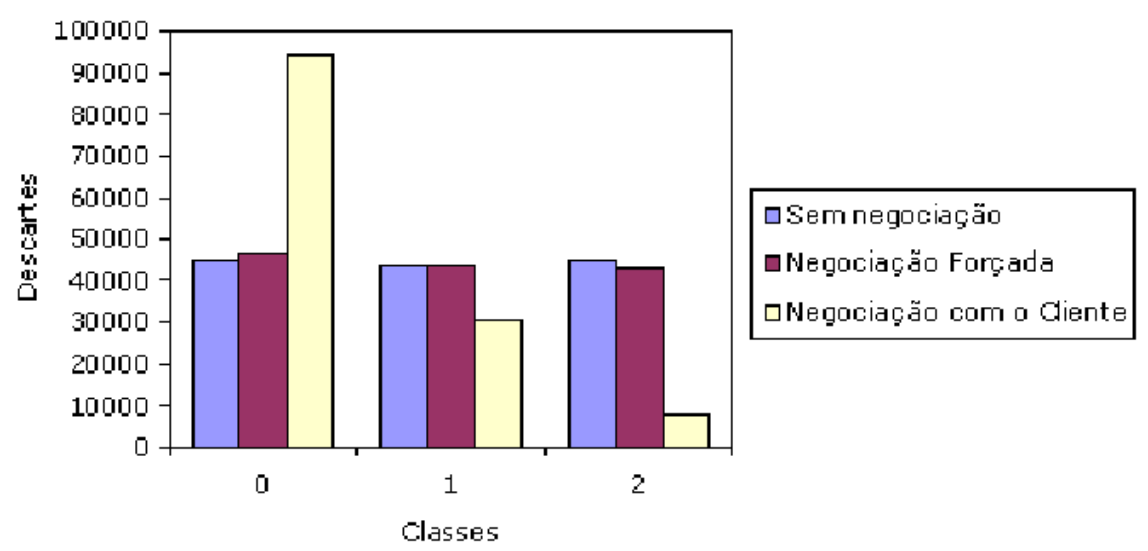

Figura 5.10: Número de descartes das simulações E e F por classe

Os resultados do quinto e sexto cenários tornam ainda mais evidentes os benefícios que o mecanismo de negociação com o cliente traz para o atendimento de classes prioritárias, neste caso a classe 2, depois a classe 1 e finalmente a classe 0 . Ao comparar os gráficos das simulações E e F e suas respectivas tabelas, é verificado ainda mais uma diminuição de descartes para uma das classes (por exemplo, a classe 2 caiu de 44931 para 8300, 


\begin{tabular}{|c|c|c|c|}
\hline Classe & Sem Negoc. & Negoc. Forçada (E) & Negoc. Cliente (F) \\
\hline 0 & 44900 & 46645 & 94288 \\
\hline 1 & 43738 & 43541 & 30506 \\
\hline 2 & 44931 & 43180 & 8300 \\
\hline
\end{tabular}

Tabela 5.7: Valores de descartes segundo as simulações E e F

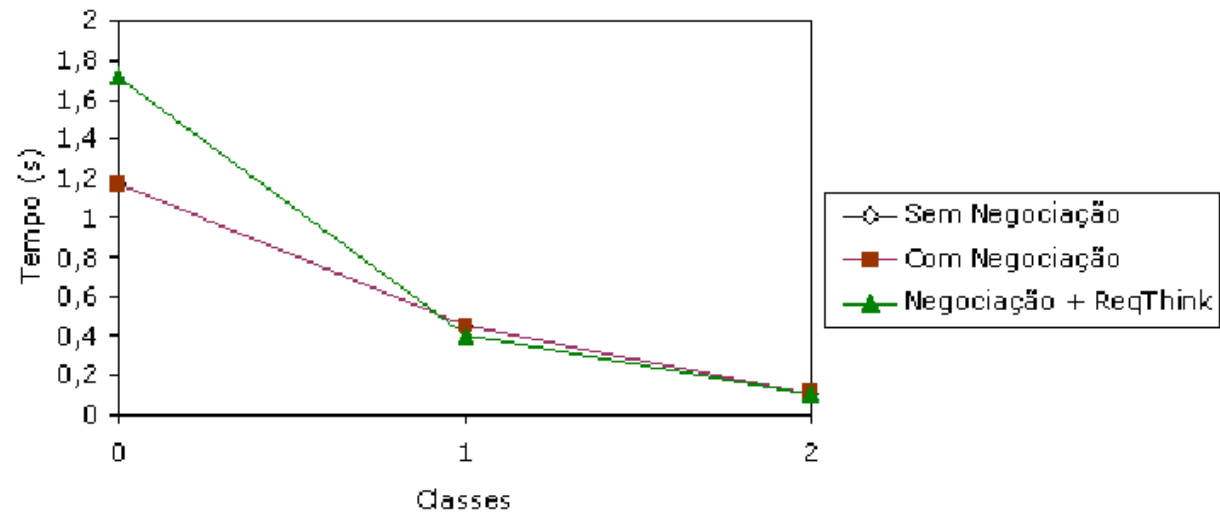

Figura 5.11: Tempo médio de fila da simulações E e F por classe

\begin{tabular}{|c|c|c|c|}
\hline Classe & Sem Negoc. & Negoc. Forçada (E) & Negoc. Cliente (F) \\
\hline 0 & 1.17 & 1.17 & 1.72 \\
\hline 1 & 0.45 & 0.45 & 0.40 \\
\hline 2 & 0.11 & 0.11 & 0.11 \\
\hline
\end{tabular}

Tabela 5.8: Valores comparativos dos tempos de fila

e ao mesmo tempo a quantidade de descartes da classe 0 aumentou consideravelmente, característica do algoritmo de negociação, explicado em seções anteriores deste trabalho). Mas o ganho primordial ocorreu com a diminuição do tempo de residência na fila para a classe 2, que caiu de 0.19 para 0.11 , o que reforça ainda mais a viabilidade da participação do cliente em todo o processo que permite melhoria na qualidade de serviço para aplicações web. Nota-se ainda que as classes 1 e 0 apresentam tempos de residência bem menores que nos cenários anteriores, visto que agora há menos requisições da classe 2 no sistema.

Modificando o parâmetro de 0.006 da função de escalonamento para o valor 0.009, foram configuradas as simulações $\mathrm{G}$ e $\mathrm{H}$, como podem ser observados nos gráficos das figuras 5.12 e 5.13. Nessas figuras pode ser observado um aumento do tempo de fila da classe 0. Isso pode ser melhor verificado na tabela 5.10. Esse aumento é resultado da diminuição de descartes na classe 1 (caiu em média de 43000 para 26000), quando se o usa o parâmetro Med_Resched com o valor 0,009. Dessa forma, mais requisições permaneceram na fila como sendo classe 1. Raciocínio análogo pode ser aplicado à classe 0. É importante ressaltar também que o tempo de 0,11 obtido para a classe 2 com o algoritmo de negociação com o cliente, é melhor que o tempo de 0,19 obtido com o mecanismo de 
controle de admissão pela média ponderada utilizado no modelo desenvolvido no trabalho de (TEIXEIRA, 2004a), o que confirma o benefício da negociação como um mecanismo eficaz para melhorar a qualidade do serviço oferecido pelo servidor $S W D S$ a seus clientes.

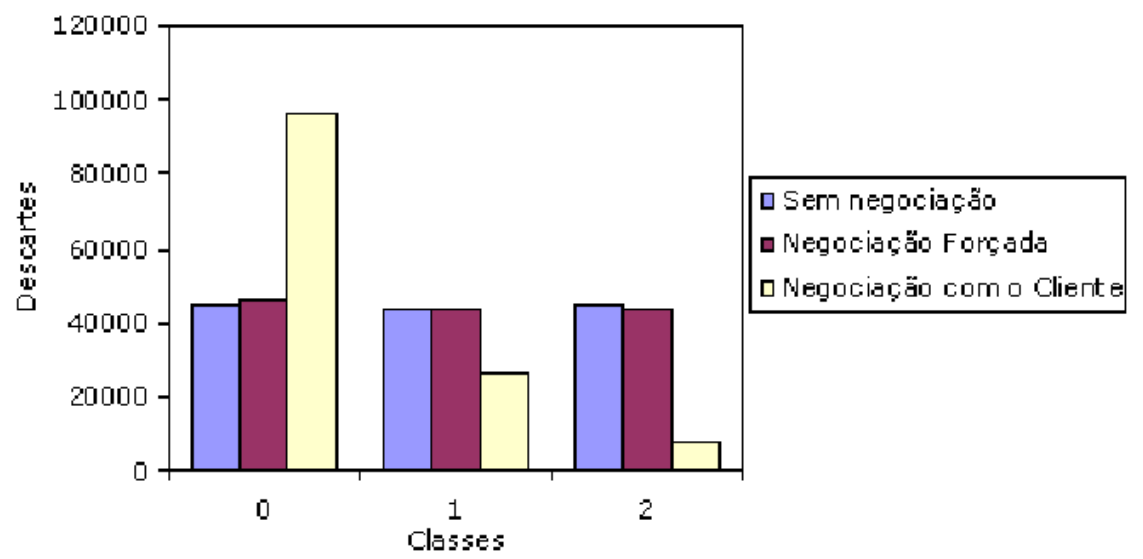

Figura 5.12: Número de descartes das simulações G e H por classe

\begin{tabular}{|c|c|c|c|}
\hline Classe & Sem Negoc. & Negoc. Forçada $(\mathrm{G})$ & Negoc. Cliente $(\mathrm{H})$ \\
\hline 0 & 44900 & 46460 & 96433 \\
\hline 1 & 43738 & 43654 & 26304 \\
\hline 2 & 44931 & 43332 & 7481 \\
\hline
\end{tabular}

Tabela 5.9: Valores de descartes segundo as simulações G e H

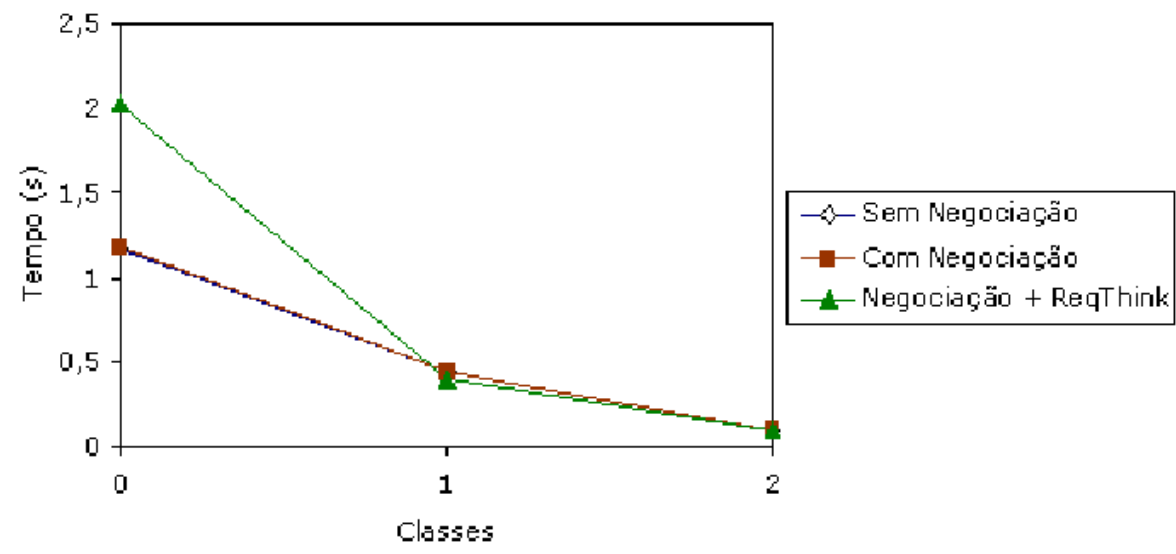

Figura 5.13: Tempo médio de fila das simulações G e H por classe

Nas simulações I e J podem ser verificadas outras características, como mostram as figuras 5.14 e 5.15 a seguir.

Nesses cenários utilizou-se Med_Resched com o valor 0.006 e taxas de chegada de $50 \%$ $25 \%$ e $25 \%$ para as classes 0,1 e 2 respectivamente. Nota-se que há uma tendência 


\begin{tabular}{|c|c|c|c|}
\hline Classe & Sem Negoc. & Negoc. Forçada $(\mathrm{G})$ & Negoc. Cliente $(\mathrm{H})$ \\
\hline 0 & 1.17 & 1.18 & 2.03 \\
\hline 1 & 0.45 & 0.45 & 0.40 \\
\hline 2 & 0.11 & 0.11 & 0.11 \\
\hline
\end{tabular}

Tabela 5.10: Valores comparativos dos tempos de fila

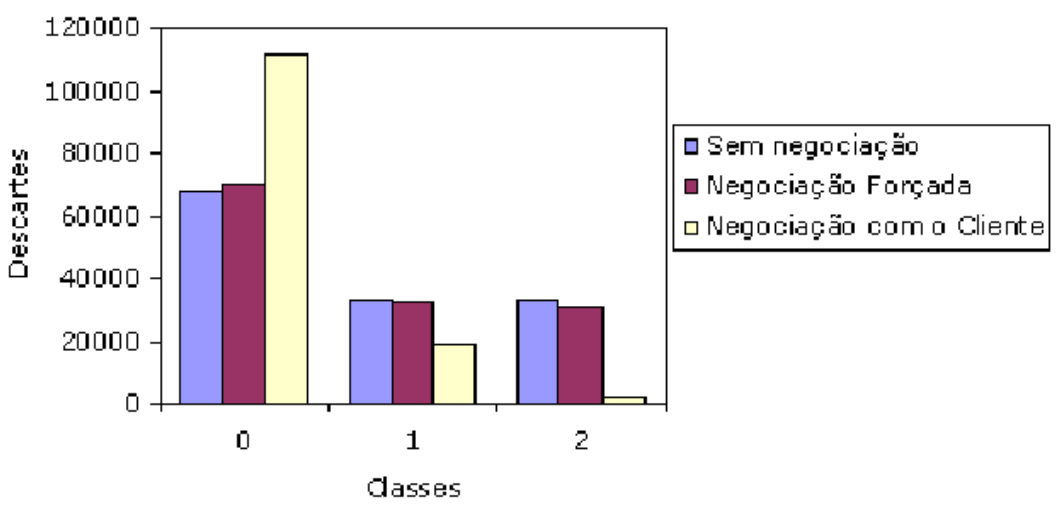

Figura 5.14: Número de descartes das simulações I e J por classe

\begin{tabular}{|c|c|c|c|}
\hline Classe & Sem Negoc. & Negoc. Forçada (I) & Negoc. Cliente (J) \\
\hline 0 & 67681 & 69701 & 111896 \\
\hline 1 & 32938 & 32478 & 18898 \\
\hline 2 & 32770 & 31154 & 2487 \\
\hline
\end{tabular}

Tabela 5.11: Valores de descartes segundo as simulações I e J

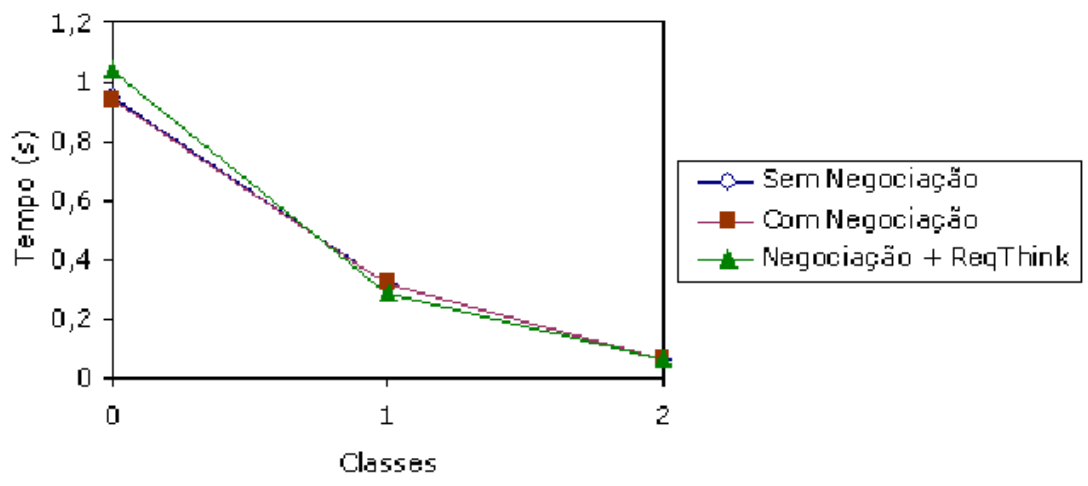

Figura 5.15: Tempo médio de fila das simulações I e J por classe

de melhoria, tanto em relação ao tempo médio de fila quanto ao número de descartes por classe. É perceptível através dos gráficos e tabelas que essa melhoria depende das configurações das taxas de chegadas, no entanto, a qualidade de serviço para a classe de maior prioridade é mantida. 


\begin{tabular}{|c|c|c|c|}
\hline Classe & Sem Negoc. & Negoc. Forçada (I) & Negoc. Cliente (J) \\
\hline 0 & 0.95 & 0.94 & 1.04 \\
\hline 1 & 0.32 & 0.32 & 0.29 \\
\hline 2 & 0.07 & 0.07 & 0.07 \\
\hline
\end{tabular}

Tabela 5.12: Valores comparativos dos tempos de fila

Para as simulações K e L, alterou-se Med_Resched para 0.009 e foram obtidos os resultados mostrados nas tabelas e gráficos a seguir.

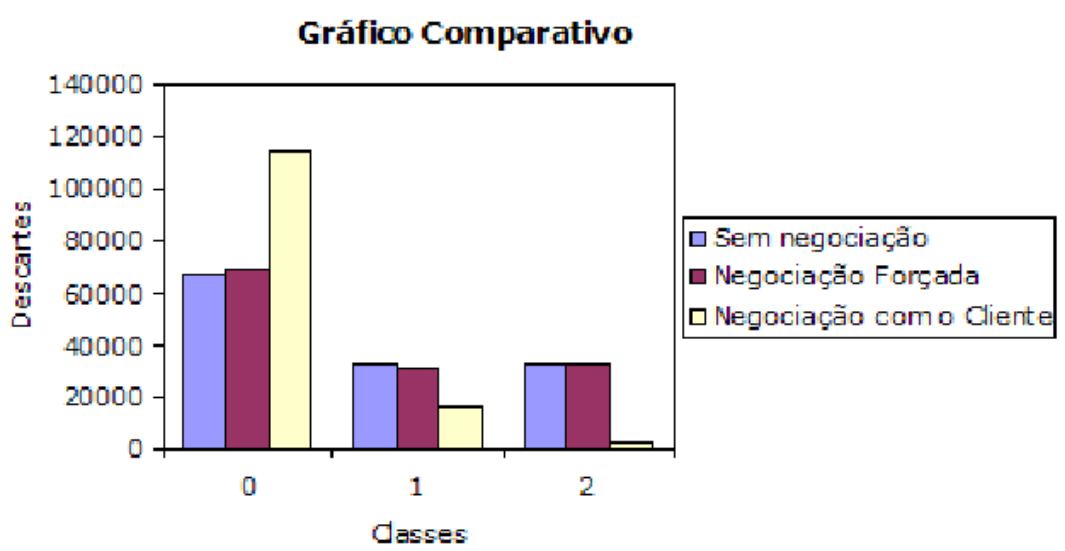

Figura 5.16: Número de descartes das simulações K e L por classe

\begin{tabular}{|c|c|c|c|}
\hline Classe & Sem Negoc. & Negoc. Forçada (K) & Negoc. Cliente (L) \\
\hline 0 & 67681 & 69005 & 114553 \\
\hline 1 & 32938 & 31462 & 15861 \\
\hline 2 & 32770 & 32782 & 2929 \\
\hline
\end{tabular}

Tabela 5.13: Valores de descartes segundo as simulações K e L

Tempo de Fila por Classe

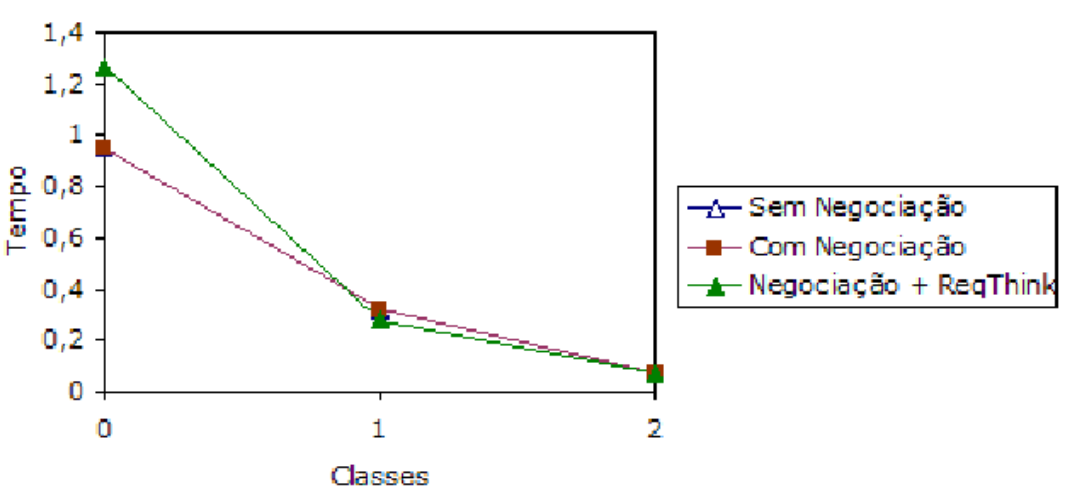

Figura 5.17: Tempo médio de fila das simulações K e L por classe 


\begin{tabular}{|c|c|c|c|}
\hline Classe & Sem Negoc. & Negoc. Forçada (K) & Negoc. Cliente (L) \\
\hline 0 & 0.95 & 0.95 & 1.27 \\
\hline 1 & 0.32 & 0.32 & 0.28 \\
\hline 2 & 0.07 & 0.07 & 0.07 \\
\hline
\end{tabular}

Tabela 5.14: Valores comparativos dos tempos de fila

\subsubsection{Número de descartes}

De modo a tornar evidente a eficácia dos mecanismos de negociação no modelo $S W D S$, esta seção apresenta alguns gráficos comparativos referentes ao número de descartes dos cenários simulados.

O gráfico da figura 5.18 mostra a variação de descartes para diferentes taxas de chegadas sem a implementação dos algoritmos de negociação. É possível perceber no caso $(33 \%, 33 \%, 33 \%)$, que a quantidade de descartes é praticamente a mesma, diferentemente dos outros casos presentes no gráfico, isto é, os descartes ocorrem igualmente para todas as classes de serviço, onde a chance de uma requisição da classe 2 ser descartada é a mesma, tanto para as requisições da classe 0 quanto para as da classe 1 . A partir desse ponto será adotado a sequência $(\mathrm{x}, \mathrm{y}, \mathrm{z})$ para representar a quantidade de clientes que chegam da classe $0(\mathrm{x})$, classe 1 (y) e classe $2(\mathrm{z})$.

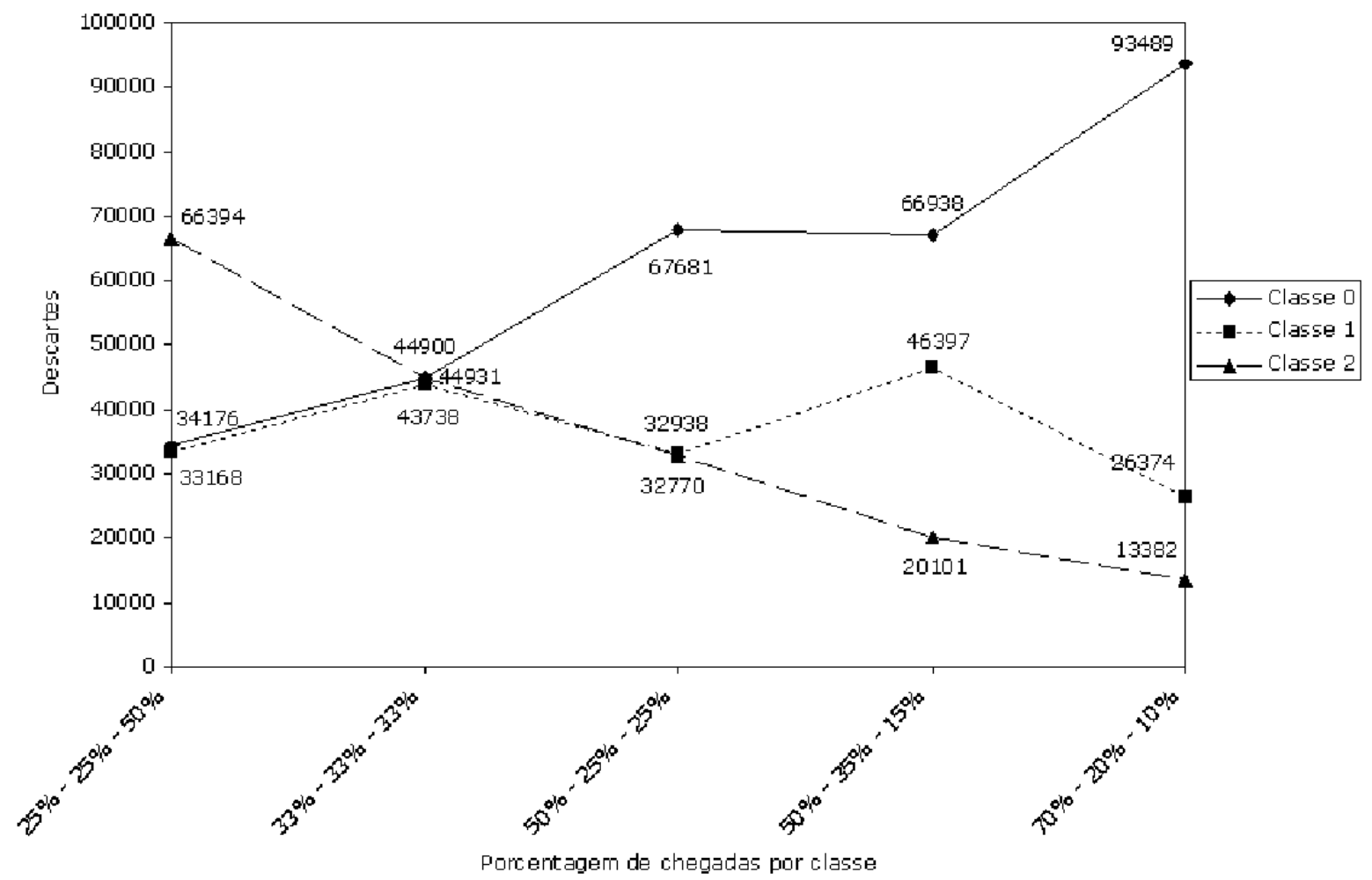

Figura 5.18: Variação de descartes segundo a taxa de chegada - Sem Negociação

Para verificar o comportamento da negociação para as diversas taxas de chegadas, 
é apresentado o gráfico referente à figura 5.19. Ao comparar o gráfico da figura 5.18 com o gráfico da figura 5.19 verifica-se um ganho considerável em relação à diminuição de descartes para as classes de serviços prioritárias (classe 2), sinalizando a eficácia do algoritmo. Como era de se esperar a quantidade de requisições descartadas para a classe inferior foi muito maior. Pelo gráfico, pode-se verificar que, mesmo com uma taxa de chegada maior (como no caso de $50 \%$ para a classe 2 ) a quantidade de descartes permanece muito menor em relação ao caso apresentado na figura 5.18. Por outro lado, a medida que a taxa de chegada de requisições diminui, o número de descartes também diminui, como pode ser acompanhado pelo gráfico 5.19.

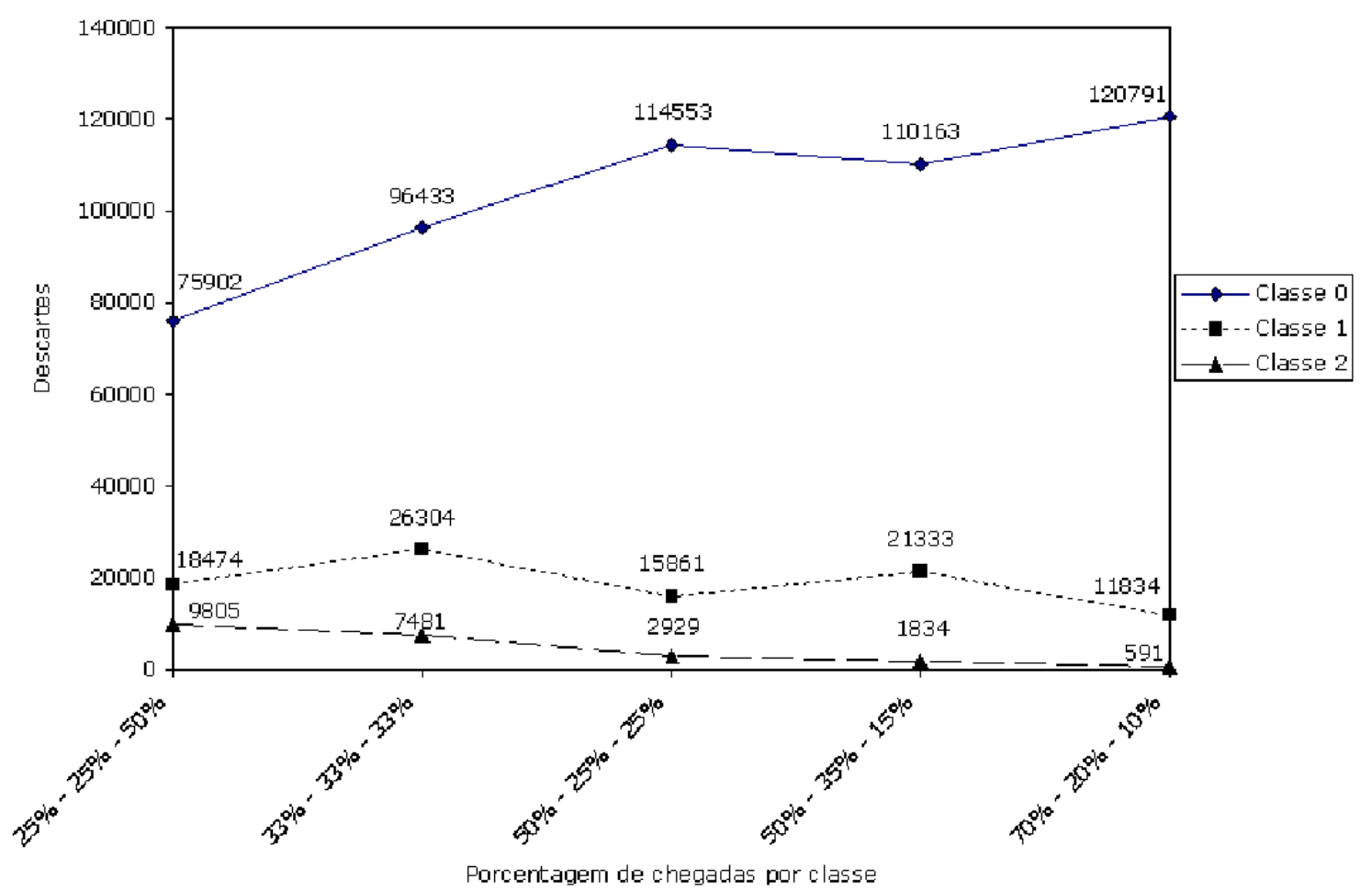

Figura 5.19: Variação de descartes segundo a taxa de chegadas - Com Negociação com o cliente

Os gráficos a seguir apresentam o comportamento isolado dos descartes para cada uma das classes de serviços consideradas nas simulações. A comparação é realizada levando em consideração a presença e a ausência do mecanismo de negociação com a participação do cliente no modelo $S W D S$. 


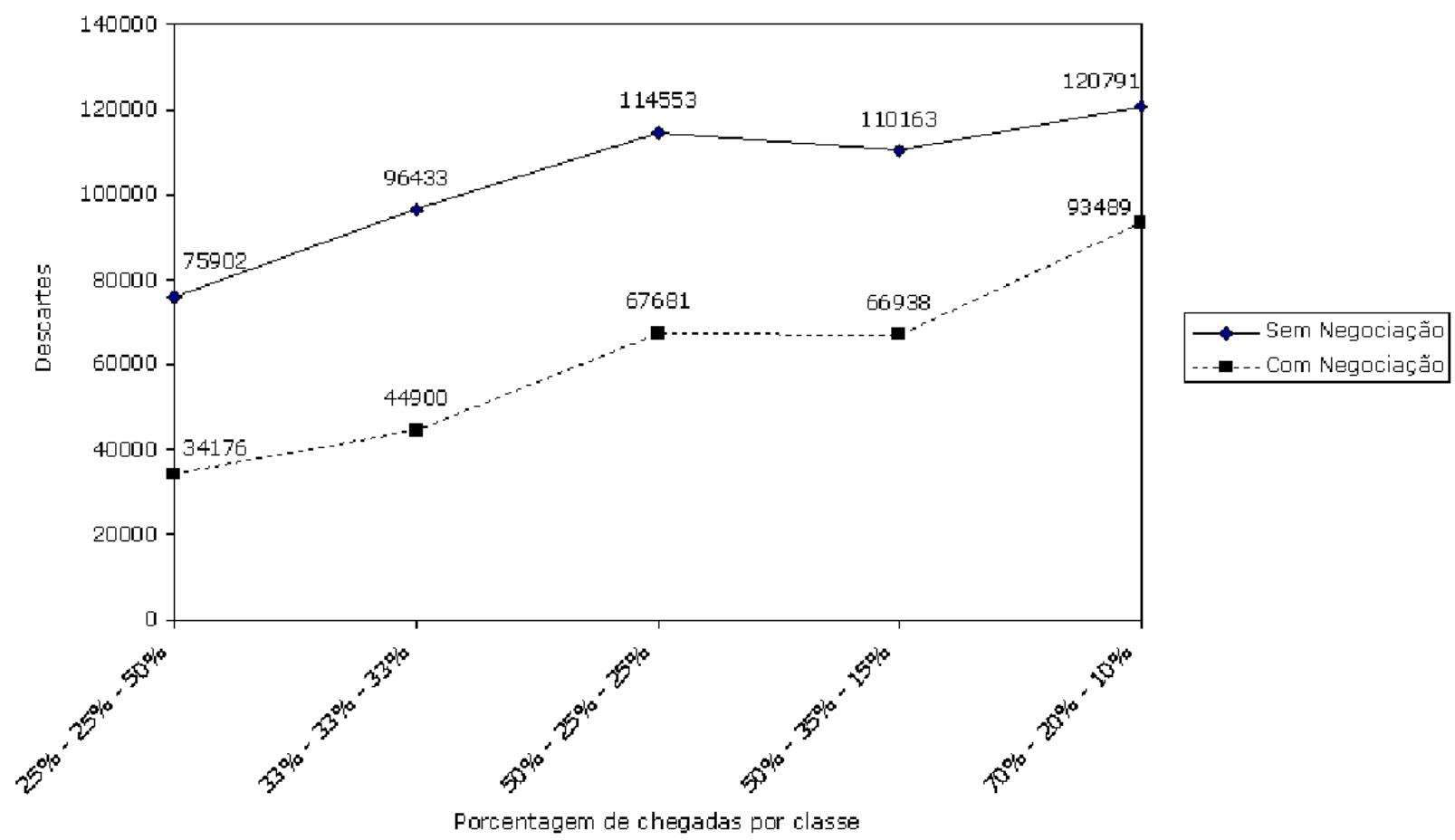

Figura 5.20: Variação de descartes segundo a taxa de chegada - Classe 0

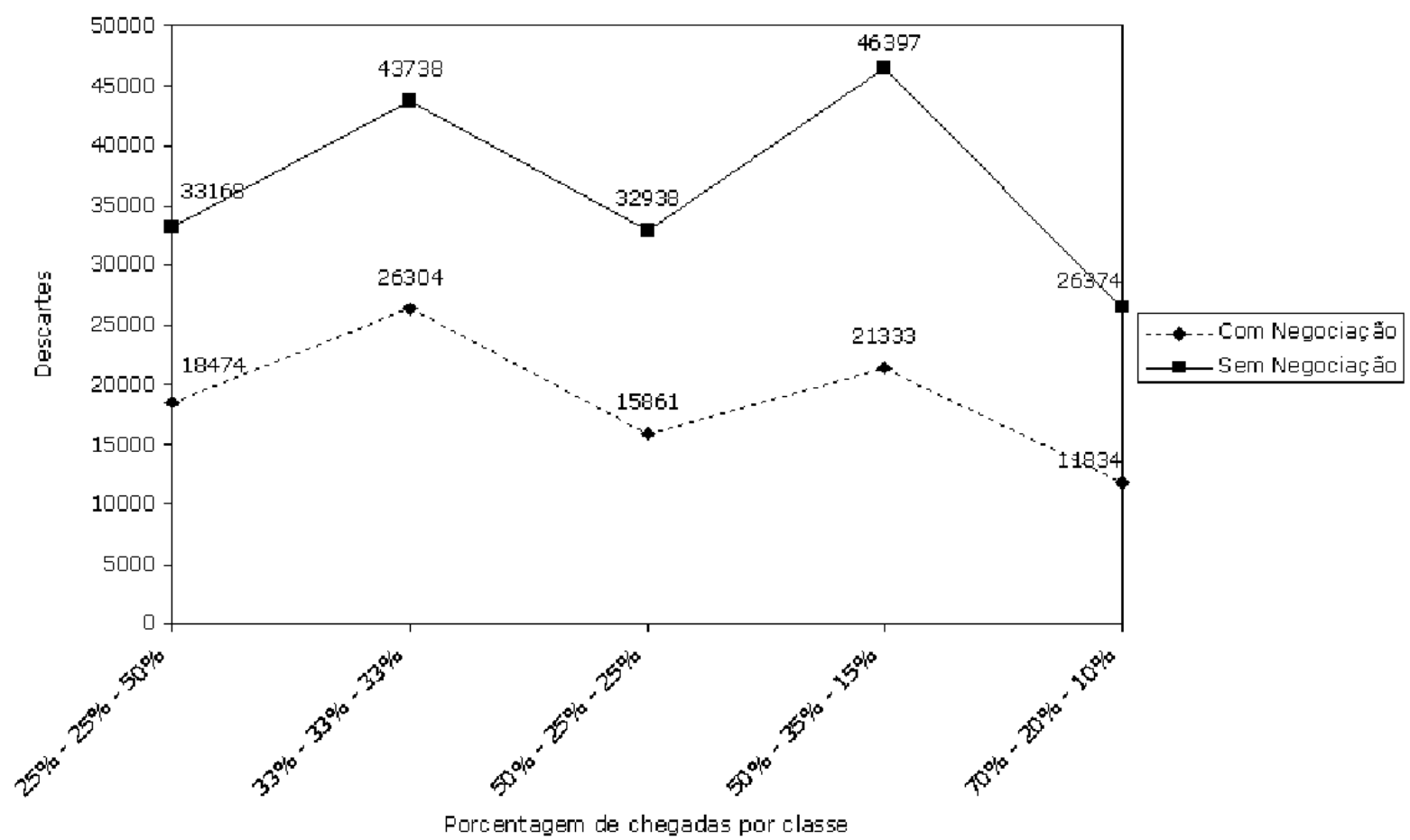

Figura 5.21: Variação de descartes segundo a taxa de chegada - Classe 1 


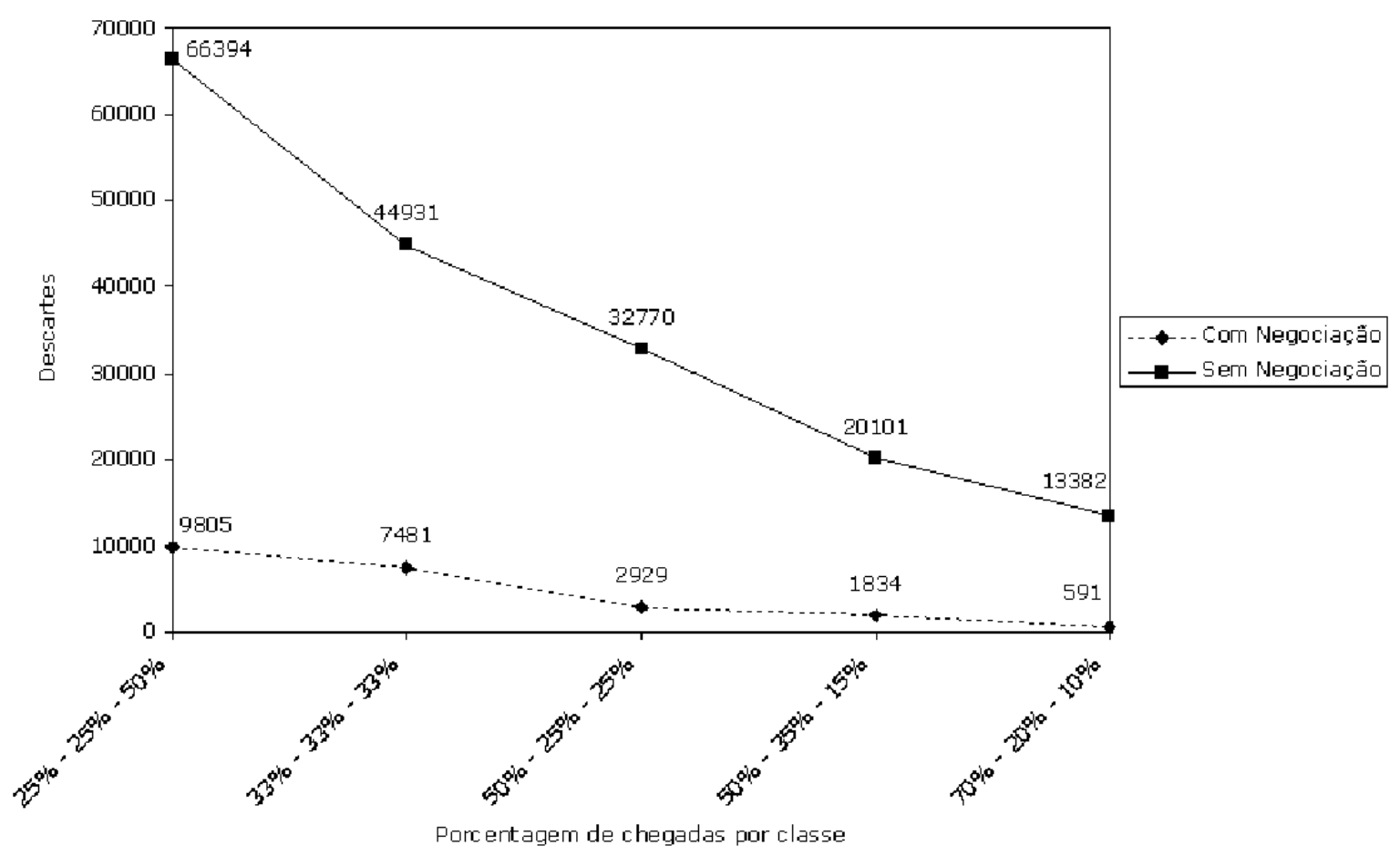

Figura 5.22: Variação de descartes segundo a taxa de chegada - Classe 2

\subsubsection{Tempo de resposta médio}

Verifica-se nesta seção o comportamento da negociação em relação ao tempo de resposta médio para as requisições das classes de serviços abordadas nas simulações. O gráfico da figura 5.23 mostra primeiramente um comportamento considerando o modelo SWDS sem o mecanismo de negociação. Observa-se que há uma diminuição considerável dos tempos de resposta para as classe 1 e 2 em relação à classe 0 , como mostra o gráfico da figura 5.23.

O gráfico da figura 5.24 por sua vez, detalha o comportamento do tempo de resposta médio considerando o mecanismo de negociação abordado no desenvolvimento do trabalho. Para esse gráfico da figura 5.24 as diferenças de tempo para as classes 0 e 1 são visíveis quando compara-se a situação $(33 \%, 33 \%, 33 \%)$ para as classe 0,1 e 2 respectivamente. A partir deste ponto a situação tende a se estabilizar principalmente para as classes prioritárias (isto é, as negociadas), visto que a mudança nas taxas de chegadas das requisições acabam influenciando neste tempo, uma vez que com uma taxa de chegada menor para essas classes (negociadas), a tendencia é que o atendimento seja mais justo. 


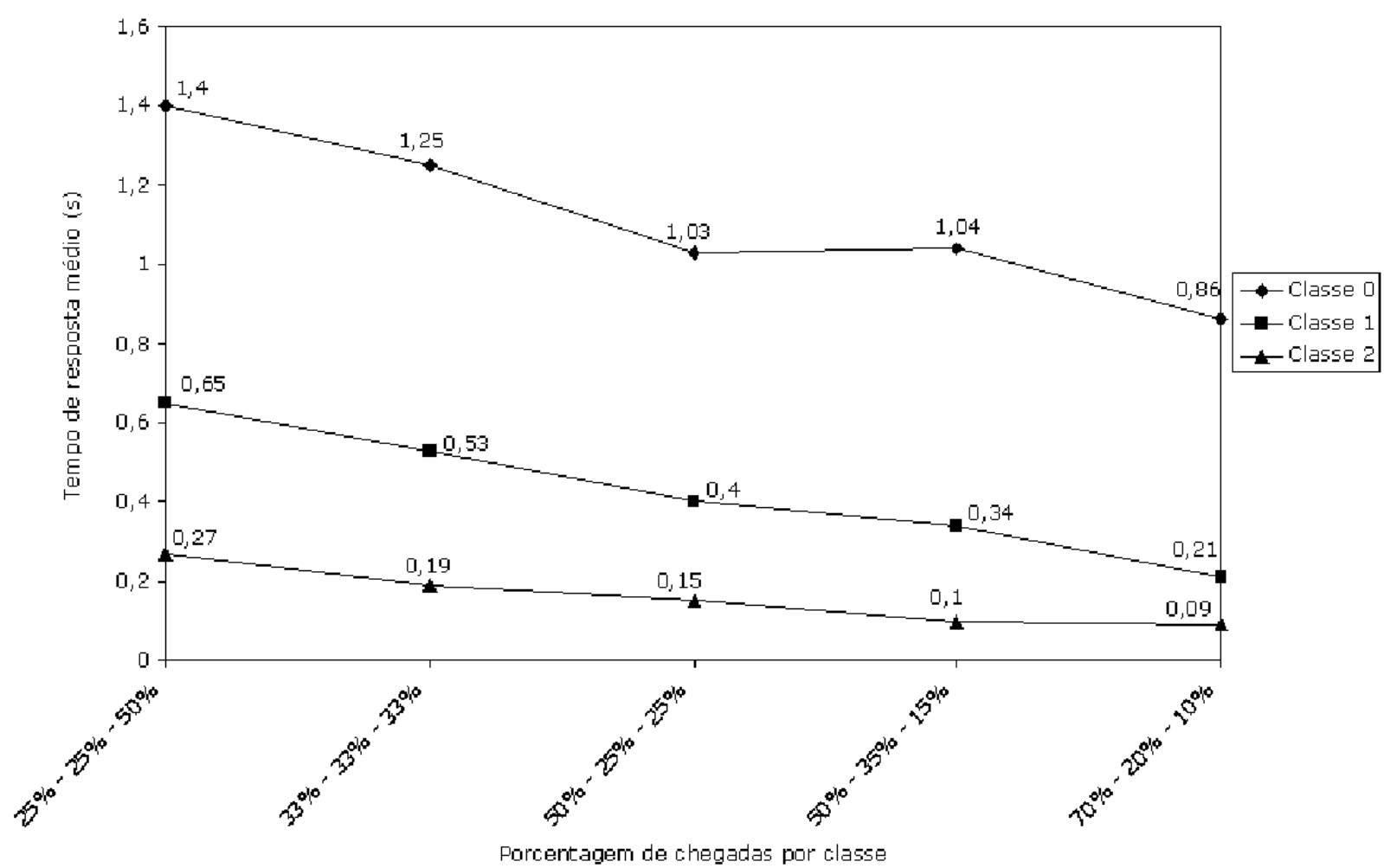

Figura 5.23: Variação do tempo de resposta médio segundo a taxa de chegada - Sem Negociação

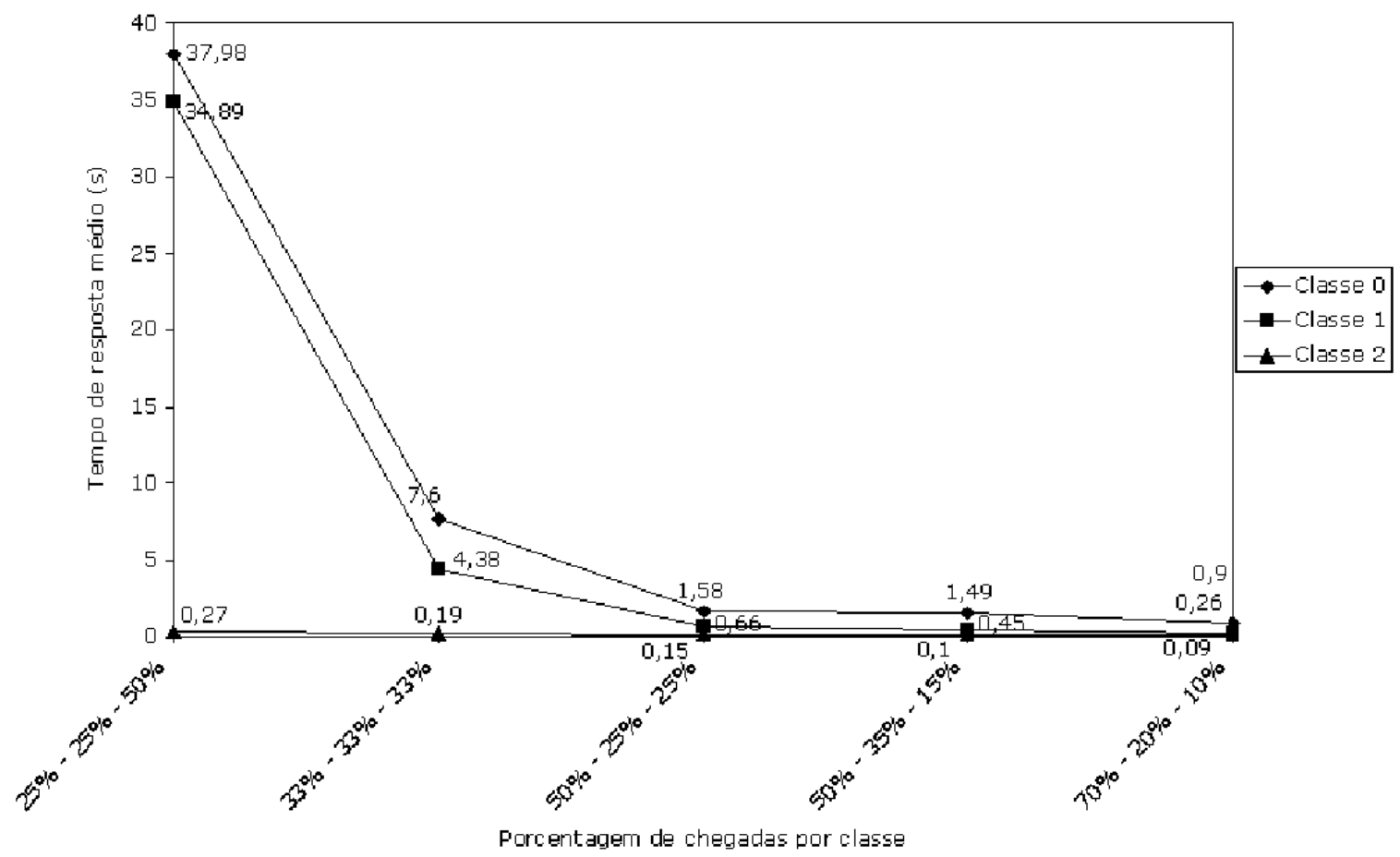

Figura 5.24: Variação do tempo de resposta médio segundo a taxa de chegada - Com Negociação 


\subsection{Considerações Finais}

Neste capítulo foram apresentados os mecanismos de negociação propostos nesta dissertação de mestrado. Dois algoritmos foram implementados: um deles denominado algoritmo de negociação rigoroso, caracterizado pelo retorno imediato das requisições ao controle de admissão, e o outro desenvolvido com o intuito de validar a negociação com a participação de um cliente web (este simulado através de um centro de serviço, caracterizado durante os procedimentos da simulação).

Como pode ser verificado neste capítulo, apresentou-se alguns resultados utilizando um valor fixo de utilização do sistema (90\% para todas as classes). Surgiu porém, a necessidade de verificar qual seria o comportamento da negociação e qual a influência da mudança desses limiares no número de descartes para as classes de serviços.

Nesse sentido, o próximo capítulo ilustra detalhadamente a composiçõa de uma métrica de avaliação de desempenho de servidores web objetivando estudar o comportamento do ambiente acima mencionado, com relação ao uso de diferentes limiares da utilização do sistema, juntamente com as diferentes taxas de chegadas de requisições para as classes de serviços. 


\section{Capítulo \\ 6 \\ Métrica para Avaliação de Servidores \\ Web}

\subsection{Considerações Iniciais}

Neste capítulo é apresentada uma métrica que permite a avaliação de desempenho de um servidor web considerando o número de requisições descartadas e o tempo médio de fila das requisições por classe. Além disso são apresentados os cenários simulados onde os limiares para atendimento dos servidores web foram alterados. Os resultados obtidos com essas simulações foram aplicados à métrica definida e são analisados.

Os resultados do capítulo anterior e os que serão apresentados neste capítulo mostram que a utilização de mecanismos de negociação faz-se necessária quando se deseja modelar e implementar servidores web com diferenciação de serviços, sendo portanto, mais uma técnica que contribui para a melhoria do atendimento das requisições em web servers. A composição da métrica e os resultados obtidos diante de sua utilização sinalizam que a diferença dos limiares para as classes de serviços são um outro modo de delimitar QoS em servidores web.

\subsection{Composição de uma métrica}

A métrica DQT (Discarding and Queue Time) é mais uma proposta apresentada neste trabalho, sendo utilizada para a avaliação dos experimentos realizados. A métrica pode representar alguns parâmetros importantes na análise de desempenho de modelos de servidores web.

A métrica $D Q T$ é composta de diversos parâmetros. O primeiro parâmetro a ser 
representado, é a prioridade relativa da classe. O segundo, por sua vez, representa o tempo relativo de fila para uma dada requisição de uma determinada classe de serviço. $\mathrm{O}$ terceiro parâmetro corresponde ao descarte relativo da classe. A equação 6.1 descreve a métrica (M) e a tabela 6.1 seus respectivos parâmetros.

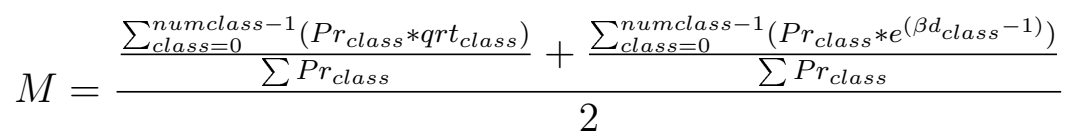

\begin{tabular}{|c|c|}
\hline \hline \multicolumn{2}{|c|}{ Parâmetros da Métrica DQT } \\
\hline \hline$P r_{\text {class }}$ & Prioridade relativa da classe \\
\hline \hline$q r t_{\text {class }}$ & Tempo relativo de fila por classe \\
\hline \hline$d_{\text {class }}$ & Porcentagem de descartes por classe \\
\hline \hline$e^{\beta d_{\text {class }}}-1$ & Descarte relativo por classe \\
\hline \hline$\beta=0.7$ & Constante \\
\hline \hline
\end{tabular}

Tabela 6.1: Composição da Métrica

O resultado da métrica obtida da equação 6.1 está na forma normalizada e deve, portanto, apresentar-se num intervalo entre 0 e 1 . Os valores resultantes do uso desta métrica devem obedecer uma funcão exponencial, no qual a idéia é que quanto mais próximo de 0 é o valor de $M$ mais justa é a qualidade de serviço para as classes de serviço. No entanto, quanto mais próximo de 1 é o valor de $M$, algumas das classes de serviço terão $Q o S$ privilegiada em detrimento das demais. Ressalta-se que o valor final de $M$ está intrinsicamente associado aos seus parâmetros, principalmente a taxa de chegada das requisições que, como pode ser verificado, é um parâmetro variável, influenciando por isso no resultado final.

O tempo relativo de fila por classe é calculado dividindo-se o tempo médio de fila $\left(q t_{\text {class }}\right)$ de cada classe de serviço pelo maior tempo de fila $\left(q t_{\max }\right)$ encontrado entre todas as classes, como pode ser observado na equação 6.2:

$$
q r t_{\text {class }}=q t_{\text {class }} / q t_{\text {max }}
$$

Para um melhor entendimento, será considerado $m^{\prime}$ como uma medida do tempo relativo de fila e $m^{\prime \prime}$ como uma medida de descarte relativo, cuja adição de $m^{\prime}+m^{\prime \prime}$ resulta em $M$, como mostra a tabela 6.2 .

Ao utilizar a métrica $D Q T$ verificou-se que quando $m^{\prime \prime}$ tende a um valor entre 0 e 1 , o resultado da métrica final sinaliza para um cenário em relação ao número de descartes. Para os experimentos realizados neste trabalho, foi possível observar dois casos extremos. O primeiro ocorre quando o valor de $d_{\text {class }}$ (taxa de descartes) é zero ou quase zero. O segundo caso é quando a taxa de descartes é total ou quase total, refletindo portanto, na métrica final. Este último, por sua vez, caracteriza pior qualidade de serviço para 


\begin{tabular}{|c|c|}
\hline \hline \multicolumn{2}{|c|}{ Significado } \\
\hline \hline$m^{\prime}$ & $\frac{\sum_{\text {class }=0}^{\text {numclass-1 }}\left(\operatorname{Pr}_{\text {class }} * q r t_{\text {class }}\right)}{\sum P r_{\text {class }}}$ \\
\hline$m^{\prime \prime}$ & $\frac{\sum_{\text {class }=0}^{\text {numclass-1 }}\left(\operatorname{Pr}_{\text {class }} * e^{\left(\beta d_{\text {class }}-1\right)}\right)}{\sum P r_{\text {class }}}$ \\
\hline$M$ & $\frac{m^{\prime}+m^{\prime \prime}}{2}$ \\
\hline \hline
\end{tabular}

Tabela 6.2: Significado da Métrica

determinada classe.

É importante enfatizar que o principal objetivo ao definir a métrica $D Q T$ é mostrar que o uso de limiares distintos para cada classe de serviço, juntamente com diferentes configurações de chegadas por classe, melhora o atendimento das requisições de classes de baixa prioridade, ainda que observado um aumento no tempo de espera na fila para tais tipos de requisições. Por outro lado, a métrica $D Q T$ comprovou que a qualidade de serviço para requisições de alta prioridade permaneceu a melhor possível.

\subsection{Cenários para os testes}

Nesse segundo conjunto de testes foi abordada a utilização de limiares distintos para as diferentes classes de serviço, uma vez que no primeiro conjunto tais limiares foram fixados igualmente em $90 \%$ (da utilização do cluster) para todas as classes. O objetivo principal é avaliar o impacto que esta modificação poderia causar no atendimento das requisições e também em relação ao tempo de fila médio por classe. Nesse sentido, elaborou-se uma métrica para refletir o comportamento acima mencionado (considerando diversos fatores), a qual será explicada na próxima seção.

Três diferentes cenários foram definidos, onde a taxa de chegada por classe é variável. Para cada cenário, cinco limiares distintos também foram considerados. Em todas as simulações do segundo conjunto de testes optou-se pela utilização do valor 0.009 para o parâmetro Med_Resched, que foi obtido, como mencionado anteriormente, a partir do tempo de atendimento médio das requisições processadas no modelo $S W D S$.

Para melhor entendimento, apresentamos a parametrização do segundo conjunto de testes nas tabelas 6.3 e 6.4. Todos os outros parâmetros são iguais aos definidos no primeiro conjunto de testes.

\begin{tabular}{|c|c|c|c|}
\cline { 2 - 4 } \multicolumn{1}{c|}{} & \multicolumn{3}{c|}{ Chegadas por Classe } \\
\hline \hline Simulação & $\mathbf{0}$ & $\mathbf{1}$ & $\mathbf{2}$ \\
\hline \hline $\mathrm{X}$ & $25 \%$ & $25 \%$ & $50 \%$ \\
\hline \hline $\mathrm{Y}$ & $33 \%$ & $33 \%$ & $33 \%$ \\
\hline \hline $\mathrm{Z}$ & $50 \%$ & $25 \%$ & $25 \%$ \\
\hline \hline
\end{tabular}

Tabela 6.3: Cenários da Simulação 


\begin{tabular}{c|c|c|c|}
\cline { 2 - 4 } \multicolumn{1}{c|}{} & \multicolumn{3}{|c|}{ Limiares por Classe } \\
\hline \hline Caso & $\mathbf{0}$ & $\mathbf{1}$ & $\mathbf{2}$ \\
\hline \hline 1 & $60 \%$ & $70 \%$ & $80 \%$ \\
\hline \hline 2 & $70 \%$ & $80 \%$ & $90 \%$ \\
\hline \hline 3 & $80 \%$ & $80 \%$ & $90 \%$ \\
\hline \hline 4 & $85 \%$ & $85 \%$ & $90 \%$ \\
\hline \hline 5 & $90 \%$ & $90 \%$ & $90 \%$ \\
\hline \hline
\end{tabular}

Tabela 6.4: Diferentes Limiares

\subsection{Desempenho do Servidor Web}

Nesta seção são apresentados os principais resultados obtidos com a execução do algoritmo de negociação, usando o conceito de limiares distintos para as classes de serviços, juntamente com a variação das taxas de chegadas de requisições, ambos detalhados no capítulo anterior.

\subsubsection{Simulação X}

Considerando a configuração de chegada de acordo com a simulação X (25\% para classe $0,25 \%$ para a classe 1 e $50 \%$ para a classe 2 ), alguns resultados foram obtidos, como pode ser observado nas figuras 6.1 (número de descartes) e 6.2 (tempo médio de fila). Ao analisar tais gráficos, pode ser verificada uma melhoria em relação ao número de descartes para a classe 0 quando o limiar da utilização do sistema é aumentado.

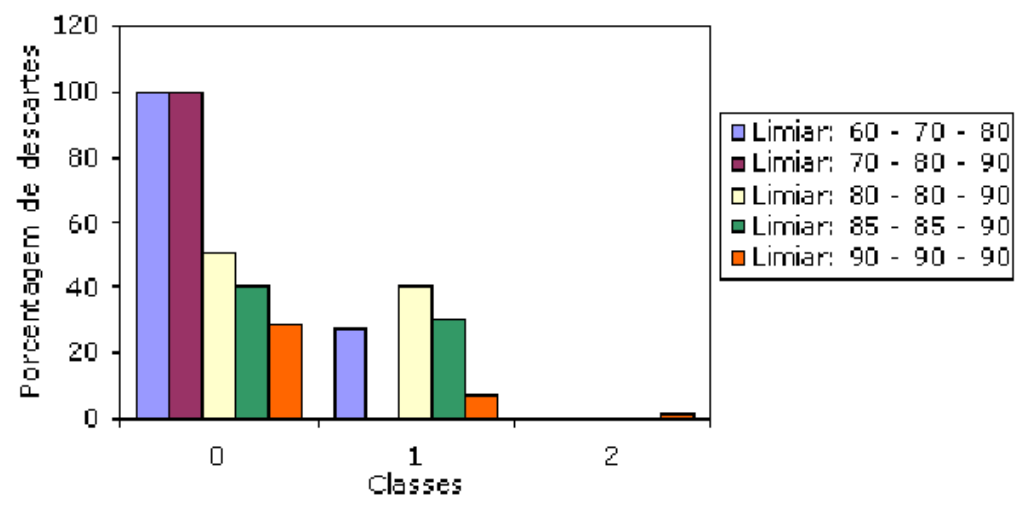

Figura 6.1: Comparação do número de descartes usando diferentes limiares - Simulação $\mathrm{X}$

No primeiro e segundo conjunto de limiares, os resultados mostram que devido a classe 2 possuir um limiar maior que qualquer outra classe, não haverá negociação e 


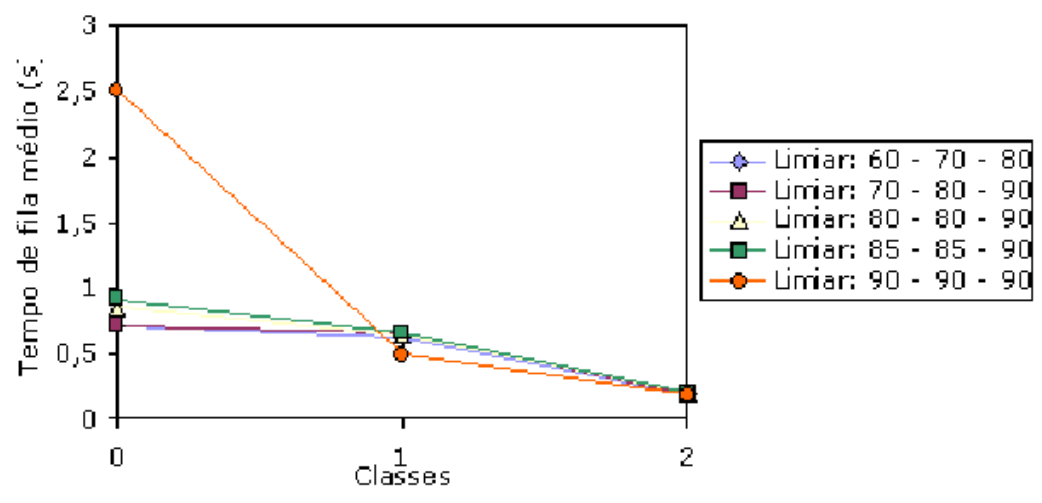

Figura 6.2: Tempo de fila médio - Simulação X

nem descartes. Além disso, a classe 0 apresenta o menor limiar, havendo ainda mais um prejuízo para esta classe, uma vez que para garantir o atendimento de $50 \%$ das requisições da classe 2, as requisições da classe 0 são descartadas.

Utilizando o terceiro conjunto de limiares, podem ser verificados melhorias no atendimento às requisições da classe 0 (a diminuição foi de $99 \%$ para $50.8 \%$ de descartes). Entretanto, ocorre o contrário com as requisições da classe 1. Esta classe começa a apresentar uma taxa de descartes maior em relação à taxa apresentada nos dois primeiros conjuntos de limiares. De acordo com o terceiro e quarto cojunto de limiares, a situação piora em relação aos limiares do primeiro conjunto, embora a porcentagem de descartes para a classe 1 tende a diminuir quando os limiares de utilização do sistema apresentam o mesmo valor para todas as classes de serviço.

Para o tempo médio de fila é observada uma redução para as requisições da classe 1. Por outro lado, o tempo de fila médio para a classe 2 permanece constante. As da classe 0, no entanto, apresentam uma aumento no tempo de fila à medida que há mudanças nos limiares.

\subsubsection{Simulação Y}

O segundo cenário define uma taxa de chegada de $33 \%$ para todas as classes. Os resultados da simulação para o tempo médio de fila e para a porcentagem de descartes podem ser observados nas figuras 6.3 e 6.4. No primeiro e segundo conjunto de limiares, verifica-se que o limiar para as requisições da classe 2 é maior que os limiares para aquelas da classe 0 e 1 . Por esse motivo, dificilmente o atendimento para as solicitações da classe 2 serão descartadas. O mesmo comportamento é apresentado para a classe 1, cujo limiar de utilização é de $70 \%$ e $80 \%$.

É importante observar que o algoritmo de diferenciação de serviço (PRIAdap) já provê 
melhor qualidade de serviço, seguindo uma ordem de prioridade de classes. O melhor cenário ocorre para a classe 2 , isto é, quando é utilizado o algoritmo de diferenciação de serviço juntamente com o maior limiar da utilização do sistema.

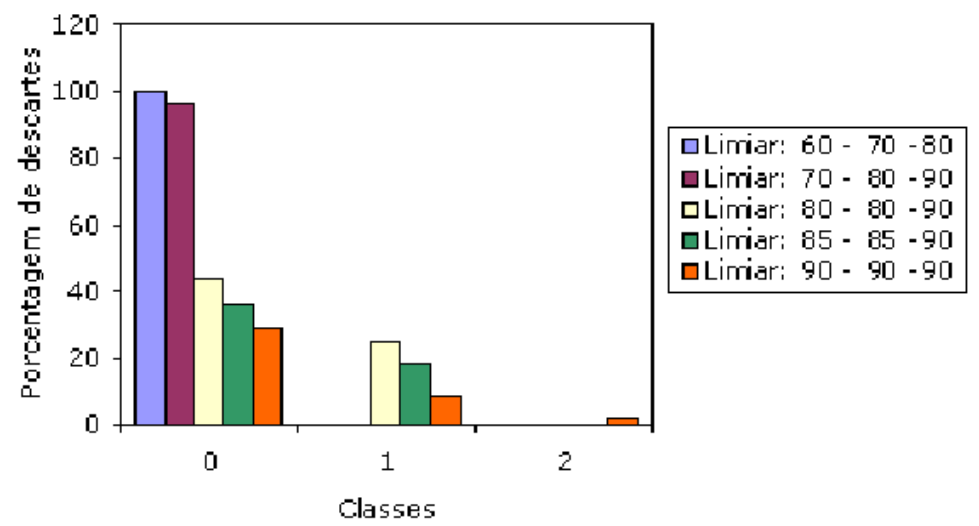

Figura 6.3: Comparação do número de descartes usando diferentes limiares - Simulação Y

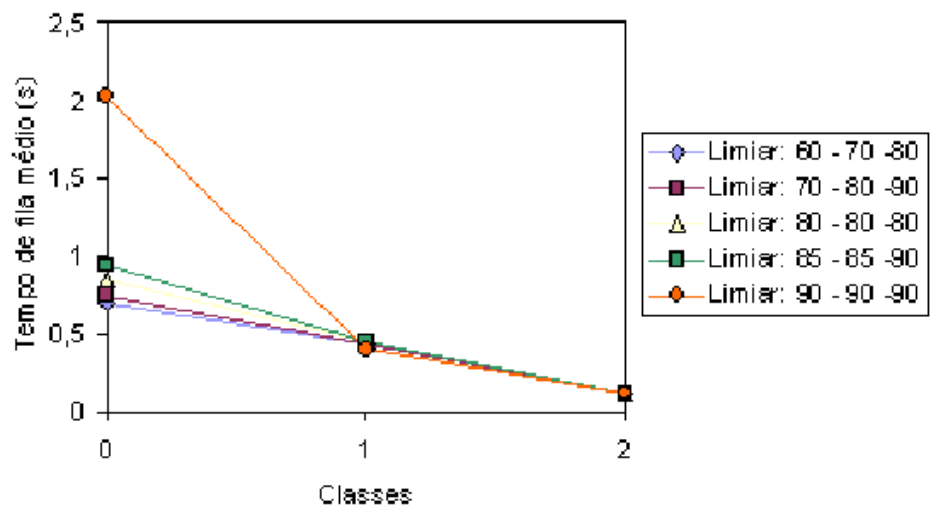

Figura 6.4: Tempo de fila médio - Simulação Y

Em resumo, se o limiar da classe 2 é o maior, não haverá negociação para esta classe e, conseqüentemente, todas as requisições desta natureza serão admitidas. O mesmo pode ocorrer com as requisições da classe 1. A classe 0, ao apresentar um menor limiar, é prejudicada para garantir melhor atendimento para as classe 2 e 1 respectivamente. É interessante notar que o uso de limiares rígidos e distintos para as classes de serviço, constitue um outro modo de prover QoS.

Com relação ao tempo médio de fila, há um aumento para a classe 0. Entretanto, para as classes 1 e 2 esse tempo se mantém constante. 
Os dois cenários apresentados até o momento confirmam que, quando há uma redução do limiar da utilização do sistema para uma classe de serviço, pior será o atendimento para essa classe e caso uma requisição desse tipo não seja negociada, ela será descartada.

\subsubsection{Simulação Z}

Este estudo de caso corresponde à simulação Z e também utiliza os valores dos limiares apresentados no capítulo anterior. As figuras 6.5 and 6.6 mostram os valores de descartes (em porcentagem) para as classes de serviço 0, 1 e 2.

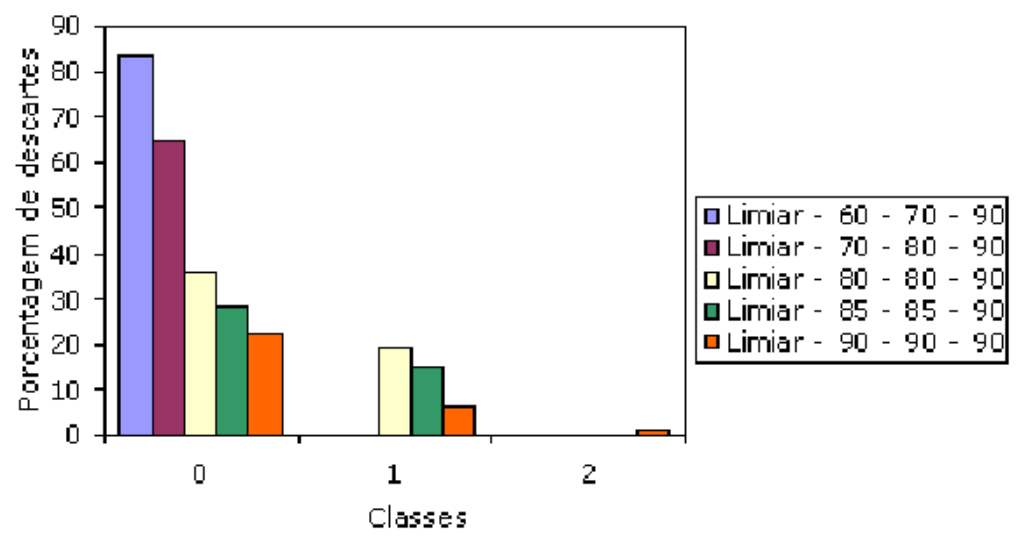

Figura 6.5: Comparação do número de descartes usando diferentes limiares - Simulação Z

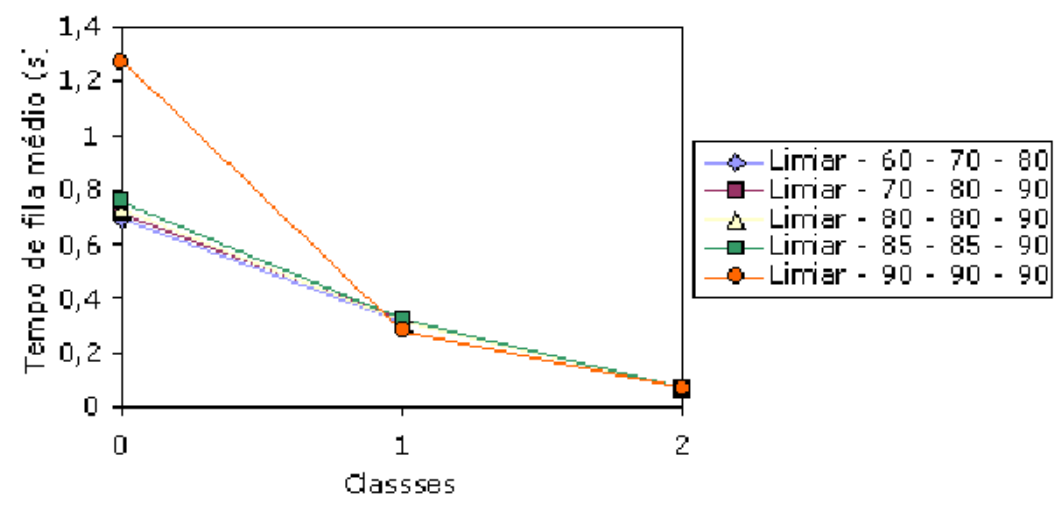

Figura 6.6: Tempo de fila médio - Simulação Z

Observando o gráfico da figura 6.5 é possível verificar que a degradação da qualidade de serviço para a classe 0 é cerca de $84 \%$ quando um limiar de $60 \%$ é utilizado. Além disso, quando o limiar da utilização do sistema aumenta, maior é a possibilidade da requisição 
ser admitida no cluster de servidores web. Para a classe 0, a situação em relação ao atendimento apresenta melhorias significativas quando o limiar de utilização para esta classe atinge $85 \%$. Nesse sentido, a quantidade de requisições tentando ser admitidas é muito maior. Nesta situação, haverá uma sobrecarga no sistema para a classe 0 e muito mais para a classe 1, devido ao fato de ambas as classes apresentarem o mesmo limiar. Sendo maior a taxa de chegada para a classe 0, na tentativa de admissão das requisições da classe 1, ocorrerá degradação da qualidade de serviço, enquanto que as requisições da classe 0 serão descartadas.

Uma vez que está sendo utilizado um mecanismo de negociação com a participação do cliente, as requisições da classe 1 que foram rebaixadas, retornam ao controle de admissão na classe inferior, em um intervalo de tempo x (obtido de acordo com a utilização de uma função exponencial). Assim, as requisições da classe 1 que retornaram ao controle de admissão, podem ser admitidas ou descartadas com uma qualidade de serviço inferior.

Com esse cenário, é possível afirmar que em função da alta utilização do sistema (muitas chegadas de requisições das classes 0 e 1), não é possível admitir todas as solicitações da classe 1 e por isso, ao aplicar o mesmo limiar para essas classes, algumas requisições da classe 1 serão prejudicadas, mesmo depois de serem negociadas. Outra observação é em relação ao tempo de fila médio para cada requisição. Verifica-se que o tempo de fila para a classe 2 se mantém em 0.007. Para a classe 1 , os valores variam de 0.28 para 0.31 , devido ao uso de limiares distintos. Por outro lado, o tempo de fila para a classe 0 tende a aumentar, principalmente em função da maior taxa de chegadas para as requisições desta classe e também em função do aumento do limiar.

\subsubsection{Validação da métrica DQT nos resultados}

Será apresentado nessa seção o uso da métrica $D Q T$ nos resultados obtidos com os experimentos referentes à negociação, utilizando diferentes limiares.

A tabela 6.5 reforça ainda mais o conteúdo dos gráficos abordados anteriormente, mostrando o valor final de M. Na simulação X pode ser observado que houve uma redução do número de descartes para as requisições da classe 0 , conforme ocorre uma aumento do limiar.

\begin{tabular}{|c|c|c|c|c|c|c|c|c|c|c|c|c|c|c|c|}
\hline \multicolumn{16}{|c|}{ Simulação X - Prioridade Relativa: 0.5 - 0.75 - 1.0} \\
\hline Caso & \multicolumn{3}{|c|}{ Tempo Fila Médio } & \multicolumn{3}{|c|}{ Tempo Relativo } & \multicolumn{3}{|c|}{ Descartes } & \multicolumn{3}{|c|}{ Descarte Relativo } & $\mathbf{m}^{\prime}$ & $\mathrm{m}^{\prime \prime}$ & $\mathbf{M}$ \\
\hline$\downarrow$ & $\mathbf{0}$ & 1 & 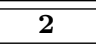 & $\mathbf{0}$ & 1 & 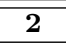 & $\mathbf{0}$ & 1 & 2 & $\mathbf{0}$ & 1 & 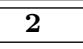 & $\downarrow$ & $\bar{\downarrow}$ & $\downarrow$ \\
\hline $60-70-80$ & 0.72 & 0.63 & 0.19 & 1.0 & 0.88 & 0.26 & 0.99 & 0.27 & 0 & 0.99 & 0.20 & 0 & 0.63 & 0.29 & 0.46 \\
\hline $70-80-90$ & 0.71 & 0.65 & 0.19 & 1.0 & 0.92 & 0.27 & 0.99 & 0 & 0 & 0.99 & 0 & 0 & 0.64 & 0.22 & 0.43 \\
\hline $80-80-90$ & 0.85 & 0.64 & 0.20 & 1.0 & 0.75 & 0.24 & 0.50 & 0.39 & 0 & 0.41 & 0.31 & 0 & 0.57 & 0.19 & 0.38 \\
\hline $85-85-90$ & 0.91 & 0.57 & 0.20 & 1.0 & 0.71 & 0.22 & 0.41 & 0.30 & U & 0.33 & 0.23 & 0 & 0.55 & 0.15 & 0.35 \\
\hline $790-90-90$ & 2.52 & 0.49 & 0.19 & 1.0 & 0.20 & 0.08 & 0.29 & 0.07 & 0.02 & 0.22 & 0.05 & 0.01 & 0.32 & 0.07 & 0.19 \\
\hline
\end{tabular}

Tabela 6.5: DQT - Simulação X 
Como o valor final de $\mathbf{M}$ deve variar entre 0 e 1 , quando o resultado se aproxima de zero, melhor será a distribuição de descartes para as classes de serviços, como pode ser verificado no caso $90 \%, 90 \%, 90 \%$. Entretanto, quando $\mathbf{M}$ se aproxima do valor 1, há um aumento da taxa de descartes para a classe 0, e em algumas situações, para a classe 1. Isso ocorre devido à variação das taxas de chegadas e também devido à diferença de limiares entre as classes de serviços.

Considerando a simulação $\mathrm{Y}$, são obtidos resultados similares ao da simulação X. A diferença reside no fato de que em função das taxas de chegadas mais baixas para as requisições da classe 2, o valor final de $M$ foi de 0.36 , menor que o apresentado na simulação X cujo resultado foi de 0.46. Há também uma melhoria com relação ao número de descartes para ambas as classes 0 e 1 . A classe 2 somente apresenta uma pequena porcentagem de descartes quando os limiares para todas as classes se igualam a $90 \%$.

\begin{tabular}{|c|c|c|c|c|c|c|c|c|c|c|c|c|c|c|c|c|}
\hline \hline \multicolumn{10}{|c|}{ Simulação Y - Prioridade Relativa: 0.5 - 0.75 - 1.0 } \\
\hline \hline Caso & \multicolumn{10}{|c|}{ Tempo Fila Médio } & \multicolumn{2}{|c|}{ Tempo Relativo } & \multicolumn{7}{c|}{ Descartes } & \multicolumn{2}{c|}{ Descarte Relativo } & $\mathbf{m}^{\prime}$ & $\mathbf{m}^{\prime}$ & $\mathbf{M}^{\prime}$ \\
\hline \hline$\downarrow$ & $\mathbf{0}$ & $\mathbf{1}$ & $\mathbf{2}$ & $\mathbf{0}$ & $\mathbf{1}$ & $\mathbf{2}$ & $\mathbf{0}$ & $\mathbf{1}$ & $\mathbf{2}$ & $\mathbf{0}$ & $\mathbf{1}$ & $\mathbf{2}$ & $\downarrow$ & $\downarrow$ & $\downarrow$ \\
\hline \hline $60-70-80$ & 0.69 & 0.44 & 0.11 & 1.0 & 0.64 & 0.16 & 0.99 & 0 & 0 & 0.99 & 0 & 0 & 0.51 & 0.21 & 0.36 \\
\hline \hline $70-80-90$ & 0.74 & 0.44 & 0.11 & 1.0 & 0.59 & 0.15 & 0.96 & 0 & 0 & 0.95 & 0 & 0 & 0.49 & 0.21 & 0.35 \\
\hline \hline $80-80-90$ & 0.85 & 0.45 & 0.12 & 1.0 & 0.53 & 0.14 & 0.44 & 0.24 & 0 & 0.36 & 0.18 & 0 & 0.46 & 0.14 & 0.30 \\
\hline \hline $85-85-90$ & 0.94 & 0.45 & 0.12 & 1.0 & 0.48 & 0.13 & 0.35 & 0.18 & 0 & 0.27 & 0.13 & 0 & 0.44 & 0.11 & 0.27 \\
\hline \hline $90-90-90$ & 2.03 & 0.40 & 0.11 & 1.0 & 0.20 & 0.05 & 0.28 & 0.08 & 0.02 & 0.21 & 0.057 & 0.014 & 0.31 & 0.07 & 0.19 \\
\hline \hline
\end{tabular}

Tabela 6.6: DQT - Simulação Y

Finalmente, a simulação $\mathrm{Z}$ reforça as melhorias em termos de redução de descartes para as classes de serviços. Quando verificado o valor de $\mathbf{M}$ para essa simulação, percebese que em relação às simulações $\mathrm{A}$ e $\mathrm{B}$, o valor é menor, principalmente devido à variação dos limiares.

\begin{tabular}{|c|c|c|c|c|c|c|c|c|c|c|c|c|c|c|c|}
\hline \multicolumn{16}{|c|}{ Simulação Z - Prioridade Relativa: 0.5 - 0.75 - 1.0} \\
\hline \multirow{2}{*}{$\begin{array}{c}\text { Caso } \\
\downarrow\end{array}$} & \multicolumn{3}{|c|}{ Tempo Fila Médio } & \multicolumn{3}{|c|}{ Tempo Relativo } & \multicolumn{3}{|c|}{ Descartes } & \multicolumn{3}{|c|}{ Descarte Relativo } & \multirow{2}{*}{$\frac{\mathbf{m}^{\prime}}{\bar{\downarrow}}$} & \multirow{2}{*}{$\frac{\mathbf{m}^{\prime \prime}}{\downarrow}$} & \multirow{2}{*}{$\frac{\mathbf{M}}{\downarrow}$} \\
\hline & 0 & 1 & 2 & 0 & 1 & 2 & 0 & 1 & 2 & 0 & 1 & 2 & & & \\
\hline $60-70-80$ & 0.69 & 0.31 & 0.07 & 1.0 & 0.45 & 0.10 & 0.86 & 0 & $\overline{0}$ & 0.82 & 0 & 0 & $\overline{0.42}$ & 0.18 & 0.30 \\
\hline $70-80-90$ & 0.73 & 0.31 & 0.07 & 1.0 & 0.42 & 0.10 & 0.64 & 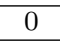 & 0 & 0.56 & 0 & 0 & 0.41 & 0.13 & 0.27 \\
\hline $80-80-90$ & 0.71 & 0.32 & 0.07 & 1.0 & 0.45 & 0.10 & 0.35 & 0.20 & 0 & 0.27 & 0.15 & 0 & 0.42 & 0.11 & 0.26 \\
\hline $85-85-90$ & 0.76 & 0.32 & 0.07 & 1.0 & 0.42 & 0.09 & 0.28 & 0.14 & 0 & 0.21 & 0.10 & 0 & 0.40 & 0.08 & 0.24 \\
\hline $90-90-90$ & 1.27 & 0.28 & 0.07 & 1.0 & 0.22 & 0.06 & 0.22 & 0.06 & 0.01 & 0.16 & 0.04 & 0.007 & 0.32 & 0.05 & 0.19 \\
\hline
\end{tabular}

Tabela 6.7: DQT - Simulação Z

\subsection{Considerações Finais}

Este capítulo apresentou resultados obtidos com a implementação dos algoritmos de negociação, propostos neste trabalho. Foi abordado mais um conjunto de testes, complementando o apresentado no capítulo 5, além da composição e a validação de uma 
métrica, objetivando verificar o comportamento dos descartes e tempo de médio de fila para as classes de serviços, principalmente quando há diversos parâmetros envolvidos. Dentre estes destacam-se a variação da taxa de chegada das requisições e também o uso de diferentes limiares da utilização do cluster de servidores web.

A necessidade da composição dessa métrica é importante para avaliar o comportamento dos servidores web com qualidade de serviço, quando estes apresentam uma carga de trabalho excessiva e precisam tomar decisões quanto ao atendimento das classes de serviços das requisições.

Muitos parâmetros são envolvidos, e certamente não abordou-se todos eles neste trabalho, mas tentou-se relacionar os mais importantes e que refletissem alguma medida de desempenho, indicando o quão bom ou ruim seria o atendimento para uma dada classe de serviço. Aliás, a grande quantidade de variáveis envolvidas quando se trabalha especificamente com servidores web é uma dificuldade que surgiu ao longo do desenvolvimento deste trabalho e que continua sendo muito explorada em trabalhos da área de análise de desempenho em servidores web ao longos dos anos.

O próximo capítulo tem como objetivo apresentar as conclusões obtidas com o desenvolvimento deste trabalho e suas contribuições, além de abordar propostas para trabalhos futuros relacionados à análise de desempenho em aplicações web. 


\section{Capítulo \\ 7}

Conclusões

\subsection{Considerações Iniciais}

O propósito deste trabalho de mestrado foi a introdução de mecanismos de negociação no modelo de servidor web com diferenciação de serviços, denominado $S W D S$. O objetivo com esses mecanismos é permitir que requisições com critérios diferenciados de QoS tenham garantia de atendimento em relação às requisições que não possuem esta característica.

Para que o objetivo fosse alcançado foi necessário fazer uma revisão geral da estrutura da web, como mostra o capítulo 2, assim como referenciar no capítulo 3 os serviços diferenciados, incluindo classes de seviços, QoS, e sua limitação na Internet atual.

O capítulo 4 abordou o modelo do $S W D S$ e seus componentes. No capítulo 5 foram explicados os dois algoritmos implementados, o algoritmo de negociação rigoroso e o algoritmo de negociação com a participação do cliente. Ambos os algoritmos foram implementados de modo a prover melhorias quanto ao atendimento de requisições segundo critérios de qualidade de serviço. No caso específico dos testes presentes nesse projeto, foi levado em consideração um algoritmo de diferenciação já implementado no modelo $S W D S$ denominado PRIAdap. Ainda com o intuito de quantificar as diferenças em relação ao uso de diferentes limiares de utilização do sistema, foi proposta a composição de uma métrica, levando em conta critérios como o descarte e prioridade relativa de cada classe de serviço. Tal métrica foi desenvolvida para a validação dos resultados. Finalmente o capítulo 6, detalhou os resultados obtidos. Este capítulo mostrará nas próximas seções as contribuições com o desenvolvimento deste trabalho, os trabalhos relacionados do grupo de pesquisa, os desafios inerentes à área de qualidade de serviço no nível de aplicação além dos trabalhos futuros. 


\subsection{Trabalhos Relacionados}

Este trabalho de mestrado é parte integrante dos projetos desenvolvidos no Laboratório de Sistemas Distribuídos e Programação Concorrente - LaSDPC. Além deste trabalho, destaca-se também a implementação de um protótipo do modelo $S W D S$ com as funcionalidades que foram apresentadas no capítulo 4 (classificador, controle de admissão, cluster de servidores, etc). O classificador está sendo projetado para realizar sua função, através do uso de uma rede neural. Prentende-se portanto, a utilização de técnicas de inteligência artificial como auxílio ao desenvolvimento do protótipo do $S W D S$.

Outro trabalho em andamento é a introdução de características de sessões, as quais serão futuramente relacionadas com os mecanismos de negociação.

Ainda com relação à qualidade de serviço, estudos estão sendo conduzidos com o objetivo de propor e avaliar uma política de escalonamento para servidores web distribuídos, visando a garantia de parâmetros temporais de $Q o S$, formulados em termos de limites superiores estatísticos do tempo de resposta. A idéia é prover uma certa garantia de qualidade de serviço a determinadas aplicações web, e também quantificar a diferenciação de serviço ao garantir que um dado cliente será atendido em no máximo $X$ unidades de tempo.

Destaca-se também a elaboração de políticas de atendimento para servidores web com serviços diferenciados baseadas nas características das requisições. Este projeto aborda a investigação de novas políticas de escalonamento e de controle de admissão para servidores Web distribuídos com suporte a serviços diferenciados. Essas políticas devem considerar as características das requisições Web para subsidiar a tomada das decisões. Pretende-se investigar a possibilidade de melhorar o desempenho do sistema, por meio da utilização mais eficiente dos seus recursos, quando são consideradas as características das requisições nas políticas de atendimento.

Com relação aos estudos com cargas de trabalho, está em fase final a construção de um gerador de cargas de trabalho sintéticas, jutamente com um estudo detalhado do comportamento de carga da web em geral. Tal ferramenta está sendo desenvolvida em outro projeto de mestrado do LaSDPC. A possibilidade de utilizar cargas de trabalho sintéticas ajudam na definição do comportamento da carga de trabalho utilizada nas simulações (requisições estáticas, dinâmicas, dentre outras características).

\subsection{Resultados e Contribuições}

Os dois algoritmos abordados no presente projeto pemitiram a evolução do modelo do $S W D S$, além de ser uma solucão inovadora, visto que originalmente o modelo não possuía características de negociação, ou seja, uma requisição era sumariamente descartada independentemente de sua classe se a carga de trabalho do cluster de servidores estivesse 
acima de um determinado limiar.

Quando da construção do algoritmo de negociação rigoroso, a maior preocupação era a validação da negociação no modelo estudado. Os ganhos obtidos não foram tão melhores que aqueles alcançados com o modelo sem as características de negociação. No entanto, a implementação do algoritmo de negociação com a participação de um cliente (simulado através de um centro de serviço) mostrou-se bastante adequada na diminuição de descartes para determinadas classes de serviços (isto é, aquelas de maior prioridade). Essa diminuição pode ser confirmada nos diversos cenários de simulações ilustrados neste trabalho.

Os resultados do primeiro conjunto de testes permitem afirmar que mecanismos de negociação são de suma importância quando se trabalha no projeto de arquiteturas de servidores web com diferenciação de serviços. Os dois algoritmos implementados e abordados neste projeto confirmam que um modelo de servidor web que aceita negociação apresenta ganhos em relação ao tempo de espera de requisições na fila do servidor (ou cluster de servidores). Além disso, dependendo do algoritmo (principalmente o algoritmo de negociação com a participação do cliente), a porcentagem de descarte para classes prioritárias torna-se muito menor.

Para o segundo conjunto de testes, verificou-se que classes de serviços inferiores foram prejudicadas quando limiares da utilização (medida que permite a admissão de uma requisição no cluster) eram diferentes. A métrica $D Q T$ mostrou a influência desses diferentes limiares no processo de descartes de requisições, quando os servidores se apresentavam sobrecarregados.

O maior desafio ao compor essa métrica, foi tentar representar numa única equação, os parâmetros que poderiam influenciar os mecanismos de negociação, tais como: taxas de chegadas das requisições, limiares distintos, classes de serviços, tempo de fila, porcentagem de descartes, e também a participação do cliente neste processo. Apesar dos inúmeros desafios, este trabalho apresenta uma contribuição para os trabalhos presentes na literatura da área ao utilizar técnicas de negociação num modelo de servidor web com qualidade de serviço.

Dentre as contribuições geradas a partir do desenvolvimento desse trabalho de mestrado destacam-se:

- Evolução do modelo $S W D S$ ao introduzir a negociação;

- Provisão de melhor QoS para classes de serviços;

- Implementação de mecanismos de negociação e a composição de uma métrica para caracterizar tais mecanismos;

- A participação de um cliente no modelo $S W D S$ mostrou-se um componente importante na redução de descartes e tempo de fila para as requisições de maior prioridade. 
Até a presente data, foram geradas as seguintes publicações a partir dos resultados obtidos durante o desenvolvimento desta dissertação:

- ESTRElla, J. C.; SANTANA, M. J.; SANTANA, R. H. C.; BRUSCHI, S. M; TEIXEIRA, M. M. Mecanismos de negociação no módulo de controle de admissão da arquitetura de servidor web com diferenciação de serviços. XI Simpósio Brasileiro de Sistemas Multimídia e Web (WebMedia), Poços de Caldas, MG. [S.l.: s.n.], 2005. v.1 , p. 100-106. ISBN: 8576669060-8 (Full Paper)

- ESTRElla, J. C.; SANTANA, M. J.; SANTANA, R. H. C.; BRUSCHI, S. M; TEIXEIRA, M. M. Qualidade de Serviço em Servidores Web: Uma nova abordagem utilizando negociação. XI Simpósio Brasileiro de Sistemas Multimídia e Web (WebMedia), Poços de Caldas, MG. [S.l.: s.n.], 2005. v.2 , p. 217-219. ISBN: 8576669060-8 (Short Paper)

- ESTRElla, J. C.; SANTANA, M. J.; SANTANA, R. H. C.; BRUSCHI, S. M; TEIXEIRA, M. M. Negotiation mechanisms on application level: A new approach to improve quality of service in web servers. In: IEEE International Workshop on Collaborative Computing, Integration and Assurance (WCCIA 2006), 9th IEEE International Symposium on Object and Component-oriented Real-time Distributed Computing (ISORC 2006), Coréia do Sul. [S.l.: s.n.], 2006. (Full Paper)

\subsection{Trabalhos Futuros}

Os mecanismos de negociação abordados neste projeto de mestrado consistem numa definição inicial, podendo portanto serem ampliados. Por isso, são apresentadas a seguir sugestões para trabalhos futuros:

- Desenvolvimento de novos algoritmos de negociação. Esses algoritmos seriam desenvolvidos para permitir melhorias quando à qualidade de serviço, mas levando em consideração outras características, diferentemente da abordada no algoritmo de prioridade adaptativo proposto por (TEIXEIRA, 2004a);

- Estudo de novas cargas de trabalho. Uma carga de trabalho real, no entanto mais atual, sinalizaria um estudo importante ao comparar o modelo $S W D S$ com negociação. Enquanto determinadas cargas estão indisponíveis no momento (infelizmente devido ao uso comercial pelas empresas), há uma concentração de esforços na produção de cargas de trabalhos sintéticas para estudos futuros;

- Teste do modelo $S W D S$, incluindo os mecanismos de negociação, por meio de uma carga de trabalho gerada sinteticamente. Uma ferramenta com essas características está em estudo no grupo de pesquisa do LaSDPC; 
- Utilização de novos algoritmos de escalonamento e a integração de mecanismos de negociação com a funcionalidade de sessões. Novos algoritmos de escalonamento poderiam melhorar ainda mais o atendimento de requisições a medida que esses fossem integrados aos mecanismos de negociação;

- Algoritmos de negociação a serem implementados futuramente devem ser definidos utilizando uma distribuição que melhor se aproxima do tempo de pensar de um cliente web real. Nesse caso, estudos seriam realizados para verificar a viabilidade de se utilizar a distribuição de Pareto, com o desafio de encontrar os parâmetros que melhor representem situações reais.

- Caracterização de novos mecanismos de diferenciação de serviços. Uma nova técnica de diferenciação de serviço seria tornar adaptativa a prioridade das classes de serviços no momento em que estão são escalonadas para serem executadas pela CPU dos servidores do cluster. Isto é, a prioridade das classes mudaria de acordo com as informações da carga de trabalho em determinado instante.

- Introdução de um módulo de inteligência artificial no modelo $S W D S$. Esse módulo funcionaria como um histórico do atendimento das requisições e ajudaria na tomada de decisões de atendimento das requisições futuras de determinada classe de serviço. Neste caso, portanto, as mudanças em relação aos algoritmos de escalonamento e diferenciação de serviços seriam dinâmicas. Ou seja, tudo seria adaptado de acordo com a carga de trabalho imposta ao cluster de servidores web, e a rede neural auxiliaria neste processo na tomada de decisões quanto ao melhores algoritmos para aquela ocasião. O principal desafio desta técnica é extrair de uma carga de trabalho os padrões de entrada para uma rede neural, além de descobrir qual o algoritmo de treinamento de rede mais adequado para o problema em questão. 


\section{Referências Bibliográficas}

ABDELZAHER, T. F.; BHATTI, N. Web content adaptation to improve sever overload behavior. In: Proceedings of the Eighth International World Wide Web Conference. Toronto, Canada: [s.n.], 1999. v. 27, n. 2, p. 25-36.

ALMEIDA, J. et al. Providing differentiated levels of service in web content hosting. In: Proceedings of the 1998 SIGMETRICS Workshop on Internet Server Performance. [S.1.]: SIGMETRICS, 1998. p. 12.

ANDREOLINI, M. et al. A cluster-based web system providing differentiated and guaranteed services. In: . [S.l.]: Cluster Computing, 2004. v. 7, n. 1, p. 7-19. ISSN 1386-7857.

ARLITT, M.; TAI, J.; FRIEDRICH, R. Workload characterization of a web proxy in a cable modem environment. In: Proceedings of the ACM SIGMETRICS Performance Evaluation. [S.l.]: SIGMETRICS, 1999. v. 27, n. 2, p. 25-36.

ARLITT, M.; WILLIAMSON, C. L. Web server workload characterization: the search for invariants. In: Proceedings of the ACM SIGMETRICS'96. Philadelphia, PA:

SIGMETRICS, 1996. p. 126-137.

BANGA, G.; DRUSCHEL, P. Measuring the capacity of a web server. In: Proceedings of the USENIX Symposium on Internet Technologies and Systems. Monterey, California: USENIX, 1997. p. 12.

BARFORD, P. et al. Changes in web client access patterns: Characteristics and caching implications. World Wide Web, Kluwer Academic Publishers, v. 2, n. 1-2, p. 15-28, 1999. ISSN 1386-145X.

BERNERS-LEE, T.; FIELDING, R.; FRYSTYK, H. Hypertext Transfer Protocol HTTP/1.0. 1996.

BHATTI, N.; FRIEDRICH, R. Web Server Support for Tiered Services. HP Laboratories Palo Alto, 121999.

BHINDER, R. et al. Evaluation of request distribution schemes for web-server clusters. In: . [S.l.]: IEEE Computer Society, 2004. p. 4.

BHOJ, P.; RAMANATHAN, S.; SINGHAL, S. Web2K: Bringing QoS to Web Servers. HP Laboratories Palo Alto, 05 2000. 21 p. 
BLAKE, S. et al. An architecture for differentiated services. Network Working Group, The Internet Society, p. 22, 1998.

BLANQUER, J. M. et al. Qos for internet services - done right. In: 11th ACM SIGOPS European Workshop. Leuven, Belgium: ACM Press, 2004. p. 6.

CARDELLINI, V. et al. Web switch support for differentiated services. In: . [S.l.]: ACM Performance Evaluation Review, 29(2), 2001. p. 14-19.

CARDELlinI, V.; COLAJANNI, M.; YU, P. Request redirection algorithms for distributed web systems. In: IEEE Transactions on Parallel and Distributed Systems. [S.l.]: IEEE, 2003. v. 14, n. 4, p. 355-368.

CARDELLINNI, V.; CASALICCHIO, E. The state of the art in locally distributed web-server systems. In: . [S.l.]: ACM Computing Surveys, 2002. v. 34, n. 2, p. 263-311.

CARDELLINNI, V. et al. Enhancing a web-cluster with quality of service mechanisms. In: Proceedings of the IEEE International Performance. [S.l.]: IEEE Computer Society, 2002. p. 8.

CASALICCHIO, E.; COLAJANNI, M. Scalable web cluster with static and dynamic contents. In: In Proceedings of the IEEE International Conference on Cluster Computing CLUSTER'00. [S.l.: s.n.], 2000.

CASALICCHIO, E.; SETOLA, R.; S.TUCCI. An overview about critical infrastructures modelling and simulation techniques. In: Proceedings of 5th EUROSIM Congress on Modelling and Simulation, Cité Descartes, France. [S.l.: s.n.], 2004.

CHEN, T.-S.; CHEN, K.-L. Balancing workload based on content types for scalable web server clusters. In: AINA '04: Proceedings of the 18th International Conference on Advanced Information Networking and Applications Volume 2. [S.l.]: IEEE Computer Society, 2004. p. 321. ISBN 0-7695-2051-0.

CHEN, X.; MOHAPATRA, P. Providing differentiated service from an internet server. In: Proceedings of the IEEE International Conference on Computer Communications and Networks. [S.l.]: IEEE, 1999. p. 214-217.

CHERKASOVA, L.; PHAAL, P. Session-based admission control: a mechanism for improving performance of commercial web sites. In: HEWLETT-PACKARD CO., PALO ALTO, CA. Quality of Service, 1999. IWQoS '99. 1999 Seventh International Workshop on. London, UK: IEEE, 1999. p. 226-235.

COMER, D. E. Internetworking with TCP/IP: Principles, protocols, and architecture. 3. ed. [S.1.]: Prentice Hall, 1995. 640 p.

COUlOURIS, G.; DOLlimORE, J.; KINDBERG, T. Distributed Systems: Concepts and design. 2. ed. Harlow: Addison Wesley, 1994. 644 p.

COUlOURIS, G.; DOLlimORE, J.; KINDBERG, T. Distributed Systems: Concepts and design. 3. ed. Harlow: Addison Wesley, 2001. 771 p.

CROVELlA, M.; FRANGIOSO, R.; HARCHOL-BALTER, M. Connection scheduling in web servers. [S.l.], 03 1999. 20 p. 
CROVELLA, M. E.; BESTAVROS, A. Self-similarity in world wide web traffic: Evidence and possible causes. In: . [S.l.]: IEEE/ACM Transactions on Networking. 5(6), 1997. p. $835-846$.

CUBERT, R. M.; FISHWICK, P. Sim++, version 1.0. Department of Computer and Information Science and Engineering, University of Florida, Gainesville, FL, p. 1-2, 1995.

EGGERT, L.; HEIDEMANN, J. Application level differentiated services for web servers. World Wide Web Journal, v. 2, p. 133-142, 1999.

ELNIKETY, S. et al. A method for transparent admission control and request scheduling in ecommerce web sites. In: Proceedings of the 13th International World Wide Web Conference. New York City, NY, USA: ACM Press, 2004. p. 276-286. ISBN $1-58113-844-\mathrm{X}$.

ESTRELLA, J. C. et al. Mecanismos de negociação no módulo de controle de admissão da arquitetura de servidor web com diferenciação de serviços. In: XI Simpósio Brasileiro de Sistemas Multimídia e Web (WebMedia), Poços de Caldas, MG. [S.l.: s.n.], 2005. v. 1, p. 100-106. ISBN 857669060-8.

ESTRELLA, J. C. et al. Negotiation mechanisms on application level: A new approach to improve quality of service in web servers. In: IEEE International Workshop on Collaborative Computing, Integration and Assurance (WCCIA 2006), 9th IEEE International Symposium on Object and Component-oriented Real-time Distributed Computing (ISORC 2006), Coréia do Sul. [S.l.: s.n.], 2006.

FERGUSON, P.; HUSTON, G. Quality of Service: Delevering QoS on the Internet and in Corporate Networks. [S.l.]: New York, 1998.

FIELDING, R. et al. Hypertext Transfer Protocol - HTTP/1.1. 1999.

FLOYD, S.; JACOBSON, V. Random early detection gateways for congestion avoidance. In: . [S.l.]: IEEE/ACM Transactions on Networking, 1993. p. 22.

GUO, C.; XIONG, Z.; YAN, P. A dynamic load scheduling algorithm for web servers. In: . [S.1.]: IEEE Computer Society, 2004. p. 259-264.

HO, L. K. et al. Improving web server performance by a clustering-based dynamic load balancing algorithm. In: AINA '04: Proceedings of the 18th International Conference on Advanced Information Networking and Applications Volume 2. [S.l.]: IEEE Computer Society, 2004. p. 232. ISBN 0-7695-2051-0.

HU, Y.; NANDA, A.; YANG, Q. Measurement, analysis and performance improvement of the apache web server. In: Proceedings of the 18thIEEE International Performance, Computing and Communications Conference. [S.l.: s.n.], 1999.

INTERNATIONAL STANDARDS ORGANIZATION. Basic Reference Model of Open Distributed processing, Part 1: Overview and guide to use. ISO/IEC JTC1/SC212/WG7 CD 10746-1, 1992.

IYENGAR, A. et al. (Ed.). Practical Handbook of Internet Computing - Chapter 1. [S.l.]: Chapman and Hall/CRC Press, Munindar P. Singh ed, 2005. 1-26 p. 
KANODIA, V.; KNIGHTLY, E. W. Ensuring latency targets in multiclass web servers. In: IEEE COMPUTER SOCIETY. IEEE Transactions on Parallel and Distributed Systems. [S.1.]: IEEE, 2003. v. 14, n. 01, p. 84-93.

KUMAR, K. H.; MAJHI, S. Queuing theory based open loop control of web server. In: Proceedings of the 2004 American Control Conference, Boston, Massachusetts. [S.l.: s.n.], 2004. p. 2.

KUROSE, J.; ROSS, K. Computer Networking: A Top-Down Approach Featuring the Internet. 3. edição. ed. [S.1.]: Person, 2005. 712 p.

LEE, S. C. M.; LUI, J. C. S.; YAU, D. K. Y. A proportional-delay diffserv-enabled web server: Admission control and dynamic adaptation. In: IEEE Transactions on Parallel and Distributed Systems. [S.1.]: IEEE Computer Society, 2004. v. 15, n. 5, p. 16.

LIM, S. S. et al. An adaptive admission control mechanism for a cluster-based web server system. In: IPDPS '02: Proceedings of the 16th International Parallel and Distributed Processing Symposium. [S.1.]: IEEE Computer Society, 2002. p. 59.

MACDOUGALL, M. H. Simulating computer systems: techniques and tools. Cambridge, MA, USA: MIT Press, 1987. 292 p.

MENASCE, D. A.; ALMEIDA, V. A. F. Planejamento de Capacidade para Serviços na Web: Métricas, modelos e métodos. [S.l.]: Editora Campus, 2003.

MENASCE, D. A.; RUAN, H.; GOMAA, H. A framework for qos-aware software components. In: WOSP '04: Proceedings of the fourth international workshop on Software and performance. [S.l.]: ACM Press, 2004. p. 186-196. ISBN 1-58113-673-0.

MULLENDER, S. (Ed.). Distributed Systems. 2. ed. New York: Addison-Wesley Publishing Company, 1993. 601 p. (ACM Press Frontier Series).

NETWORKS, N. Introduction to Quality of Service (QoS). [S.1.], 2003. 14 p.

PAI, V. S.; DRUSCHEL, P.; ZWAENEPOEL, W. Flash: An efficient and portable web server. In: Proceedings of the 1999 Annual Usenix Technical Conference. Monterey, CA: Usenix, 1999. p. 1-14.

PANDEY, R.; BARNES, J. F.; OLLSSON, R. Supporting quality of service in HTTP servers. In: Symposium on Principles of Distributed Computing. [S.l.: s.n.], 1998. p. $247-256$.

QUINN, M. J. Parallel Computing: Theory and practice. 2. ed. New York: McGraw Hill, 1994. $446 \mathrm{p}$.

ROBERTSSON, A. et al. Desing and evaluation of load control in web server systems. In: Proceedings of the 2004 American Control Conference, Boston, Massachusetts. [S.l.: s.n.], 2004. p. 6.

SANTANA, R. H. C. et al. Técnicas para Avaliação de Desempenho de Sistemas Computacionais. Monografia (Notas Didáticas) — ICMC-USP, São Carlos, 1994. 
SOARES, L. F. G.; LEMOS, G.; COLCHER, S. Redes de Computadores - Das Lans, Mans e Wans às Redes ATM. 2. edição. ed. Rio de Janeiro: Editora Campus, 1995. $705 \mathrm{p}$.

STALLINGS, W. High-speed networks and internets: Performance and quality of service. In: . [S.1.]: Prentice Hall, 2. edition, 2002.

STALLINGS, W. Arquitetura e Organização de Computadores: Projeto para o desempenho. 5. ed. São Paulo: Prentice Hall, 2003. 786 p. Tradução: Carlos Camarão de Figueiredo e Lucília Camarão de Figueiredo.

STARDUST.COM, I. White Paper - QoS Protocols and Architecture, QoS Forum. 1999.

TAI, J.; SALEHI, J. D. Capacity guarantees for web servers. HP Laboratories Palo Alto, 1998.

TAI, M. A. an J. Workload characterization of the 1998 World Cup web site. HP Laboratories, Palo Alto, 091999.

TANEMBAUM, A. S. Computer Networks. 4. edição. ed. [S.l.]: Pearson, 2002. 982 p.

TANEnBAUM, A. S. Distributed Operating Systems. New Jersey: Prentice Hall, 1995. $614 \mathrm{p}$.

TANENBAUM, A. S.; STEEN, M. van. Distributed Systems: Principles and paradigms. Upper Saddle River, NJ: Prentice Hall, 2002. 803 p.

TEIXEIRA, M. A. M. Suporte a serviços diferenciados em servidores web: modelos e algoritmos. Tese (Doutorado) - ICMC-USP, São Carlos - SP, Março. 2004a.

TEIXEIRA, M. A. M.; SANTANA, M. J.; SANTANA, R. H. C. Analysis of task scheduling algorithms in distributed web-server systems. In: Proceedings of the International Sysmposium on Performance Evaluation of Computer and Telecommunication Systems (SPECTS 2003). [S.1.]: SPECTS 2003, 2003a. p. 655-663.

TEIXEIRA, M. A. M.; SANTANA, M. J.; SANTANA, R. H. C. Avaliação de algoritmos de escalonamento de tarefas em servidores web distribuídos. In: XXXIII CONGRESSO DA SBC. XXX Seminário Integrado de Hardware e Software (SEMISH 2003). Campinas, SP: SEMISH 2003, 2003b.

TEIXEIRA, M. A. M.; SANTANA, M. J.; SANTANA, R. H. C. Using adaptative priority controls for service differentiation in qos-enabled web servers. In: International Conference on Computational Science (ICCS). Lecture Notes on Computer Science. Cracóvia, Polônia: IEEE Computer Society, 2004b. v. 3039, p. 537-540.

TEIXEIRA, M. A. M.; SANTANA, M. J.; SANTANA, R. H. C. Using adaptative priority scheduling for service differentiation in qos-enabled web servers. In: Proceedings of the IEEE International Performance, Computing and Communications Conference. Workshop on End-to-End Service Differentiation (IPCCC - EESD). Fênix, Arizona, Arizona: IEEE Computer Society, 2004c. 
TEIXEIRA, M. A. M.; SANTANA, M. J.; SANTANA, R. H. C. Servidor web com diferenciação de serviços: Fornecendo QoS para serviços da internet. In: XXIII Simpósio Brasileiro de Redes de Computadores - SBRC - Fortaleza - CE. [S.l.: s.n.], 2005. v. 15, n. 5 , p. $745-770$.

THOMPSON, K.; WILDER, G. M. R. Wide area internet traffic patterns and characteristics. IEEE Network, v. 11, p. 10-23, 1997.

VASILIOU, N. Overview of Internet QoS and Web Server QoS. 2000.

VEGESNA, S. IP Quality of Service for ther Internet and Intranets. Indianapolis: Cisco Press, 2000.

VOIGT, T.; GUNNIMGBERG, P. Adaptative resource-based web server admission control. In: Proceedings od the Seventh International Symposium on Computers and Communications. (ISCC'02). [S.l.]: IEEE Computer Society, 2002. p. 06.

ZOMAYA, A. Y. (Ed.). Parallel and Distributed Computing Handbook. New York: McGraw-Hill, 1996. 1198 p. (Computer Engineering Series). 
